\title{
Rocket Nozzle Design with Ejector Effect Potential
}

by

\author{
David J. Cerantola \\ B.A.Sc.
}

\begin{abstract}
A thesis submitted to
the Faculty of Graduate Studies and Research

in partial fulfillment of

the requirements for the degree of

Master of Applied Science
\end{abstract}

Ottawa-Carleton Institute for

Mechanical and Aerospace Engineering

Department of Mechanical and Aerospace Engineering Carleton University

Ottawa, Ontario, Canada

November 2007

(C) David J. Cerantola 2007

All rights reserved. 


$\begin{array}{ll}\begin{array}{l}\text { Library and } \\ \text { Archives Canada }\end{array} & \begin{array}{l}\text { Bibliothèque et } \\ \text { Archives Canada }\end{array} \\ \begin{array}{l}\text { Published Heritage } \\ \text { Branch }\end{array} & \begin{array}{l}\text { Direction du } \\ \text { Patrimoine de l'édition }\end{array} \\ \begin{array}{l}\text { 395 Wellington Street } \\ \text { Ottawa ON K1A 0N4 }\end{array} & \begin{array}{l}\text { 395, rue Wellington } \\ \text { Ottawa ON K1A ON4 }\end{array} \\ \text { Canada } & \begin{array}{l}\text { Canada } \\ \end{array}\end{array}$

Yourfile Votre référence

ISBN: 978-0-494-36821-3

Ourfile Notre référence

ISBN: 978-0-494-36821-3

NOTICE:

The author has granted a nonexclusive license allowing Library and Archives Canada to reproduce, publish, archive, preserve, conserve, communicate to the public by telecommunication or on the Internet, loan, distribute and sell theses worldwide, for commercial or noncommercial purposes, in microform, paper, electronic and/or any other formats.

The author retains copyright ownership and moral rights in this thesis. Neither the thesis nor substantial extracts from it may be printed or otherwise reproduced without the author's permission.
AVIS:

L'auteur a accordé une licence non exclusive permettant à la Bibliothèque et Archives Canada de reproduire, publier, archiver, sauvegarder, conserver, transmettre au public par télécommunication ou par l'Internet, prêter, distribuer et vendre des thèses partout dans le monde, à des fins commerciales ou autres, sur support microforme, papier, électronique et/ou autres formats.

L'auteur conserve la propriété du droit d'auteur et des droits moraux qui protège cette thèse. $\mathrm{Ni}$ la thèse ni des extraits substantiels de celle-ci ne doivent être imprimés ou autrement reproduits sans son autorisation.
In compliance with the Canadian

Privacy Act some supporting forms may have been removed from this thesis.

While these forms may be included in the document page count, their removal does not represent any loss of content from the thesis.
Conformément à la loi canadienne sur la protection de la vie privée, quelques formulaires secondaires ont été enlevés de cette thèse.

Bien que ces formulaires aient inclus dans la pagination, il n'y aura aucun contenu manquant.

\section{Canadä}


The undersigned recommend to the Faculty of Graduate Studies and Research acceptance of the thesis

\title{
Rocket Nozzle Design with Ejector Effect Potential
}

\author{
Submitted by David J. Cerantola
}

in partial fulfillment of the requirements for the degree of Master of Applied Science

\author{
J. Etele, Supervisor
}

J. Beddoes, Department Chair

Carleton University

2007 


\section{Abstract}

The ejector mode of rocket-based combined cycles is a concept that has the ability to gain thrust from atmospheric air and reduce fuel consumption and thus reduce the cost of rocket launches. This thesis develops a three-dimensional rocket nozzle design that includes the potential for incorporating the ejector effect. The nozzle is designed such that the diverging portion of the nozzle geometry must pass through a gate that is placed on the outer perimeter whose shape does not have to remain axisymmetric, thus creating a void for air intake into the centre of an annular rocket exhaust stream. Viscous effects are included via Edenfield's displacement thickness $\delta^{*}$ correlation for turbulent boundary layers. Comparison of computational fluid dynamics to a predefined Mach number distribution is within $1.6 \%$ of an inviscid solution and $6.8 \%$ for a viscous simulation using the $k$ - $\varepsilon$ turbulence model. 
I hereby declare that I am the sole author of this thesis.

I authorize Carleton University to lend this thesis to other institutions or individuals for the purpose of scholarly research.

I further authorize Carleton University to reproduce this thesis by photocopying or by other means, in total or in part, at the request of other institutions or individuals for the purpose of scholarly research. 
For those that have encountered impossible situations and remained dedicated to the cause either as a selfless act or because it was the right thing to do. In their humbleness and humility, they are the true heroes. 


\section{Acknowledgments}

For the past two years, Prof. Etele has convinced me through multiple attempts, as I can be a rather uncanny fellow, of a vision that has unique potential in the rocketry business. Upon recognizing my luck in acquiring such an interesting project, dedication into the research provided me the opportunity to present a paper in Australia with the benefit of disappearing for a month down-under. It is from Prof. Etele's tolerance and support that I now have one of my finest memories, and for it, I am extremely grateful. I must also recognize that it is through Prof. Etele's guidance that this thesis has transformed from a sequential summary of steps completed into a relevant and logical flowing document. Additionally, funding provided by the Natural Sciences and Engineering Research Council of Canada has been appreciated. 


\section{Table of Contents}

Abstract $\ldots \ldots \ldots \ldots \ldots \ldots \ldots \ldots \ldots \ldots \ldots \ldots \ldots$ iv

Acknowledgments . . . . . . . . . . . . . . . vi

Table of Contents . . . . . . . . . . . . . . . vii

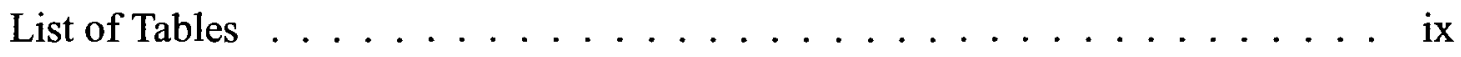

List of Figures . . . . . . . . . . . . . . .

Nomenclature . . . . . . . . . . . . . . xiii

1 Introduction 1

1.1 Rocket Performance Assessment . . . . . . . . . . . . . . . . 2

1.1.1 Problem Statement . . . . . . . . . . . . . . . 13

2 Model Formulation $\quad 15$

2.1 Inviscid Geometry Design $\ldots \ldots \ldots \ldots \ldots$

2.1.1 Inviscid Theory Summary $\ldots \ldots \ldots \ldots . \ldots . \ldots 34$

2.2 Implementation of Viscous Effects . . . . . . . . . . . . . 35

2.2.1 Adding Displacement Thickness to Geometry . . . . . . . . . . 43

2.3 Computational Implementation . . . . . . . . . . . . . . . 45

3 Numerical Setup $\quad 46$

3.1 Design Selection . . . . . . . . . . . . . . . 46

3.2 Numerical Methods . . . . . . . . . . . . . . . . . . . . 49

3.3 Fluid Properties . . . . . . . . . . . . . . . . . 54

3.4 Boundary Conditions $\ldots \ldots \ldots \ldots \ldots \ldots \ldots$

3.5 Mesh Generation and Convergence Study . . . . . . . . . . . 56

3.6 Convergence . . . . . . . . . . . . . . . . 61 vii 
5 Viscous Results

6 Conclusions and Recommendations

References 


\section{List of Tables}

2.1 Geometry reference values for the sensitivity analysis $\ldots \ldots \ldots \ldots$

2.2 Deviation from ideal gas law behaviour . . . . . . . . . . . . . 39

3.1 Input geometry variables for selected design . . . . . . . . . . . 49

3.2 Turbulence model influence on outlet values . . . . . . . . . . 52

3.3 Design fluid properties . . . . . . . . . . . . . . 54

3.4 Mesh characteristics . . . . . . . . . . . . . . . . . 60

$3.5 \quad M$ and $P$ variation between medium and fine meshes $\ldots \ldots \ldots 60$ 


\section{List of Figures}

1.1 Dual-bell nozzle . . . . . . . . . . . . . . . . . . . . 6

1.2 Extendible bell nozzle . . . . . . . . . . . . . . . . . . . 7

1.3 Influence of altitude on pressure for an aerospike nozzle $\ldots \ldots \ldots 7$

1.4 Rocket multistaging . . . . . . . . . . . . . . . . . . . . . 9

1.5 Ejector schematic for RBCC application . . . . . . . . . . . . 10

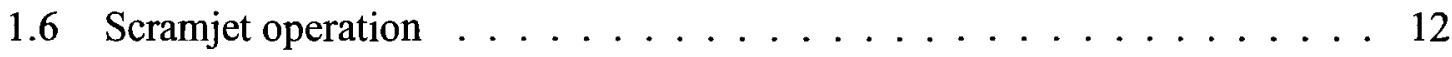

1.7 Proposed rocket nozzle/ejector schematic for RBCC application . . . . . 13

$2.1 A(z)$ function matching the predefined isentropic expansion . . . . . . . 17

2.2 Initial cross sections . . . . . . . . . . . . . . . . . 18

2.3 Orthographic nozzle views $\ldots \ldots \ldots \ldots \ldots \ldots \ldots$

2.4 Varying clover nozzle configurations . . . . . . . . . . . . . . . . . 19

2.5 Influence of gate parameters on $P 1$ line $\ldots \ldots \ldots \ldots$

2.6 Swept side development $\ldots \ldots \ldots \ldots$. . . . . . . . . . 21

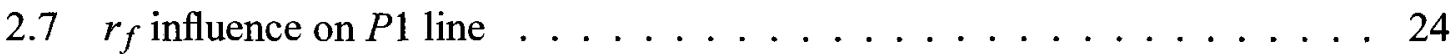

2.8 Nozzle radial contour . . . . . . . . . . . . . . . . . . . . . . . . 24

2.9 Influence of gate parameters on radial contour . . . . . . . . . . 25

$2.10 r_{f}$ influence on arclength $[\psi r](z)$ profile $\ldots \ldots \ldots \ldots \ldots$

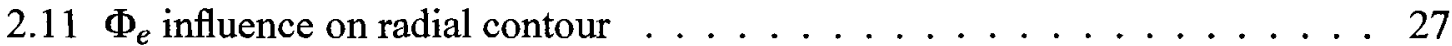

2.12 Influence of $r_{e}$ on the radial contour $\ldots \ldots \ldots \ldots \ldots \ldots$

2.13 Influence of outlet parameters on $P 1$ line $\ldots \ldots \ldots \ldots \ldots$

2.14 Initial values required for filling in remaining cross sections . . . . . . . 29

2.15 Nozzle cross sections . . . . . . . . . . . . . . . . . . . . . 29 
2.16 Intersecting points between the $P 1$ line and $r_{i} \ldots \ldots \ldots 30$

2.17 Cross section orientation (2D) $\ldots \ldots \ldots \ldots \ldots \ldots \ldots$

2.18 Cross section orientation (3D) $\ldots \ldots \ldots \ldots \ldots \ldots \ldots$

2.19 Cross section shape $\left(z^{\prime}\right.$-plane $) \ldots \ldots \ldots \ldots$

2.20 Boundary layer definition $\ldots \ldots \ldots \ldots \ldots \ldots \ldots$

2.21 Addition of displacement thickness to inviscid design $\left(z^{\prime}\right.$-plane $) \ldots \ldots 4$

2.22 Viscous cross section orientation (2D) $\ldots \ldots \ldots \ldots \ldots \ldots$

2.23 Swept wall correction . . . . . . . . . . . . . . . . . . . . 45

2.24 Processor computing times for nozzle design generation . . . . . . . . . 45

3.1 Predefined Mach number distribution . . . . . . . . . . . 47

3.2 Displacement thickness comparison . . . . . . . . . . . . . . 47

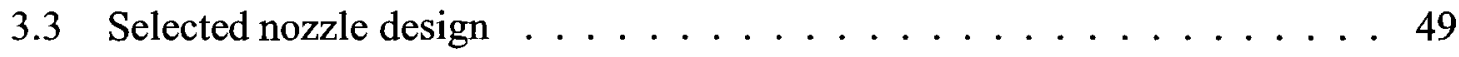

3.4 Turbulence model influence on Mach number distribution . . . . . . . . 51

3.5 Turbulence model influence on pressure distribution . . . . . . . . . 51

3.6 Mesh element . . . . . . . . . . . . . . . . . . . . . 53

3.7 Nozzle boundary labels . . . . . . . . . . . . . . . . 55

3.8 Outlet mesh . . . . . . . . . . . . . . . . . . . . . . . 57

3.9 Centreline mesh . . . . . . . . . . . . . . . . . . . . . . 58

3.10 Comparison of grid Mach number distributions $\ldots \ldots \ldots \ldots 60$

3.11 Comparison of grid pressure distributions $\ldots \ldots \ldots \ldots 60$

3.12 Residual convergence history . . . . . . . . . . . . . . 62

3.13 Velocity monitor points convergence history . . . . . . . . . 63

4.1 Inviscid analysis Mach number distribution $\ldots \ldots \ldots \ldots 65$

4.2 Inviscid analysis pressure distribution $\ldots \ldots \ldots \ldots \ldots$

4.3 Inviscid analysis $\Psi^{\prime}$-plane velocity contours $\ldots \ldots \ldots \ldots \ldots$

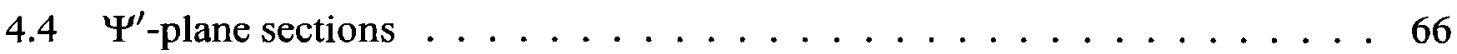

4.5 Inviscid analysis $z$-plane velocity contours $\ldots \ldots \ldots \ldots . \ldots 67$

$4.6 z$-plane sections . . . . . . . . . . . . . . . . . . . 67

4.7 Swept wall $\Psi^{\prime}(z)$ profile $\ldots \ldots \ldots \ldots \ldots \ldots$. . . . . . . . 67 
4.8 Inviscid analysis $z$-plane total pressure contours $\ldots \ldots \ldots \ldots$. . . . 68

4.9 Comparison of outlet velocity along mid-thickness of exit plane . . . . 69

4.10 Inviscid analysis $z$-plane temperature contours . . . . . . . . 70

4.11 Inviscid analysis $z$-plane pressure contours . . . . . . . . . 71

5.1 Viscous analysis Mach number distribution $\ldots \ldots \ldots \ldots 72$

5.2 Viscous analysis $\Psi^{\prime}$-plane velocity contours $\ldots \ldots \ldots \ldots \ldots 73$

5.3 Velocity profile cross section locations throat to outlet . . . . . . . 75

5.4 Velocity profiles at $0.0 \Psi^{\prime} \ldots \ldots \ldots \ldots \ldots \ldots \ldots$

5.5 Comparison of boundary layer thicknesses on the centreline $\ldots \ldots .76$

5.6 Viscous analysis $z$-plane velocity contours . . . . . . . . . 78

5.7 Viscous analysis $z$-plane total pressure contours $\ldots \ldots \ldots \ldots 78$

5.8 Velocity profiles at $0.76 \Psi^{\prime} \ldots \ldots \ldots \ldots \ldots \ldots$

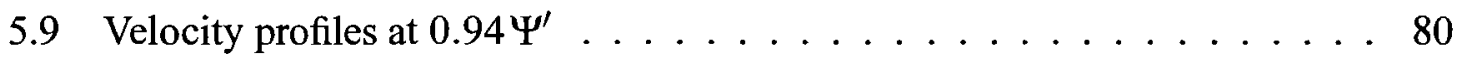

5.10 Velocity profiles at $0.995 \Psi^{\prime} \ldots \ldots \ldots \ldots \ldots$ 


\section{Nomenclature}

\begin{tabular}{|c|c|c|c|}
\hline$A$ & cross section area, $\mathrm{m}^{2}$ & $\dot{m}$ & mass flow rate, $\frac{\mathrm{kg}}{\mathrm{s}}$ \\
\hline$A_{\text {intake }}$ & air intake area, $\mathrm{m}^{2}$ & $r$ & radial contour radius, $\mathrm{m}$ \\
\hline$C_{f}$ & skin friction coefficient & $r_{f}$ & fillet radius, $\mathrm{m}$ \\
\hline$C_{p}$ & $\begin{array}{l}\text { constant pressure specific } \\
\text { heat, } \frac{\mathrm{J}}{\mathrm{kgK}}\end{array}$ & $t$ & $\begin{array}{l}\text { cross section thickness, } m \text {, } \\
\text { time, } s(\S 3.2)\end{array}$ \\
\hline$F_{T}$ & rocket thrust, $\mathrm{kN}$ & $x, y$ & Cartesian coordinates, ori- \\
\hline$I_{s p}$ & specific impulse, $s$ & & gin at throat centre \\
\hline$L$ & nozzle wall length, $\mathrm{m}$ & $y^{+}$ & boundary layer dimension- \\
\hline$M$ & Mach number & & less wall distance \\
\hline$M W$ & molar mass, $\frac{\mathrm{kg}}{\mathrm{kmol}}$ & $z$ & depth, $m$ \\
\hline$N$ & number of cross sections & Subscripts & \\
\hline$P$ & absolute static pressure, $\mathrm{kPa}$ & 0 & total \\
\hline$P_{c}$ & chamber pressure, $\mathrm{kPa}$ & $\infty$ & ambient conditions \\
\hline & total pressure, $\mathrm{kPa}$ & $a$ & after-gate tangent (Ch. 2), \\
\hline$P 1, P 2$ & cross section swept wall & & \\
\hline & corner points & $a w$ & adiabatic wall \\
\hline$P 3, P 4$ & $\begin{array}{l}\text { cross section centreline cor- } \\
\text { ner points }\end{array}$ & $b$ & before-gate tangent \\
\hline $\operatorname{Pr}$ & Prandtl number & $c t$ & centrel \\
\hline$R$ & gas constant, $\frac{\mathrm{J}}{\mathrm{kgK}}$ & $\begin{array}{l}e \\
e j\end{array}$ & $\begin{array}{l}\text { outlet } \\
\text { ejector outlet }\end{array}$ \\
\hline$R_{u}$ & $\begin{array}{l}\text { universal gas constant, } \\
8.314 \frac{\mathrm{kJ}}{\mathrm{kmol} \mathrm{K}}\end{array}$ & $f$ & fillet \\
\hline $\operatorname{Re}$ & Reynolds number & $\begin{array}{l}g \\
i\end{array}$ & index \\
\hline$R F$ & recovery factor & in & inner wall \\
\hline$T$ & static temperature, $\mathrm{K}$ & $i p$ & integration point \\
\hline$\tilde{T}$ & $\begin{array}{l}\text { boundary layer tempera- } \\
\text { ture } \mathrm{K}\end{array}$ & out & outer wall \\
\hline & total temperature, $\mathrm{K}$ & ref & reference \\
\hline $\begin{array}{l}10 \\
y\end{array}$ & $\begin{array}{l}\text { total temperature, } K \\
\text { freestream velocity, } \frac{\mathrm{m}}{\mathrm{N}}\end{array}$ & $s w$ & swept wall \\
\hline$V$ & freestream velocity, $\frac{\mathrm{m}}{\mathrm{s}}$ & th & throat \\
\hline $\mathbb{V}$ & discrete control volume & vis & including viscous effects \\
\hline$h$ & enthalpy & $w$ & wall \\
\hline$\kappa$ & $\frac{\mathrm{m}^{2}}{2}$ & Symbols & \\
\hline & & $\alpha$ & ir/rocket mass flc \\
\hline
\end{tabular}




\begin{tabular}{|c|c|}
\hline$\chi$ & symmetry angle \\
\hline$\delta$ & boundary layer thickness, $\mathrm{m}$ \\
\hline$\delta^{*}$ & displacement thickness, m \\
\hline$\varepsilon$ & $\begin{array}{l}\text { turbulence eddy dissipation } \\
\text { rate, } \frac{\mathrm{m}^{2}}{\mathrm{~s}^{3}}\end{array}$ \\
\hline$\gamma$ & specific heat ratio \\
\hline$\lambda$ & thermal conductivity, $\frac{\mathrm{W}}{\mathrm{mK}}$ \\
\hline$\mu$ & dynamic viscosity, $\frac{\mathrm{kg}}{\mathrm{ms}}$ \\
\hline$\mu_{t}$ & turbulence viscosity, $\frac{\mathrm{kg}}{\mathrm{ms}}$ \\
\hline$\omega$ & turbulent frequency, $s^{-1}$ \\
\hline$\Phi$ & tangential angle to $r(z)$ \\
\hline$\psi$ & arc angle \\
\hline$\Psi^{\prime}$ & arclength direction axis \\
\hline$\rho$ & density, $\frac{\mathrm{kg}}{\mathrm{m}^{3}}$ \\
\hline$\tilde{\rho}$ & boundary layer density, $\frac{\mathrm{kg}}{\mathrm{m}^{3}}$ \\
\hline \multicolumn{2}{|c|}{ Superscripts } \\
\hline 1 & normal-tangent coordinate \\
\hline- & $\begin{array}{l}\text { system designation } \\
\text { averaged }\end{array}$ \\
\hline \multicolumn{2}{|l|}{ Acronyms } \\
\hline CFD & $\begin{array}{l}\text { Computational Fluid Dy- } \\
\text { namics }\end{array}$ \\
\hline GCI & grid convergence index \\
\hline NASA & $\begin{array}{l}\text { National Aeronautics and } \\
\text { Space Administration }\end{array}$ \\
\hline $\mathrm{RBCC}$ & $\begin{array}{l}\text { rocket-based combined cy- } \\
\text { cles }\end{array}$ \\
\hline RMS & root-mean-square \\
\hline RNG & $\begin{array}{l}\text { renormalization group } k-\varepsilon \\
\text { turbulence model }\end{array}$ \\
\hline SST & $\begin{array}{l}\text { shear stress transport turbu- } \\
\text { lence model }\end{array}$ \\
\hline
\end{tabular}




\section{Chapter 1}

\section{Introduction}

HE rocket engine was conceived over 100 years ago with major contributions into
the early development by the rocketry pioneers Tsiolkovsky, Goddard, Oberth, and von Braun. Konstantin E. Tsiolkovsky was a Russian visionary that proposed concepts with sound mathematical fundamentals of space flight and rocket engines from 1895-1903. Some of Tsiolkovsky's accomplishments include identification of exhaust velocity as an important performance factor, that liquid oxygen and liquid hydrogen give higher exhaust velocity due to higher temperature and lower molar mass, and the concept of multistaging $[1-4]$.

Robert H. Goddard was an American scientist and inventor that designed and tested numerous rocket concepts and obtained 214 patents for his efforts (35 posthumously and 131 later filed by his wife). Goddard's accomplishments were astounding, and to name a few: he was the first to successfully launch a sounding rocket with a liquid-propellant rocket engine in 1926; he realized the benefits of turbo-pumps and thrust chamber cooling; he proved that thrust could be created in a vacuum; and he designed the gimballed thrust chamber that acted as a movable tail fin [1-4]. Although he was the first in many aspects, Goddard's reclusiveness and unfortunately early death in 1945 prevented the sharing of his knowledge and so many of his achievements were independently re-realized by others 
working in the field. As a result, it was not until the publishing of his papers in 1970 that many in the rocket business realized his brilliance [3].

Hermann Oberth worked in Germany and was very influential in gaining public interest through publishing his rejected thesis "The Rocket to the Planets" and directed the movie "Woman in the Moon." Oberth was a conceptualist that achieved many of his accomplishments during the 1920s and 1930s. To list several: Oberth formulated the equations for isentropic flow through nozzles; he realized the flight velocity, vehicle and propellant mass relationship; and he introduced the parachute as a means of introducing aerodynamic drag to slow down a re-entering spacecraft $[1-4]$.

Lastly, Wernher von Braun was Oberth's assistant early on in his career. von Braun contributed to the A-4 rocket - the first practical and reproducible liquid-fuelled rocket that also served as a medium-range missile. After World War II, von Braun and most of his team immigrated to the United States where they were responsible for sending the first men to the moon on a Saturn V rocket in 1969. von Braun was also a visionary in some regard as he helped realize the concept of a reusable space launch vehicle $[1,2,4]$.

These four pioneers by no means generate the entire foundation of rocketry, but their contributions to the aerospace field were significant. Others include General Arturo Crocco and his son Luigi Crocco from Italy, Robert C. Truax of the U.S. Naval Academy, Austrian Eugen Sänger, and Robert Esnault-Pelterie of France [3]. Again, this list could go on and so the reader is directed to Sutton [3] and Kraemer [4] for further information.

\subsection{Rocket Performance Assessment}

Since propellants can account for upwards of $90 \%$ of the vehicle's initial mass $[2,5]$ and the high costs required for launch [6,7], extensive efforts have gone into the improvement of rocket systems. Major work since the inception of rockets has gone into several fields: 
(1) propellant choice; (2) feed system design; (3) increasing thrust chamber performance;

(4) maximizing area expansion ratio through improved nozzle design; and (5) multistaging. Concepts still in development include (6) rocket-based combined cycles and (7) liquid-air cycle engines. The motivation behind these seven concepts is to increase the performance qualifiers - thrust $F_{T}$ or specific impulse $I_{s p}$ —or reduce initial rocket mass.

\section{(1) Propellant Choice}

Propellant choice is instrumental in the amount of kinetic energy gained through combustion. Since the early 1920 s, more than 1800 liquid propellants have been tested including toxic energetic and exotic chemicals. The results of these evaluations have dramatically reduced the selection to several options identified in their appropriate propellant classes: cryogenic, hypergolic, petroleum, and solid [3].

\section{(2) Feed System Cycles}

Feed systems have progressed from the heavy pressurized gas tanks of the 1920s to simple gas generator cycles and then on to expander-engine and staged-combustion cycles. The expander-engine cycle is usually applied to cryogenic fuels and gasifies the fuel in the thrust chamber cooling jacket. This concept eliminates the need for gas generators or preburners and additionally has the benefit of reducing the pressure drop across the turbine since the propellant in now heated and evaporated. Although the staged-combustion cycle requires a preburner, it offers roughly the same performance as an expander cycle and has been implemented on the RD-170 and Space Shuttle main engine $[1,3]$

The advent of computational modelling has provided the means of optimizing feed systems and improving performance through increased efficiency and reduced mass, in part due to improved construction materials. The capability now exists to examine hydraulic 
flow through impellers, optimize turbine blade contours through flow simulations, and generate stress and thermal analyses. Development of health monitors allows for automated control and real time response for adjustment of turbine and pump speeds to maintain performance. Risk of failure from cavitation or flow rate fluctuation is also reduced through the monitoring of pressures and temperatures in the system [3].

\section{(3) Thrust Chamber Design}

Increasing chamber pressure $P_{c}$ allows for higher kinetic energy and smaller chambers. Since heat transfer increases almost linearly with chamber pressure, an upper pressure limit is dictated by thrust chamber material choice [3]. Thrust chamber material selection is critical in preventing burnout and ultimately failure. This does not imply that the thrust chamber is reusable since excessive temperatures and rocket launching practice dictate a one-time use; however, for safety consideration, cooling concepts are available to prevent temperatures in excess of the thrust chamber material's melting temperature. Two popular cooling methods are film cooling and regenerative cooling. Film cooling injects fluid (usually fuel in the U.S. and oxidizer by the Soviets) along the walls, absorbing heat from the walls and combustion exhaust, and acts as a protective boundary layer of relatively cool gas. Subsequently, heat transfer and wall temperature are reduced $[1,3,8]$.

Since film cooling wastes propellant, regenerative cooling is more common. The walls of the thrust chamber act as a heat exchanger for heat to be transferred from the exhaust gases to fuel flowing along the walls. The heat exchanger (commonly called a cooling jacket) implements a double-wall design such that exhaust gases flow between the inner wall and liquid fuel passes between the inner hot wall and cooler outer wall in a spiral pattern starting from the nozzle outlet $[1,3,8]$.

Typical materials that are used for the thrust chamber include aluminum alloys, stainless steels, copper, titanium, nickel, and niobium. Trace materials added to alloys include 
metals such as silver and zirconium. Alternatively, ablative materials including glass, silica, and carbon fibre have found successful application in thrust chambers [3]. Although composites such as carbon fibre have much lower densities than traditional metals, application of composites is limited since corrosive propellants such as oxygen cause buckling and collapse [1].

Increasing chamber pressure has provided a 4-8\% increase in specific impulse [3]; however, given today's knowledge of suitable metals and ablative materials along with cooling practice, chamber pressure cannot influence further improvement [1].

\section{(4) Nozzle Design}

Converging-diverging nozzles were pioneered by Carl de Laval in 1882 and have been demonstrated to produce the highest exhaust velocities [9]. Maximizing area expansion ratio is desirable to generate the most thrust for a given mass flow. Early designs consisted of either axisymmetic conical or bell shapes-bell nozzles are still common today. After a circular arc defining the throat region, the wall contour on conical nozzles expands linearly outward whereas the diverging section of a bell nozzle after the circular arc is often expressed by a cubic polynomial such that expanding gases are deflected inward at the nozzle outlet [9]. For conical nozzles, the ideal exit half angle should be between 4 and $5^{\circ}$ to minimize flow divergence losses; however, this makes for a very long nozzle. Bell nozzles can be upwards of $60 \%$ shorter than $15^{\circ}$ conical nozzles of the same area ratio [4] but still require gradual expansion at high altitude $[3,10]$.

Due to the fixed outlet area ratio, conical and bell nozzles must select a set outlet pressure $P_{e}[3,10]$. Consideration of outlet pressure takes into account potential underexpansion and particularly overexpansion, both of which generate performance losses of up to $15 \%$ [10]. Underexpansion occurs when $P_{e}$ is greater than atmospheric pressure $P_{\infty}$ and causes the formation of expansion fans at the nozzle outlet whereas overexpansion is when 
$P_{e}<P_{\infty}$ and has the possibility of separated flow and shocks propagating into the nozzle $[3,10,11]$. As a result, atmospheric pressure places an upper limit on exhaust expansion to ensure $P_{e}>P_{\infty}$.

Dual-bell nozzle designs accommodate several outlet pressures and provide a significant net impulse gain over the entire trajectory as compared to conventional bell nozzles. The concept proposes a typical inner base nozzle accompanied by an outer nozzle addition. The connecting point between radial contours is a wall inflection point. Figure 1.1(a) shows that the exhaust flow for lower altitude operation separates at the inflection point whereas Fig. 1.1(b) shows that higher altitude flow remains attached until the exit plane of the outer nozzle extension [10]. Alternatively, Figs. 1.2(a) and 1.2(b) show that an extendible bell design is composed of several annular segments corresponding to different area ratios that are stored one inside the other. The segments of an extendible nozzle are extended as required to provide best performance with respect to atmospheric pressure. The extendible extension has the advantage of reducing the package volume of upper stage nozzles but has the disadvantage of movable parts $[3,10]$.

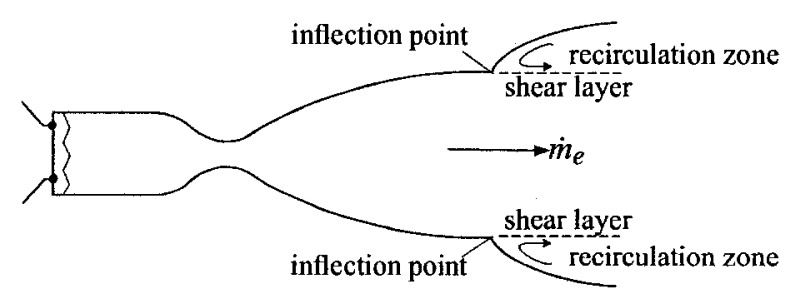

(a) low altitude

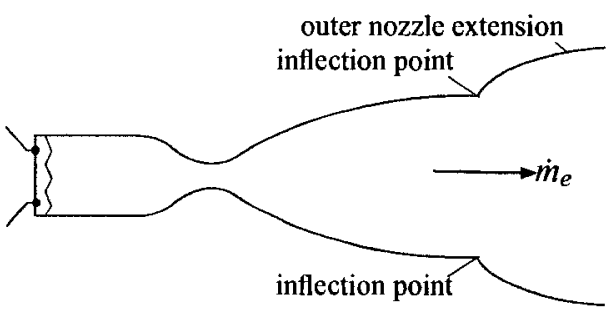

(b) high altitude

Figure 1.1: Dual-bell nozzle

Manipulating rocket nozzle geometry from the common bell shape has been demonstrated to achieve higher performance as is evident by the plug, aerospike (truncated plug), and expansion-deflection nozzles. The physics behind the plug and aerospike nozzles are 


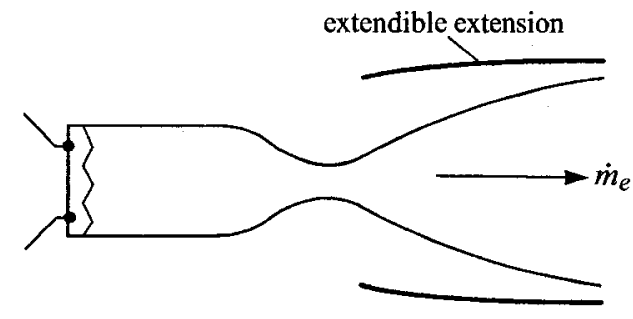

(a) low altitude

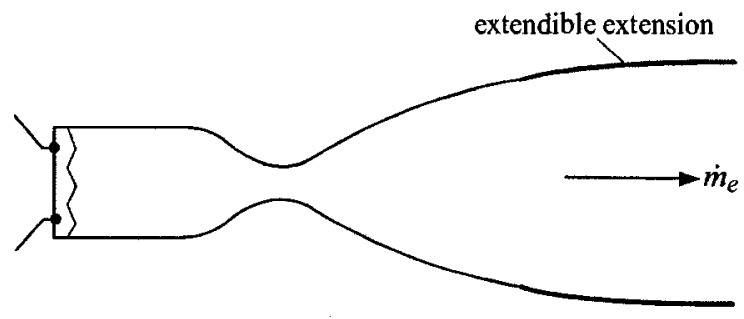

(b) high altitude

Figure 1.2: Extendible bell nozzle

very similar in that Fig. 1.3 shows that the plume size increases as atmosphere gets thinner thus providing near maximum performance independent of altitude $[1-3,12,13]$ and exhibit similar performance ability [3]. Thrust from the plug nozzle is developed on the outer surface of a conical plug that terminates as a cusp whereas the aerospike nozzle achieves thrust by creating a recirculating flow with an outer boundary approximating the plug nozzle shape (see Fig. 1.3). The expansion-deflection nozzle works based on the same pressure independence principle but has not been pursued since 1966 because the aerospike nozzle demonstrated better performance [3].

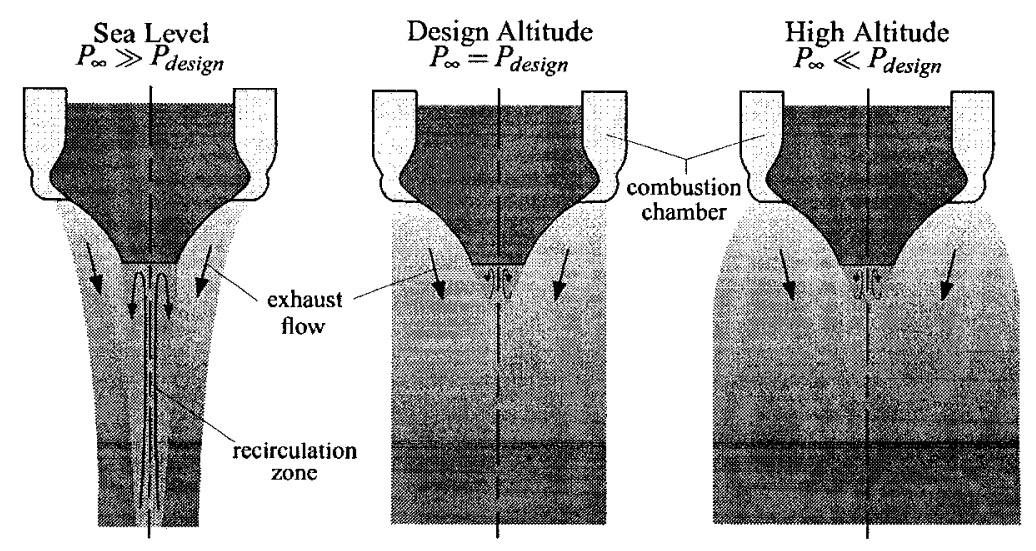

Figure 1.3: Influence of altitude on pressure for an aerospike nozzle 
The problem with these altitude-independent nozzle designs lie in the requirement of an annular combustion chamber rather than a normal cylindrical chamber. Aside from the brief revival of the aerospike nozzle on NASA's X-33 that ended in 2001, no application has been developed to include inside-out nozzles $[1-3,13]$.

Another nozzle performance qualifier is nozzle efficiency. Nozzle efficiency is the product of kinetic efficiency (losses caused by kinetic effects), divergence efficiency (losses caused by shocks), and friction efficiency (friction and heat flux induced losses). Since these efficiencies are dependent on chamber pressure, engine size, and nozzle exit area ratio for a given outlet pressure [14], further improvement is difficult for single-stage orbital launches.

\section{(5) Multistaging}

Area ratio altitude problems contributed to the advent of multistaging. Figure 1.4 shows that a typical rocket launch vehicle can consist of several stages. For example, the Space Shuttle, Saturn V, and Ariane 5 use two stages along with strap-on boosters. When a stage runs out of propellant, it can be jettisoned with an explosive charge away from the rocket. There are several reasons for staging: stages are independent of each other meaning that they can have different propellants and operating characteristics; propellant tanks are smaller and so sloshing is reduced; and by jettisoning empty stages, energy is not expended to accelerate empty tanks. The first stage is at the bottom of the rocket and fired first and is generally designed to have high thrust to overcome gravity forces. Second and subsequent upper stages are stacked on top of the first stage and are designed to have high specific impulse to provide maximum velocity. Additionally, zero-stage strap-on boosters operate in parallel to propel the entire rocket upwards $[1,3,8]$. 


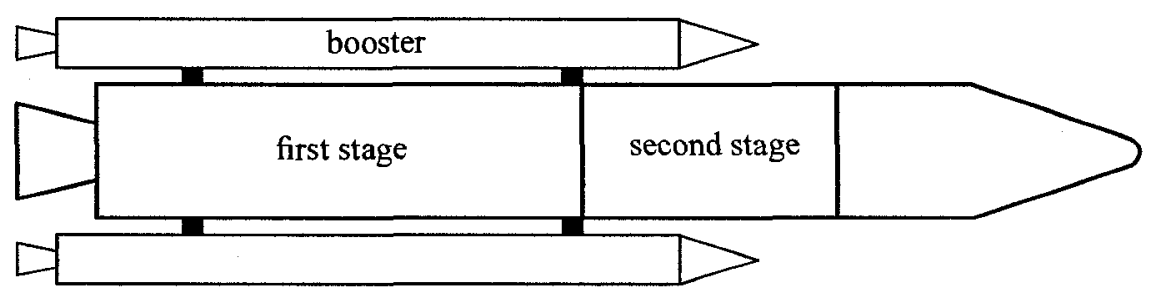

Figure 1.4: Rocket multistaging

\section{(6) Combined Cycles}

Rocket-Based Combined Cycles (RBCC), also known as air-augmented rockets, are concepts first introduced in the 1960s that present the notion of increasing thrust through the addition of mass flow, reducing propellant mass fraction to $70 \%$, and augmenting specific impulse by $10-20 \%$ at static conditions [5], leading to reduced launch costs for transatmospheric flight $[1,15]$. RBCC is classified as a hybrid rocket/ramjet engine that operates better than either the rocket or ramjet separately. RBCC can be achieved through the addition of an ejector (has been referred to as a diffuser) downstream of the thrust chamber [3].

Figure 1.5 shows that traditional RBCC consist of three components: thrust chamber, air intake, and ejector (also referred to as an ejector duct or a mixer). The thrust chamber is responsible for converting propellant internal energy into kinetic energy and accelerating the exhaust gases. The air intake entrains air into the ejector. Inside the ejector, the two flows mix and achieve the ejector effect: momentum from the high rocket exhaust velocity is transferred to entrained air; this transfer of momentum causes some reduction to the effective rocket exhaust velocity; however, the increase in mass flow from the entrained air results in a greater specific impulse and causes thrust augmentation $[5,16]$. In addition to thrust augmentation, ejectors are capable of creating a vacuum-like outlet, which reduces the risk of plume overexpansion [3].

Numerous numerical and experimental investigations in the past five years have focused 


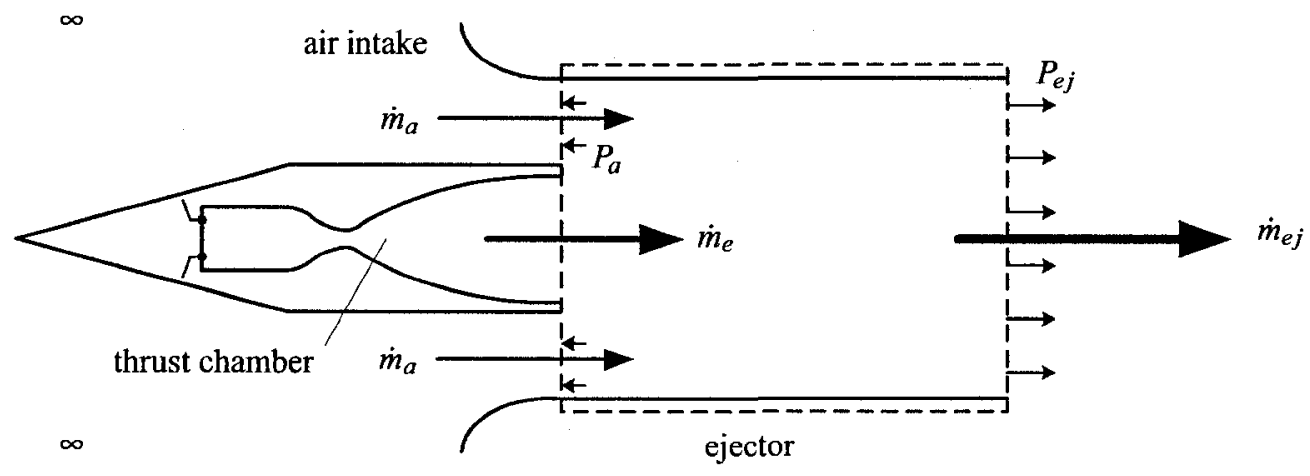

Figure 1.5: Ejector schematic for RBCC application

on the mixing capability of the ejector [17-24]. The investigations include influence of variable length ducts, square ducts, cylindrical ducts, conical constriction ducts, annular rocket exhaust streams, and total pressure and area ratio effects between the rocket flow and air flow. Additionally, Presz and Werle [19] demonstrated the potential of a multistaged ejector providing a back pressure benefit, noise and infra-red suppression, thrust augmentation, higher diffusion rates, and more efficient wall cooling.

During subsonic flight, air is entrained into the ejector duct by a rocket exhaust pumping action (ejector mode), acting like the compression stage for a jet engine [2, 5, 21-23]. Once flight reaches supersonic velocity, the rocket is in ram rocket mode and the air inflow is determined by external conditions including the flight Mach number and inlet shock structure [5,21-23]. Subsequently, several studies $[15,24]$ have been conducted to identify the influence of intake aerodynamics on air suction performance.

To assist in the quantification of the ejector abilities, $\alpha$, the ratio by mass of air flow to rocket exhaust flow

$$
\alpha=\frac{\dot{m}_{a}}{\dot{m}_{e}}
$$

should exceed some minimum value. Additionally, thrust augmented ejector operation is 
limited to low-altitude environments where there is enough atmosphere to maintain $\alpha$. On Earth, ejector operation is restricted to altitudes below $100[\mathrm{~km}]$, or only during the initial stage of a rocket launch. One-hundred kilometres is identified as the von Kármán line such that $99.99997 \%$ of the atmosphere by mass is below this altitude and is commonly used to define the boundary between the Earth's atmosphere (field of aeronautics) and outer space (astronautics). This may be an optimistic upper limit for air augmented systems since atmosphere decreases on an exponential scale with respect to height. For example, the common cruising altitude for commercial airliners is about $10[\mathrm{~km}]$ because $90 \%$ of the atmosphere by mass is below an altitude of $16[\mathrm{~km}][25,26]$. In comparison, low-Earth orbit starts at $300-400[\mathrm{~km}][3]$.

Regardless of atmospheric issues, a flight plan has been developed-such as that of NASA's GTX single-stage-to-orbit concept design [27] — consisting of rocket-ejector operation at takeoff, acceleration from Mach 3-6 during ram rocket mode, a scramjet mode if velocity exceeds Mach 6 in atmosphere, and rocket-only mode for insertion into orbit $[5,16,20,27]$.

\section{(7) Liquid-Air Cycle Engines}

The Liquid-Air Cycle Engine (LACE) entrains air for operation and collects and compresses air to liquid for later stages of flight. Air collection allows for smaller oxidant tanks; however, more time is spent in lower atmosphere to collect sufficient oxygen causing increased vehicle heating and drag [28]. The SABRE—a hybrid air-breathing/rocket engine concept-has the capability of reaching low-Earth orbit after closing the air inlet at Mach 5.5, $26[\mathrm{~km}]$ altitude and operating solely on the rocket engines and collected air for the remainder of the mission [29].

Two additional engines requiring air entrainment for operation include the ramjet and scramjet. These engines only operate in an air-augmented mode and are subsequently not 
candidates for transatmospheric flight [5]. Ramjets and scramjets have the benefits of few moving parts in the engine, can operate at stoichiometric air-to-fuel ratios, and are selfsustaining once operational but have the consequence of requiring forward motion such that air can be compressed sufficiently. Ramjets compress supersonic inlet velocities of Mach 1-2 due to aerodynamic diffusion for subsonic combustion and then a nozzle accelerates the exhaust to a supersonic Mach 2-6 range [28]. Ramjets were experimented with mainly in the 1950-60s and have been successfully implemented on the Hiller Hornet helicopter, Lockheed D-21 reconnaissance drone, interceptor Republic XF-103 aircraft, and the SM64 Navaho and Bomarc missiles to name a few.

Scramjets, as depicted in Fig 1.6, are similar to ramjets except the intake velocity must be at least Mach 5, combustion is supersonic, and scramjets are predicted to generate Mach 12-24 hypersonic flow; however, only Mach 5-10 has been achieved in experiment. Scramjets have the benefit of reducing shock waves at the intake, thus reducing total pressure loss [28]. Scramjet programs have included NASA's Hyper X and Australia's HyShot; however, the only current program is HyCAUSE - the Hypersonic Collaborative Australian/United States Experiment - that launches a scramjet on a rocket into space and during re-entry, the scramjet is activated [30].

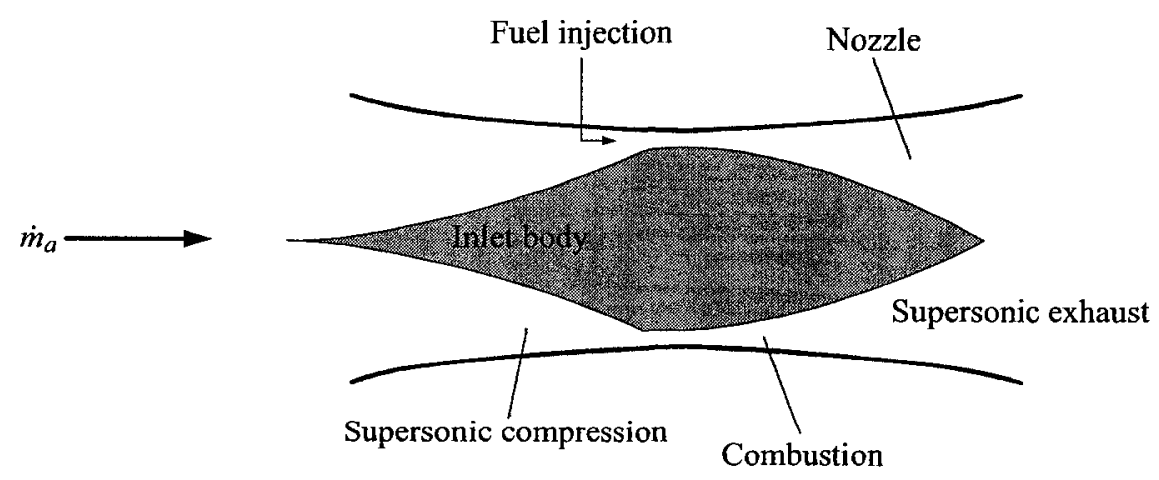

Figure 1.6: Scramjet operation 


\subsubsection{Problem Statement}

Five of the seven fields for improving rocket design—propellant choice, feed system design, thrust chamber performance, nozzle improvements, and multistaging-have been well examined and implemented to the extent that there is very little room for additional improvement. Furthermore, liquid-air cycle engines are only seen as applicable for atmospheric flight. Based on the seven fields examined, rocket-based combined cycles have the most potential of substantial improved performance for transatmospheric flight.

The focus of this research is based on the expectation that entraining air into the centre of an annular rocket exhaust stream as shown in Fig. 1.7 causes the ejector effect necessary for the ejector mode of RBCC operation. Anticipated benefits to pursuing this concept include higher thrust due to increased mixing ability between the higher annular rocket exhaust velocity and entrained air along the central axis as compared to entraining air on the annulus with the rocket located along the central axis (see Fig. 1.5) and a more convenient mounting configuration for an axisymmetric ejector duct since it can be attached directly to the outer wall of the rocket nozzle.

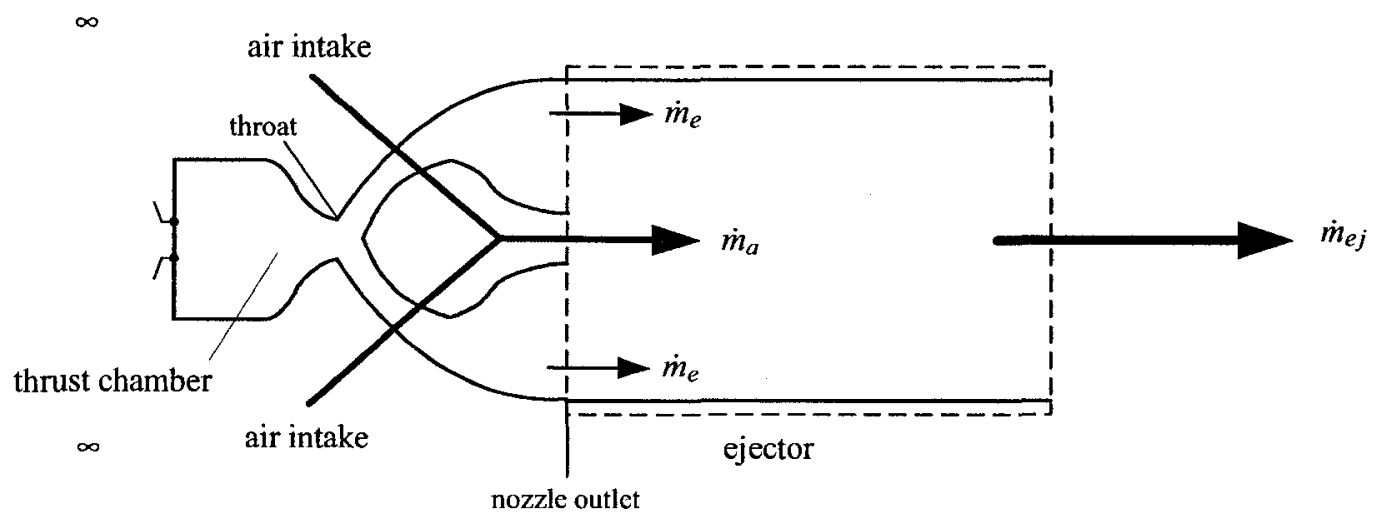

Figure 1.7: Proposed rocket nozzle/ejector schematic for RBCC application 
Since existing bell nozzle designs are axisymmetric, a new nozzle design must be developed to accommodate the ability for air entrainment. Although an annular exhaust stream is required at the nozzle outlet, the proposed nozzle concept is based on a different operating principle than that of the plug and aerospike nozzles. Constraints placed on the developed nozzle concept include the requirement for a normal cylindrical combustion chamber such that Fig. 1.7 shows that the converging portion of the nozzle remains unchanged from existing manufactured converging-diverging nozzle designs, the launch vehicle must be capable of taking off from the ground, and that the inlet and outlet conditions of the nozzle must be similar to existing nozzle performance characteristics.

This thesis addresses several objectives: describe the theory for a computer program that is capable of generating three-dimensional nozzle designs (including viscous considerations) based on provided input variables; assess the abilities and limitations of the input variables; and conduct a computational fluid dynamics study to assess the accuracy of a selected nozzle configuration against its expected performance. 


\section{Chapter 2}

\section{Model Formulation}

The developed program solves the isentropic equations assuming a compressible, steadystate, one-dimensional, frozen flow through a series of finite cross sections that consider boundary layer effects. Development of a three-dimensional geometry with viscous consideration for the diverging portion of a converging-diverging rocket nozzle first generates an inviscid geometry profile and then adds a displacement thickness to create the viscous design.

\subsection{Inviscid Geometry Design}

Input variables are divided into two categories: geometric variables necessary for geometry creation and fluid property variables necessary to define a constant specific heat fluid and inlet properties. Additionally, a predefined Mach number distribution $M(z)$ is necessary to define the nozzle's inviscid area expansion $A(z)$ from the throat depth $z=0$ (corresponds to sonic flow where $M_{t h}=1$ ) to the nozzle outlet depth $z=z_{e}$ using the isentropic relation 
as found in White [11];

$$
\frac{A(z)}{A_{t h}}=\frac{1}{M(z)}\left[\frac{1+\frac{1}{2}(\gamma-1) M(z)^{2}}{\frac{1}{2}(\gamma+1)}\right]^{\frac{\gamma+1}{2 \gamma-2}}
$$

Equation 2.1 is non-dimensionalized with respect to the throat area $A_{t h}$.

Rather than interpolate to generate intermediate cross sections, the $A(z)$ data calculated from Eq. (2.1) using the predefined $M(z)$ is represented by a continuous function developed from the Agnesi family of curves:

$$
\frac{A(z)}{A_{t h}}=F\left(1+\cos \left(\frac{\sqrt{\pi}}{\tan ^{-1} \frac{z_{e} G}{r_{t h} D}} \tan ^{-1} \frac{\frac{z}{r_{t h}}-\frac{z_{e}}{r_{t h}} G}{D}\right)^{2}\right)+1
$$

The depth $z$ in Eq. (2.2) is non-dimensionalized with respect to a user defined throat radius $r_{t h}$. The constant $F$ in Eq. (2.2) is evaluated such that the outlet depth $z_{e}$ and area $A_{e}$ lie on the curve

$$
F=\frac{\frac{A_{e}}{A_{t h}}-1}{1+\cos \left(\frac{\sqrt{\pi}}{\tan ^{-1} \frac{z_{e} G}{r_{t h}}} \tan ^{-1} \frac{\frac{z_{e}}{r_{t h}}(1-G)}{D}\right)^{2}}
$$

Equation (2.2) is rearranged to iteratively solve for $D$ using Newton-Raphson's method and is determined based on gate depth $z_{g}$ and area $A_{g}$,

$$
D=\frac{\frac{z_{g}}{r_{t h}}-\frac{z_{e}}{r_{t h}} G}{-\tan \left(\sqrt{\frac{1}{\pi} \cos ^{-1} \frac{\frac{A_{g}}{A_{t h}}-(F+1)}{F}} \tan ^{-1}\left(\frac{z_{e} G}{r_{t h} D}\right)\right)}
$$

In order to obtain a value for $\frac{A_{g}}{A_{t h}}, M_{g}$ is interpolated from the predefined $M(z)$ data based on a user defined $z_{g}$ input with the restriction that $0<z_{g}<z_{e}$. Equation (2.1) then solves for $A_{g}$ from the interpolated value of $M_{g}$.

Lastly, the $G$ constant in Eq. (2.2) is selected such that the area function (Eq. (2.2)) 
shows best agreement to the predefined data. In general, the rate of area expansion at the nozzle outlet is minimal and so $G$ should be defined as one or slightly higher. For example, Fig. 2.1 shows that for $G=1.05$, Eq. (2.2) matches a predefined data set representative of $M_{e}=2.75$ performance characteristics of an Atlas E/F rocket nozzle to within $5.9 \%$ over the range $0<\frac{z}{r_{t h}}<16.9$ with the maximum variation occurring at $\frac{z}{r_{t h}}=3.7$.

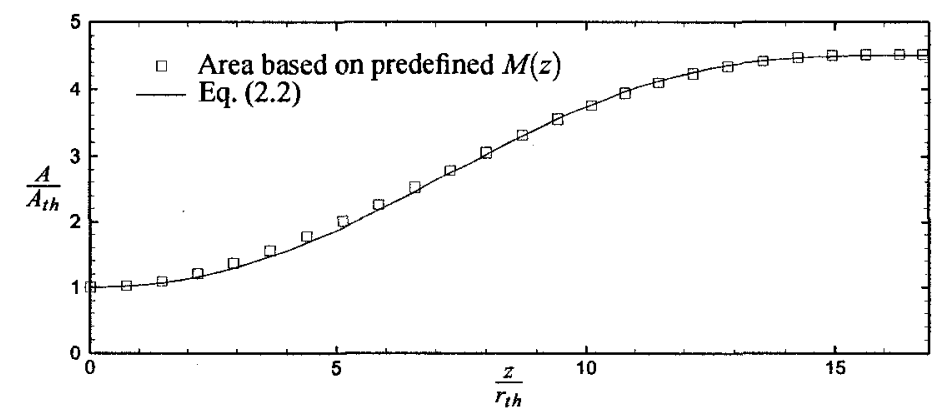

Figure 2.1: $A(z)$ function matching the predefined isentropic expansion

Figure 2.2 identifies the necessary input variables required for inviscid geometry generation. Cartesian coordinates are implemented where the origin is placed at the throat centre and the geometry is designed in the positive $x-y$ quadrant such that streamlines proceed in the positive $z$-direction. The geometry being modelled as shown in Fig. 2.2 represents half a clover due to symmetry about the $\chi$-plane (the dotted line in Fig. 2.2). A clover is one of the branches on the diverging nozzle through which the rocket exhaust must pass. To better appreciate the flow path of the rocket exhaust, Fig. 2.3 shows orthographic views for a four-clover nozzle configuration. The corresponding four-clover isometric view is shown in Fig. 2.4(b).

The throat, gate, and outlet shown in Fig. 2.2 are three fully constrained cross sections. The throat must maintain an axisymmetric shape such that it can be matched to existing converging nozzle designs. The required inputs for the throat are its radius $r_{t h}$ and angle of symmetry $\chi$. Throat radius is critical for the dimensionalizing of the design as all lengths 


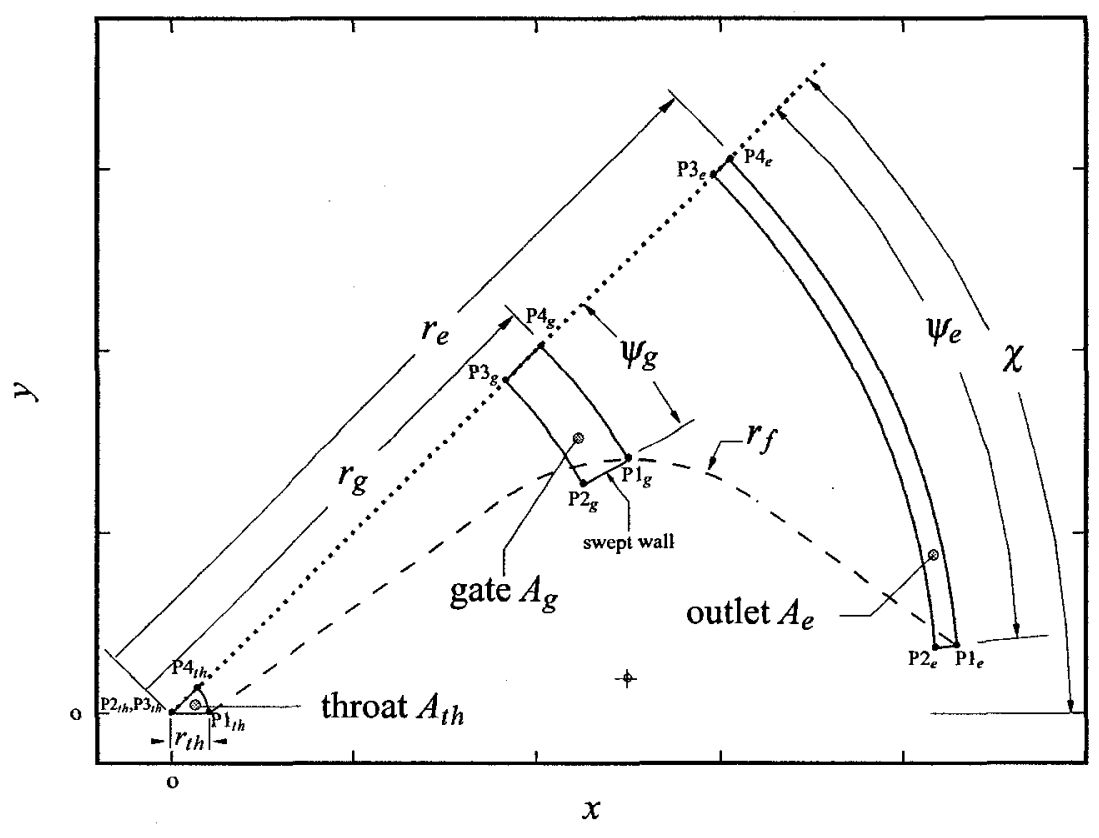

Figure 2.2: Initial cross sections

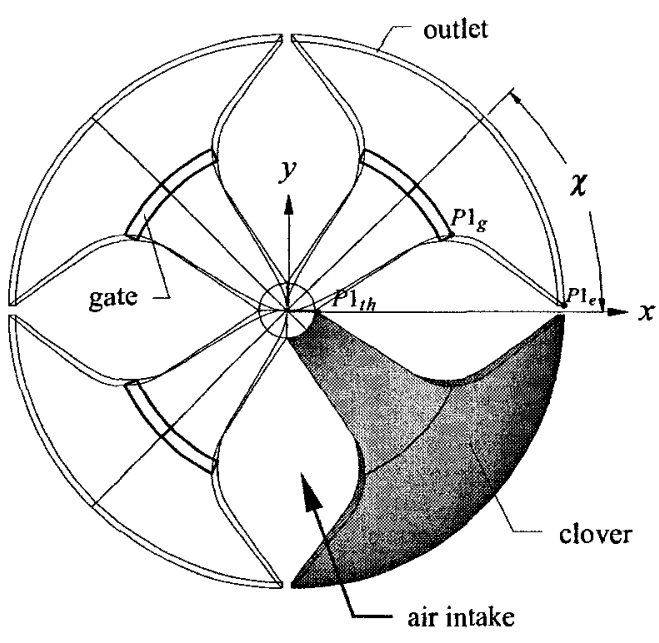

(a) front view

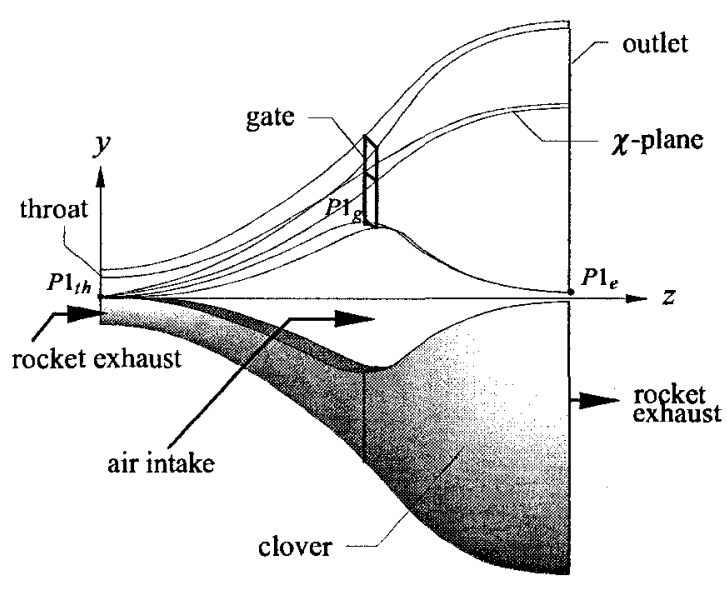

(b) side view

Figure 2.3: Orthographic nozzle views 
are non-dimensionalized by $r_{t h}$ and all cross sectional areas by

$$
A_{t h}=\frac{\chi}{2} r_{t h}^{2}
$$

The clover half-angle $\chi$ can accommodate the possibility of using multiple clovers as shown in Figs. 2.4(a)-2.4(c). Since the number of clovers must span the entire circumference at the throat, $180^{\circ}$ divided by the clover half-angle $\chi$ must yield a whole number. Figures 2.4(a)-2.4(c) show that through reducing the number of clovers, the intake area $A_{\text {intake }}$ proportional to $A_{e}$ increases. The intake area $A_{\text {intake }}$ can be represented by the void between the dashed line passing through the $P 1$ points (the swept wall-outer wall corner points) and the positive $x$-axis shown in Fig. 2.2 and is generated because the exhaust flow is restricted to flowing through a clover. This results in an annular rocket exhaust stream at the nozzle outlet (see Fig. 2.3).

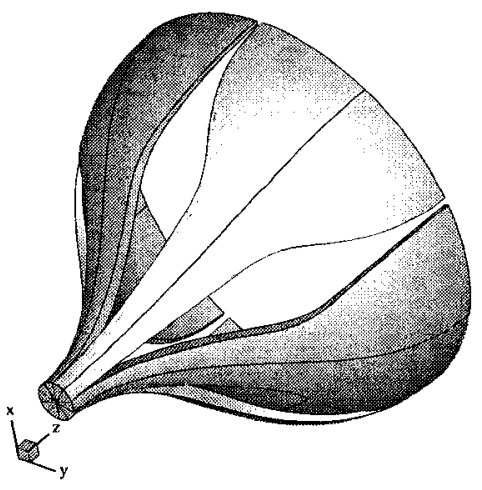

(a) 5 clovers $\chi=36^{\circ}$

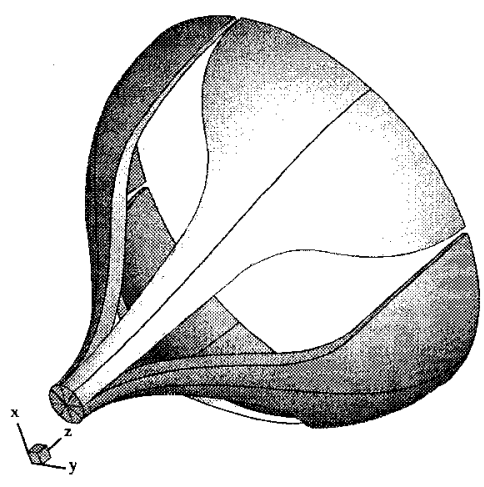

(b) 4 clovers $\chi=45^{\circ}$

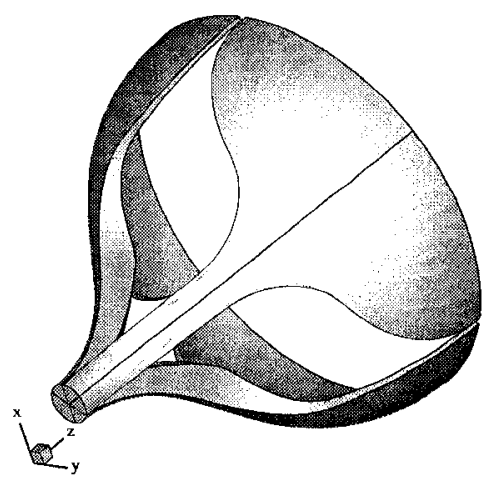

(c) 3 clovers $\chi=60^{\circ}$

Figure 2.4: Varying clover nozzle configurations

The gate section exists on the outer perimeter of the nozzle through which the nozzle geometry must pass; however, the shape is given freedom so that it does not have to remain axisymmetric. The two inputs for the gate shown in Fig. 2.2, radius $r_{g}$ and arc angle $\psi_{g}$, influence the line connecting the $P 1$ points as shown in Figs. 2.5(a) and 2.5(b) and directly 
influence the air intake size. For increasing $r_{g}$, Fig. 2.5(a) shows that $A_{\text {intake }}$ increases when $\psi_{g}$ remains constant as $P 1_{g}$ moves farther away from the $x$-axis. Figure 2.5(b) shows that an increase in $\psi_{g}$ for a given $r_{g}$ forces the gate to cover more of the circumference and causes a reduction in $A_{\text {intake }}$.

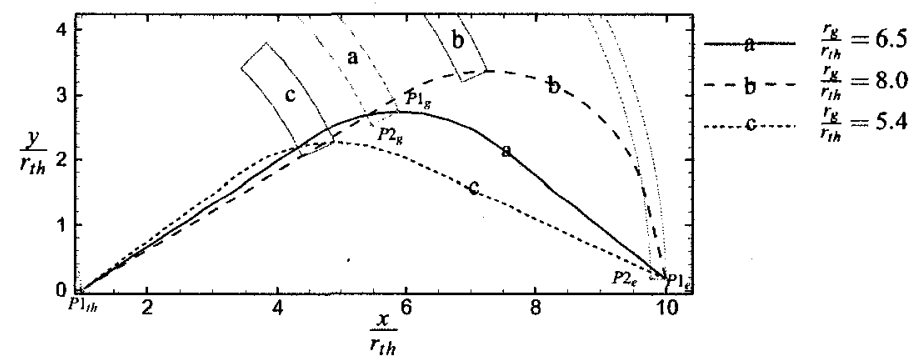

(a) Change in $r_{g}$

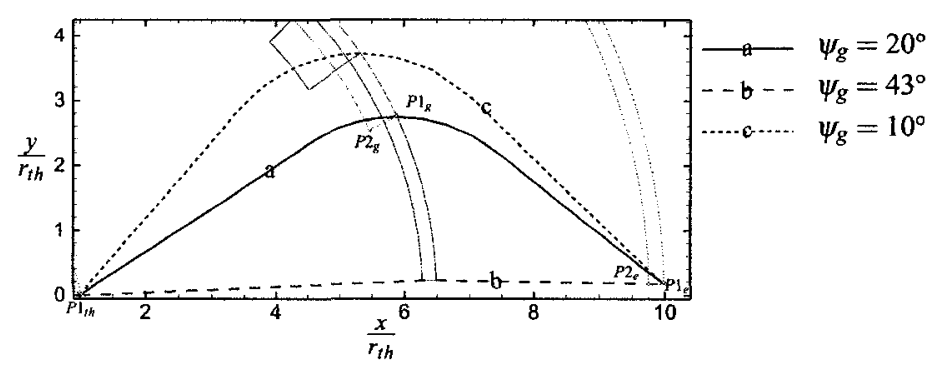

(b) Change in $\psi_{g}$

Figure 2.5: Influence of gate parameters on $P 1$ line

Creation of the air intake shape requires a function to describe the line passing through the $P 1$ points. The goal is to develop a smooth swept wall defining the nozzle/air intake interface where the outer edge passes through the three $P 1$ points shown in Fig. 2.2. Subsequently, a fillet radius $r_{f}$ is introduced to assist in generation of a piecewise function to define the line passing through the $P 1$ points. The line shown in Fig. 2.6 is drawn from a topview perspective such that it exists on the $x-y$ plane.

Figure 2.6 shows that in addition to the three user-defined $P 1$ points at the throat, gate, and outlet, the slope $\frac{d y}{d x}$ of the fillet circle at the gate is set to zero resulting in the placement 


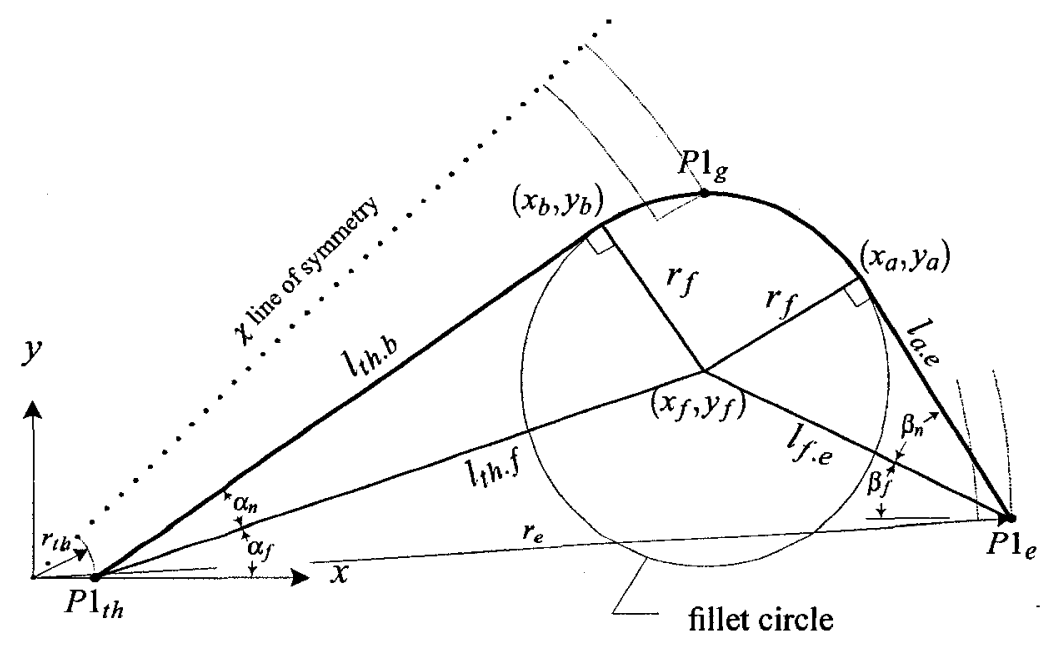

Figure 2.6: Swept side development

of the fillet circle centre at

$$
\left(x_{f}, y_{f}\right)=\left(x_{g},\left[y_{g}-r_{f}\right]\right)
$$

where $x_{g}$ and $y_{g}$ are found from the position of $P 1_{g}$ :

$$
P 1_{g} \equiv\left(x_{g}, y_{g}, z_{g}\right)=\left(\left[r_{g} \cos \left(\chi-\psi_{g}\right)\right],\left[r_{g} \sin \left(\chi-\psi_{g}\right)\right], z_{g}\right)
$$

Upon drawing the fillet circle, Fig. 2.6 shows that inclusion of the throat and outlet $P 1$ points on the curve occurs by projecting linear tangents off the fillet circle through the prescribed points labelled as before-gate tangent $\left(x_{b}, y_{b}\right)$ and after-gate tangent $\left(x_{a}, y_{a}\right)$. Determination of the $\left(x_{b}, y_{b}\right)$ location requires drawing a right-angled triangle using $P 1_{t h}$ and $\left(x_{f}, y_{f}\right)$ as the other two vertices. Since $\left(x_{b}, y_{b}\right)$ is on the $r_{f}$ circle, the distance between $\left(x_{b}, y_{b}\right)$ and the fillet circle centre is $r_{f}$; however, the other two lengths defining the triangle are

$$
l_{t h . f}=\sqrt{\left(x_{f}-r_{t h}\right)^{2}+y_{f}^{2}}
$$


and

$$
l_{\text {th.b }}=l_{\text {th.f }} \cos \alpha_{n}
$$

where the angle $\alpha_{n}$ is found as

$$
\sin \alpha_{n}=\frac{r_{f}}{l_{t h . f}}
$$

The length $l_{\text {th. }}$ is now known and so the angle it creates with respect to the $x$-axis is

$$
\alpha_{\text {sum }}=\alpha_{f}+\alpha_{n}
$$

where

$$
\tan \alpha_{f}=\frac{y_{f}}{x_{f}-r_{t h}}
$$

As a result, the location of the before-gate tangent point is at

$$
\left(x_{b}, y_{b}\right)=\left(\left[r_{t h}+l_{t h . b} \cos \alpha_{s u m}\right],\left[l_{t h . b} \sin \alpha_{s u m}\right]\right)
$$

Similarly, the after-gate tangent is found by first drawing a right-angled triangle using $\left(x_{a}, y_{a}\right),\left(x_{f}, y_{f}\right)$, and $P 1_{e}$ as its vertices where

$$
P 1_{e} \equiv\left(x_{e}, y_{e}, z_{e}\right)=\left(\left[r_{e} \cos \left(\chi-\psi_{e}\right)\right],\left[r_{e} \sin \left(\chi-\psi_{e}\right)\right], z_{e}\right)
$$

The length between the fillet centre and the after-gate tangent point $\left(x_{a}, y_{a}\right)$ is $r_{f}$, whereas

$$
l_{f . e}=\sqrt{\left(x_{e}-x_{f}\right)^{2}+\left(y_{f}-y_{e}\right)^{2}}
$$

and

$$
l_{\text {a.e }}=l_{f . e} \cos \beta_{n}
$$


where $\beta_{n}$ is the angle between $l_{f . e}$ and $l_{a . e}$ and is determined from

$$
\sin \beta_{n}=\frac{r_{f}}{l_{f . e}}
$$

Length $l_{a . e}$ is now known such that the angle it creates with respect to a line parallel to the $x$-axis is

$$
\beta_{\text {sum }}=\beta_{f}+\beta_{n}
$$

where

$$
\tan \beta_{f}=\frac{y_{f}-y_{e}}{x_{e}-x_{f}}
$$

As a result, the after-gate tangent point is placed at

$$
\left(x_{a}, y_{a}\right)=\left(\left[x_{e}-l_{\text {a.e }} \cos \beta_{\text {sum }}\right],\left[y_{e}+l_{\text {a.e }} \sin \beta_{\text {sum }}\right]\right)
$$

Figure 2.7 shows the influence of $r_{f}$ on the curve passing through the $P 1$ points. As the value of $r_{f}$ increases, $A_{\text {intake }}$ increases. Maximizing $r_{f}$ generates a larger air intake area; however, care must be taken since very large $r_{f}$ may be unable to generate a curve passing through the necessary points at the throat and/or the outlet.

The variation in the nozzle's outer radius $r$ with respect to streamwise depth $z$ used to define the outer wall is referred to as a radial contour $r(z)$. Figure 2.8 shows that the radial contour is represented by a function that is axisymmetric about the $z$-axis. In order to avoid requiring piecewise $r(z)$ functions to define the higher radial expansion rate at the throat and a more gradual radial slope for the remainder of the contour that are typical for bell nozzles, a continuous $r(z)$ function is also developed from the Agnesi family of curves:

$$
\frac{r(z)}{r_{t h}}=F\left(1+\cos \left(\frac{\sqrt{\pi}}{\tan ^{-1} \frac{z_{e} G}{r_{t h} D}} \tan ^{-1} \frac{\frac{z}{r_{t h}}-\frac{z_{e}}{r_{t h}} G}{D}\right)^{2}\right)+1
$$




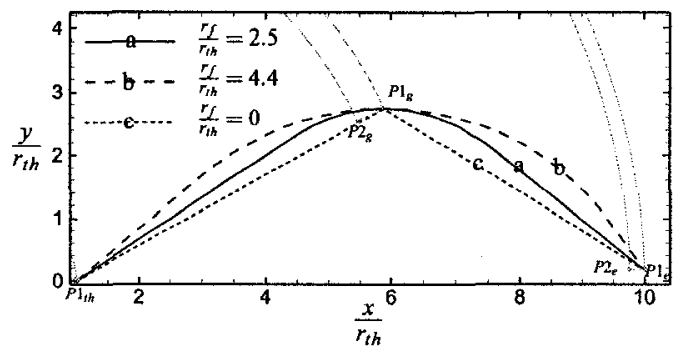

Figure 2.7: $r_{f}$ influence on $P 1$ line

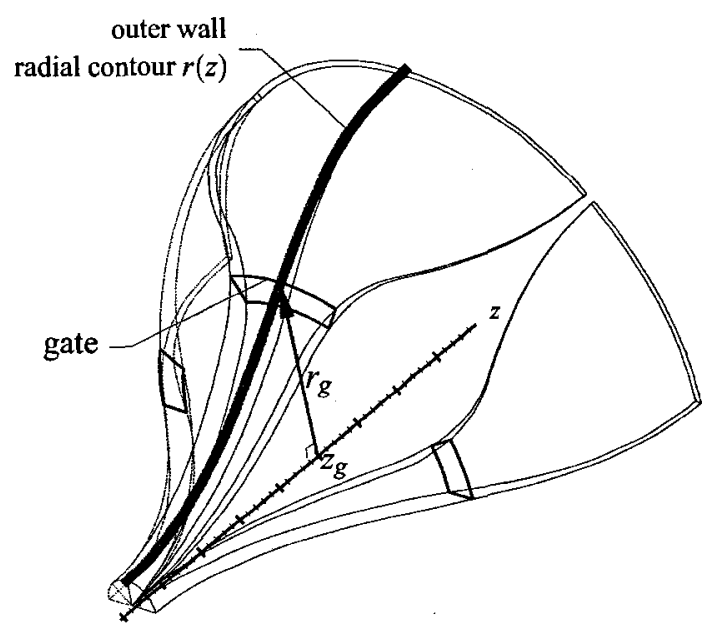

The expression for $F$ is found based on the outlet depth $z_{e}$ from the predefined $M(z)$ data and a user defined outlet radius $r_{e}$

$$
F=\frac{\frac{r_{e}}{r_{t h}}-1}{1+\cos \left(\frac{\sqrt{\pi}}{\tan ^{-1} \frac{z_{e} G}{r_{t h} D}} \tan ^{-1} \frac{\frac{z_{e}}{r_{t h}}(1-G)}{D}\right)^{2}}
$$

Evaluation of $D$ in Eq. (2.21) uses the gate $\left(z_{g}, r_{g}\right)$ input values to obtain an expression

$$
D=\frac{\frac{z_{g}}{r_{t h}}-\frac{z_{e}}{r_{t h}} G}{-\tan \left(\sqrt{\frac{1}{\pi} \cos ^{-1} \frac{\frac{r_{g}}{r_{t h}}-(F+1)}{F}} \tan ^{-1}\left(\frac{z_{e} G}{r_{t h} D}\right)\right)}
$$

Figures 2.9(a) and 2.9(b) show the direct influence of $r_{g}$ and $z_{g}$ on $r(z)$. For increasing $r_{g}$, Fig. 2.9(a) shows that the radial contour slope at the gate $\frac{d r_{g}}{d z}$ decreases. Additionally, increasing $r_{g}$ pushes the radial contour point of inflection nearer to the throat resulting in a shorter region with convex curvature and longer concave region along the outer wall. For supersonic flow, a wall with convex curvature is suggestive of a curved expansion corner, which causes a Mach number increase and diverging Mach waves [11]. In a similar 


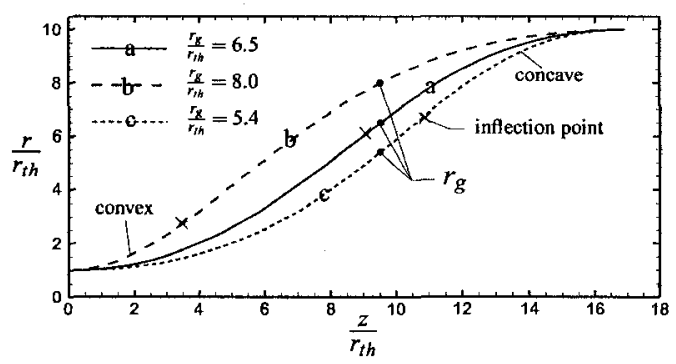

(a) Change in $r_{g}$

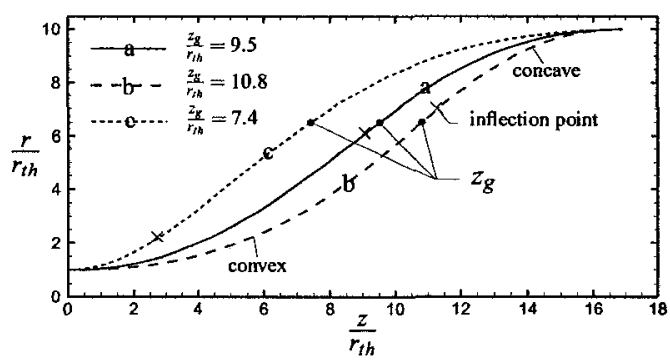

(b) Change in $z_{g}$

Figure 2.9: Influence of gate parameters on radial contour

fashion, Fig. 2.9(b) notes that increasing $z_{g}$ causes an increase to $\frac{d r_{g}}{d z}$ and places the point of inflection nearer to the outlet. Since the expansion of the flow through the nozzle is between an outer wall and an inner wall, the curvature trends reverse for the inner wall such that the contour region nearer to the throat is concave and the outlet region is convex.

Similarly to the inner and outer walls, the swept wall also has curvature. Figure 2.10 shows that the fillet radius is influential to the arclength $(\psi r)$ relationship with respect to depth. From a top view perspective, these curves are shown in Fig. 2.7; however, the curvature considered is based on viewing the line passing through the $P 1$ points in the direction of the $r_{g}$ vector shown in Fig. 2.8. The three curves in Fig. 2.10 show that there is a much more significant increase in the circumferential direction after the gate than before the gate and hence Fig. 2.8 shows that the nozzle spans more of the circumference after the gate.

The differences between the three curves shown in Fig. 2.10 is evident at the gate $z_{g}$ location. Line (c) produces a discontinuity at the gate and the sudden transition to a concave profile after the gate is suggestive of a sharp expansion corner. Similar to the existence of a separation bubble downstream of a backward facing step, sudden expansion corners could potentially produce boundary layer separation if the expansion corner angle is great enough. To reduce the likeliness of this from occurring, increasing $r_{f}$ as shown by line 


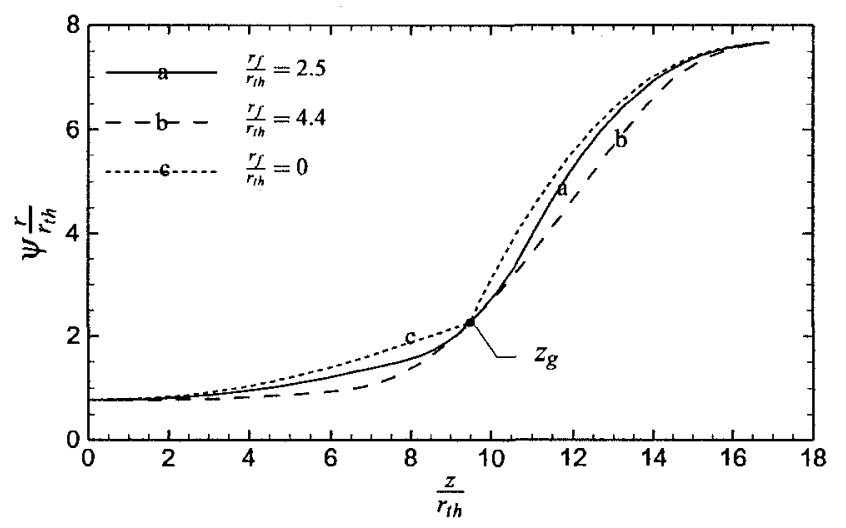

Figure 2.10: $r_{f}$ influence on arclength $[\psi r](z)$ profile

(b) results in a smoother transition at the gate and the concave curvature between the gate and the outlet approaches linearity. A potential downside to the higher $r_{f}$ value is that it also results in the swept wall having a greater arclength slope at the outlet $\frac{d(\psi r)_{e}}{d z}$ and hence a higher outlet circumferential velocity component since streamlines are expected to parallel the wall contours. This may cause the formation of strong oblique shocks or flow recirculation issues after the nozzle outlet since the exhaust flow from a clover on the other side of an air intake will have an equal but opposite circumferential velocity component.

The constant $G$ in Eq. (2.21) is dependent on the specification of an outlet radial contour slope, where in general the contour slope is defined as

$$
\tan \Phi=\frac{d r}{d z}
$$

Taking the derivative of Eq. (2.21), solving for $G$ based on the outlet depth $z_{e}$ and slope $\tan \Phi_{e}=\frac{d r_{e}}{d z}$ gives

$$
G=1-\frac{r_{t h} D}{z_{e}} \tan \left(\frac{-D\left(\tan ^{-1} \frac{z_{e} G}{r_{t h} D}\right)^{2}\left(1+\left(\frac{z_{e}(1-G)}{r_{t h} D}\right)^{2}\right) \tan \Phi_{e}}{2 \pi F \sin \left(\frac{\sqrt{\pi}}{\tan ^{-1} \frac{z_{e} G}{r_{t h} D}} \tan ^{-1} \frac{z_{e}(1-G)}{r_{t h} D}\right)^{2}}\right)
$$


Because Eqs. (2.23) and (2.25) are implicit and coupled, Newton-Raphson's multivariable method is implemented to find a unique solution. Choice of the geometry inputs $z_{g}, r_{g}, r_{e}$, and $\Phi_{e}$ is critical in ensuring that Eqs. (2.23) and (2.25) are capable of finding real-value solutions for $D$ and $G$.

Figure 2.11 shows the $r(z)$ curves that Eq. (2.21) can generate for varying outlet angles. Since $\Phi_{e}$ corresponds to the exhaust flow vector in the radial direction, maintaining $\Phi_{e}=0^{\circ}$ (line (c)) is preferable for maximum thrust; however, line (b) has the benefit of a smaller gate radial contour slope $\frac{d r_{g}}{d z}$. In addition to varying $\Phi_{e}$, lines (d) and (e) also vary $z_{g}$ to show that Eq. (2.21) can generate nearly conical nozzles that maintain convex curvature along most of the outer wall and nozzles with inverted exit angles respectively.

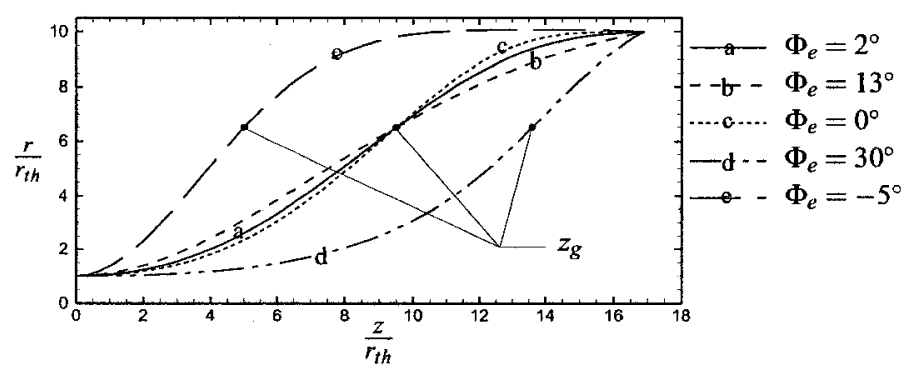

Figure 2.11: $\Phi_{e}$ influence on radial contour

The outlet depth $z_{e}$ is defined by the given $M(z)$ relation and through Eq. (2.1) this defines a set value for $A_{e}$; however, $r_{e}$ and $\psi_{e}$ give flexibility to the outlet shape and assist in defining the air intake size. Figure 2.12 shows the influence that $r_{e}$ has on $r(z)$. Increasing $r_{e}$ causes the nozzle to become much wider at the outlet, increases the radial contour slope at the gate, and places the inflection point nearer to the outlet.

Figures 2.13(a) and 2.13(b) show the influence that $r_{e}$ and $\psi_{e}$ have on the line passing through the $P 1$ points. For increasing $r_{e}$, Fig. 2.13(a) identifies that $A_{\text {intake }}$ increases since it is stretched out along the $x$-axis; whereas Fig. 2.13(b) shows that increasing $\psi_{e}$ causes the outlet cross section to span more of the circumference and results in a reduction to $A_{\text {intake }}$. 


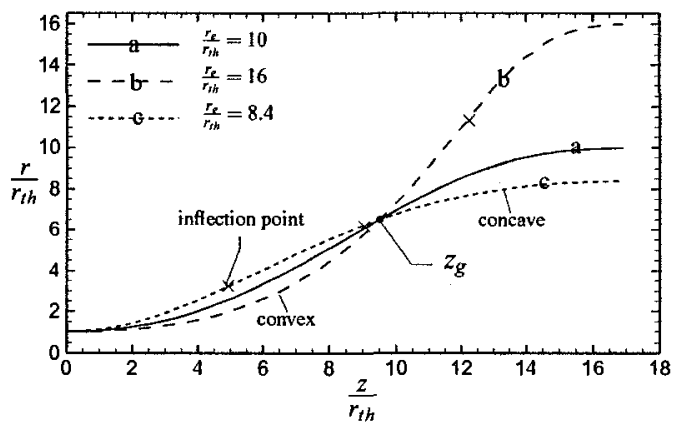

Figure 2.12: Influence of $r_{e}$ on the radial contour

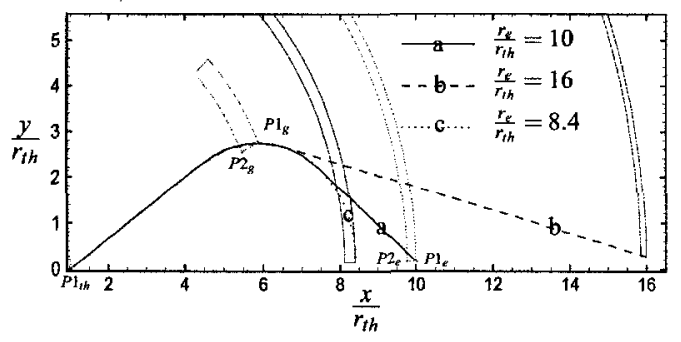

(a) Change in $r_{e}$

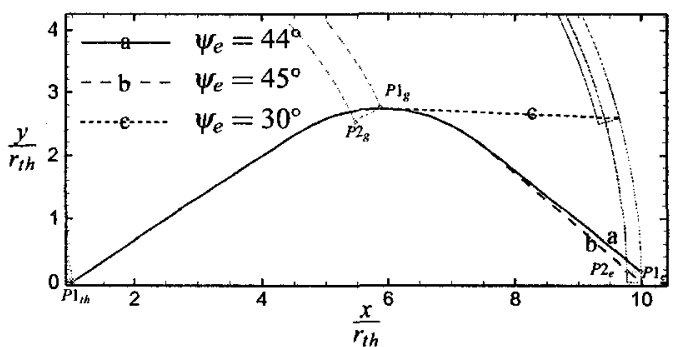

(b) Change in $\psi_{e}$

Figure 2.13: Influence of outlet parameters on $P 1$ line

Determination of the intermediate cross section locations requires the user to specify the total number of cross sections to define the nozzle where $i=N$ corresponds to the outlet cross section. To ensure that cross sections are placed at the fillet tangents as well as the gate, the user must specify three additional values as shown in Fig. 2.14. Since the throat is defined as the first cross section $i=1$, the before-gate tangent cross section is located at $i=N_{b}$ such that there are $N_{b}-1$ intermediate cross sections between the throat and the before-gate tangent point $\left(x_{b}, y_{b}, z_{b}\right)$. The location of the gate cross section is located at $i=N_{g}$ resulting in the placement of $N_{g}-N_{b}$ intermediate cross sections between $\left(x_{b}, y_{b}, z_{b}\right)$ and $\left(x_{g}, y_{g}, z_{g}\right)$. Similarly, the after-gate tangent cross section is located at $i=N_{a}$ such that there are $N_{a}-N_{g}$ cross sections between $\left(x_{g}, y_{g}, z_{g}\right)$ and $\left(x_{a}, y_{a}, z_{a}\right)$. The depths of the before-gate tangent and after-gate tangent points as shown in Fig. 2.14 are found by 


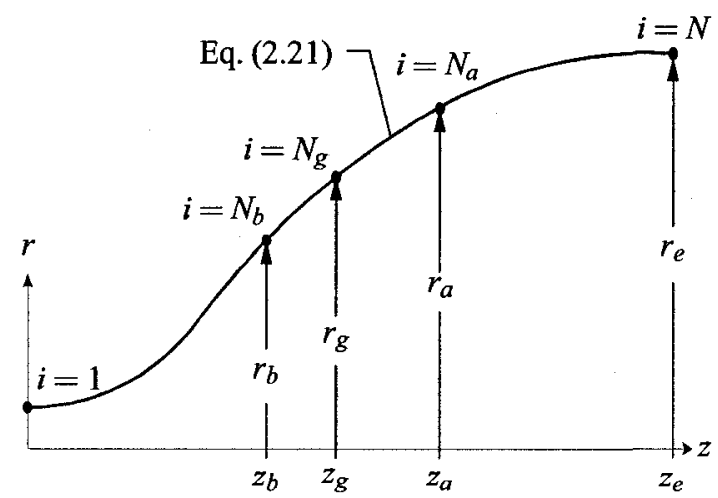

Figure 2.14: Initial values required for filling in remaining cross sections

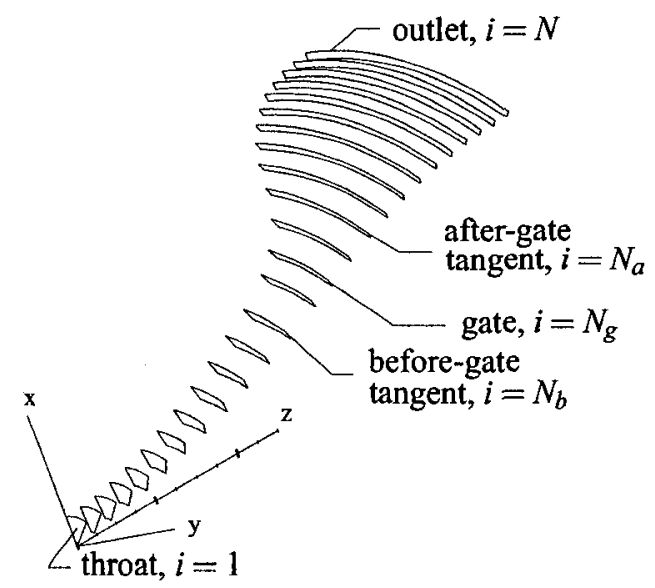

Figure 2.15: Nozzle cross sections

solving Eqs. (2.13) and (2.20) for $r_{b}$ and $r_{a}$ where $r^{2}=x^{2}+y^{2}$ and then using Eq. (2.21) to solve for $z_{b}$ and $z_{a}$.

Figure 2.15 shows the cross sections placed at the before-gate tangent, gate, and aftergate tangent locations along with the remaining intermediate cross sections at various depths $z_{i}$. The equations implemented to solve for $z_{i}$ involve assigning uniform stepsizes between four regions: throat to before-gate tangent, before-gate tangent to gate, gate to after-gate tangent, and after-gate tangent to outlet.

$$
\begin{aligned}
& \text { if } \quad i \leq N_{b} \\
& z_{i}=\frac{z_{b}}{N_{b}-1}(i-1) \\
& \text { elseif } i>N_{b} \text { and } i \leq N_{g} \\
& z_{i}=z_{b}+\frac{z_{g}-z_{b}}{N_{g}-N_{b}}\left(i-N_{b}\right) \\
& \text { elseif } i>N_{g} \text { and } i \leq N_{a} \\
& z_{i}=z_{g}+\frac{z_{a}-z_{g}}{N_{a}-N_{g}}\left(i-N_{g}\right)
\end{aligned}
$$

else

$$
z_{i}=z_{a}+\frac{z_{e}-z_{a}}{N-N_{a}}\left(i-N_{a}\right)
$$


Once all the $z_{i}$ depths are known, Eq. (2.21) is used to determine $r_{i}$ for each of the sections whereas the cross section area $A_{i}$ is calculated using Eq. (2.2). After calculating the radial contour radius $r_{i}$, the $P 1_{i}$ point on each cross section can be located on the line defining the $P 1$ points as redrawn in Fig. 2.16 (see also Fig. 2.6). The procedure for determining the $\left(x_{i}, y_{i}\right)$ values at a particular cross section requires first finding the $y_{i}$ value at the intersection between a circle of radius $r_{i}$ whose origin is placed on the $z$-axis and the previously defined line connecting all of the $P 1$ points. For $i \leq N_{b}$, the intersection is located along the $l_{t h . b}$ line segment and so $y_{i}$ is found from

$$
\text { if } \begin{array}{r}
i \leq N_{b} \\
\qquad \begin{array}{r}
\left(1+\left(\frac{y_{b}}{x_{b}-r_{t h}}\right)^{2}\right) y_{i}^{2}+2 \frac{r_{t h} y_{b}}{x_{b}-r_{t h}} y_{i} \\
+\left(\frac{r_{t h} y_{b}}{x_{b}-r_{t h}}\right)^{2}-\left(r_{i} \frac{y_{b}}{x_{b}-r_{t h}}\right)^{2}=0
\end{array}
\end{array}
$$

For $N_{b}<i \leq N_{a}$, the expression changes because the $\left(x_{i}, y_{i}\right)$ point is at the intersection

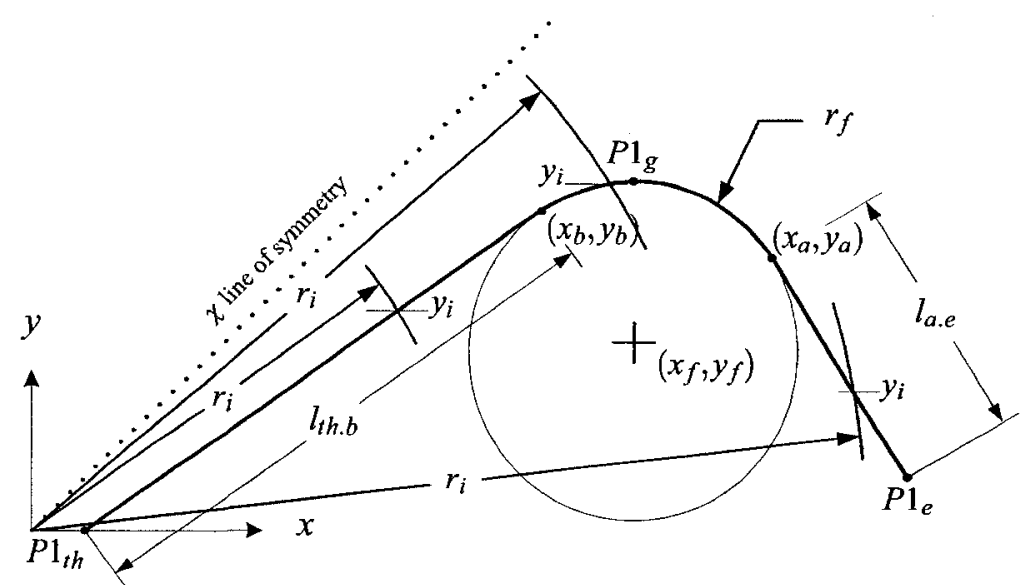

Figure 2.16: Intersecting points between the $P 1$ line and $r_{i}$ 
between a circle of radius $r_{i}$ and the $r_{f}$ circle

$$
\begin{aligned}
& \text { elseif } i>N_{b} \text { and } i \leq N_{a} \\
& \qquad \begin{array}{r}
4\left(x_{f}^{2}+y_{f}^{2}\right) y_{i}^{2}-4 y_{f}\left(r_{i}^{2}-r_{f}^{2}+x_{f}^{2}+y_{f}^{2}\right) y_{i} \\
+\left(r_{i}^{2}-r_{f}^{2}+x_{f}^{2}+y_{f}^{2}\right)^{2}-4 x_{f}^{2} r_{i}^{2}=0
\end{array}
\end{aligned}
$$

Finally, for $i>N_{a},\left(x_{i}, y_{i}\right)$ occurs along the $l_{\text {a.e }}$ line segment and can be found from

$$
\begin{aligned}
& \text { else } \quad i>N_{a} \\
& \qquad \begin{array}{l}
\left(1+\left(\frac{y_{e}-y_{a}}{x_{e}-x_{a}}\right)^{2}\right) \\
y_{i}^{2}-2\left(y_{a}-x_{a} \frac{y_{e}-y_{a}}{x_{e}-x_{a}}\right) y_{i} \\
+\left(y_{a}-x_{a} \frac{y_{e}-y_{a}}{x_{e}-x_{a}}\right)^{2}-\left(r_{i} \frac{y_{e}-y_{a}}{x_{e}-x_{a}}\right)^{2}=0
\end{array}
\end{aligned}
$$

In each case, the corresponding $x_{i}$ is the result of

$$
x_{i}=\sqrt{r_{i}^{2}-y_{i}^{2}}
$$

The placement of the $P 1_{i}$ points are now known to exist at

$$
P 1_{i}=\left(x_{i}, y_{i}, z_{i}\right)
$$

Since Fig. 2.2 shows that the $P 4_{i}$ points (outer wall points on the $\chi$-plane of symmetry) have the same radius $r_{i}$ as the $P 1_{i}$ points, in Cartesian coordinates,

$$
P 4_{i}=\left(\left[r_{i} \cos \chi\right],\left[r_{i} \sin \chi\right], z_{i}\right)
$$

Subsequently, the arc angle $\psi$ shown in Fig. 2.2 to define the angle for both the inner and 
outer walls at each section is

$$
\psi_{i}=\chi-\tan ^{-1} \frac{y_{i}}{x_{i}}
$$

Figure 2.2 shows that cross sections are bounded by the corner points $P 2_{i}$ and $P 3_{i}$ in addition to the known locations of $P 1_{i}$ and $P 4_{i}$. Since Eq. (2.1) is derived from the conservation of mass, the resulting $A_{i}$ are defined as being normal to the flow direction. Figure 2.17 shows that the radial contour tangential angle $\Phi_{i}$ can assist in properly orienting a cross section of thickness $t_{i}$ where the $r^{\prime}$ and $z^{\prime}$ axes define the normal and tangent directions respectively to the outer wall radial contour $r(z)$. Placement of the cross sections requires that the depths of the inner wall points $P 2_{i}$ and $P 3_{i}$ are offset from the outer wall depth $z_{i}$ found from Eq. (2.26) by $t_{i} \sin \Phi_{i}$. This means that all cross sections shown on the $x-y$ plane are actually projections and so the shape shown in Fig. 2.18 more accurately depicts a cross section. This shape exists on a $z^{\prime}$-plane and is defined such that the outer wall arclength $\left(\psi_{i} r_{i}\right)$ occurs on the circumferential $\Psi^{\prime}$-axis. In a similar fashion to the change in inner wall depth, the inner wall radii are $t_{i} \cos \Phi_{i}$ less than the $r_{i}$ values calculated by Eq. (2.21).

Since the cross section thickness $t_{i}$ is still unknown, Fig. 2.19 shows that a uniform thickness $t_{i}$ is used such that the cross section area can be represented by a rectangular shape (region $\square$ ) and a triangular shape (region $\triangle$ ). The area defining the $\square$ region is

$$
A_{\square}=\psi_{i}\left(r_{i}-t_{i} \cos \Phi_{i}\right) t_{i}
$$

and the area defining the $\triangle$ region is

$$
A_{\triangle}=\frac{1}{2} \psi_{i} t_{i}^{2} \cos \Phi_{i}
$$

Adding the rectangular and triangular areas together result in a cross section area of

$$
A_{i} \approx \psi_{i} r_{i} t_{i}-\frac{1}{2} \psi_{i} t_{i}^{2} \cos \Phi_{i}
$$




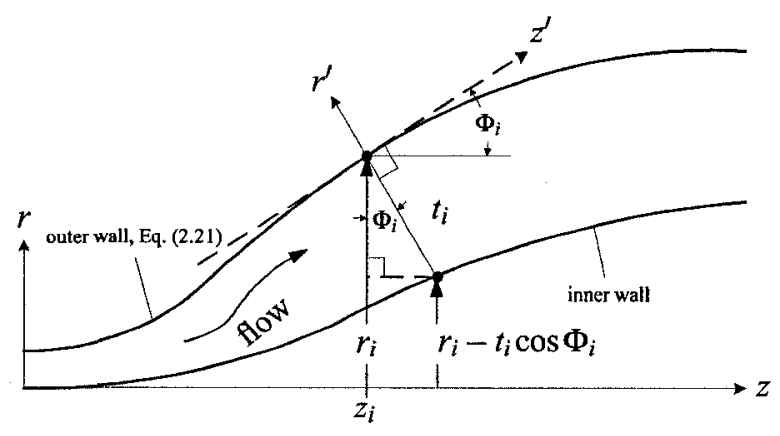

Figure 2.17: Cross section orientation (2D)

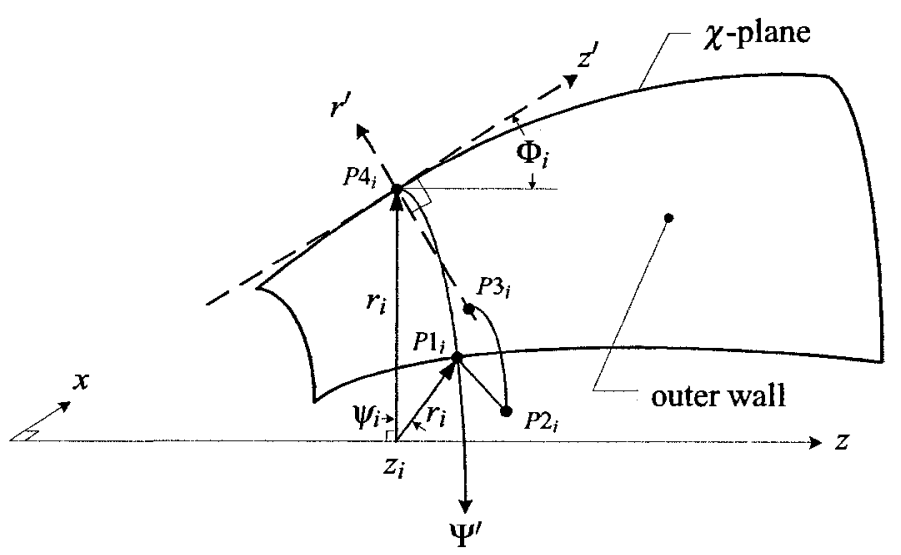

Figure 2.18: Cross section orientation (3D)

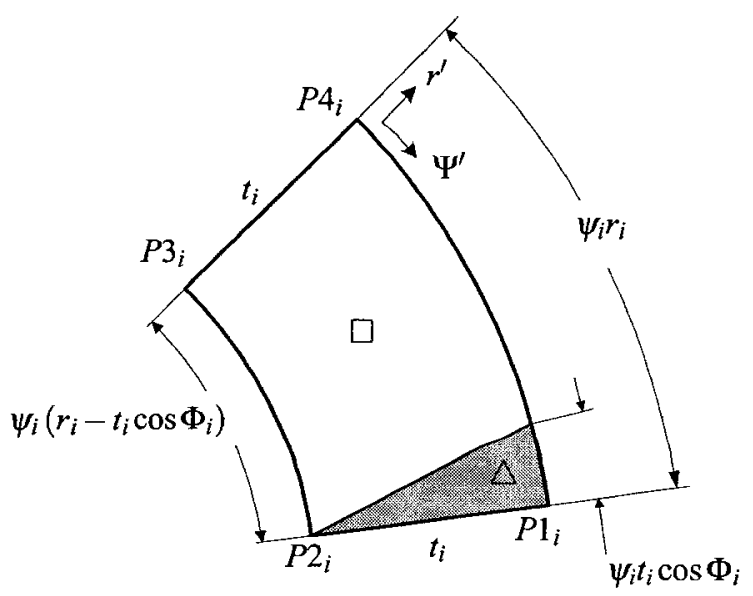

Figure 2.19: Cross section shape ( $z^{\prime}$-plane) 
Everything is known in Eq. (2.36) at a given cross section except for its thickness so Eq. (2.36) is rearranged into a quadratic expression that can solve for $t_{i}$

$$
\cos \left(\Phi_{i}\right) t_{i}^{2}-2 r_{i} t_{i}+\frac{2 A_{i}}{\psi_{i}}=0
$$

Since implementing the quadratic formula on Eq. (2.37) solves for two roots, the positive real root is selected to define $t_{i}$. With the cross section thickness known, the placement of the inner wall corner points shown in Fig. 2.19 are

$$
P 3_{i}=\left(\left[\left(r_{i}-t_{i} \cos \Phi_{i}\right) \cos \chi\right],\left[\left(r_{i}-t_{i} \cos \Phi_{i}\right) \sin \chi\right],\left[z_{i}+t_{i} \sin \Phi_{i}\right]\right)
$$

and

$$
P 2_{i}=\left(\left[\left(r_{i}-t_{i} \cos \Phi_{i}\right) \cos \left(\chi-\psi_{i}\right)\right],\left[\left(r_{i}-t_{i} \cos \Phi_{i}\right) \sin \left(\chi-\psi_{i}\right)\right],\left[z_{i}+t_{i} \sin \Phi_{i}\right]\right)
$$

\subsubsection{Inviscid Theory Summary}

Table 2.1 summarizes the values provided to generate the solid reference lines (line (a)) in the previous figures. These reference values are not suggestive of an ideal design but are used to gain an appreciation for the required input variables. The $r-z$ figures identify the variable influence on the radial contour whereas the $x-y$ figures correspond to variables that influence the line passing through the $P 1$ points and hence $A_{\text {intake }}$. Line (b) in the figures indicates the maximum value for the varied variable whereas line (c) is the minimum. The bounds are established either because the solution to Eq. (2.21) for $D$ and $G$ are not real values beyond this range or that the thickness $t_{i}$ calculated from Eq. (2.37) exceeds the distance in the normal direction between the radial contour and the $z$-axis. Table 2.1 also shows how to individually vary a given input variable to increase the size of the air intake area. 
Table 2.1: Geometry reference values for the sensitivity analysis

\begin{tabular}{ccccc}
\hline \hline Input variable & Value & $r$-z Fig. & $x$-y Fig. & For $A_{\text {intake }} \uparrow$ \\
\hline$\chi$ & $45^{\circ}$ & $2.4(\mathrm{a})-2.4(\mathrm{c})$ & $\uparrow$ \\
$\frac{r_{g}}{r_{t h}}$ & 6.5 & $2.9(\mathrm{a})$ & $2.5(\mathrm{a})$ & $\uparrow$ \\
$\psi_{g}$ & $20^{\circ}$ & & $2.5(\mathrm{~b})$ & $\downarrow$ \\
$r_{f}$ & 2.5 & & 2.7 & $\uparrow$ \\
$r_{t h}$ & 9.5 & $2.9(\mathrm{~b})$ & & $\downarrow$ \\
$\underline{r}_{t h}$ & $2^{\circ}$ & 2.11 & & $\downarrow$ \\
$\Phi_{e}$ & 10 & 2.12 & $2.13(\mathrm{a})$ & $\uparrow$ \\
$\frac{r_{e}}{r_{t h}}$ & $44^{\circ}$ & & $2.13(\mathrm{~b})$ & $\downarrow$ \\
$\psi_{e}$ & & & \\
\hline \hline
\end{tabular}

\subsection{Implementation of Viscous Effects}

To ensure that the desired Mach number distribution $M(z)$ is maintained, the isentropic area $A(z)$ determined by Eq. (2.1) must be increased to account for the mass flow deficit caused by wall shear forces that reduce velocity in the near-wall region. The viscous effects present in the boundary layer can be compensated for through the addition of a displacement thickness $\delta^{*}$. Figure 2.20 offers a schematic of how addition of $\delta^{*}$ to an inviscid region of thickness $t$ with freestream velocity $V$ can represent the mass flow of a real fluid through a cross section of thickness $t_{v i s}$ that has a velocity profile corresponding to an internal flow with boundary layers of thickness $\delta$. Two $\delta^{*}$ methods under consideration include Edenfield's correlation [31] and a solution to the integral equation requiring expressions derived by Barnhart [32] and Hunter [33]. 


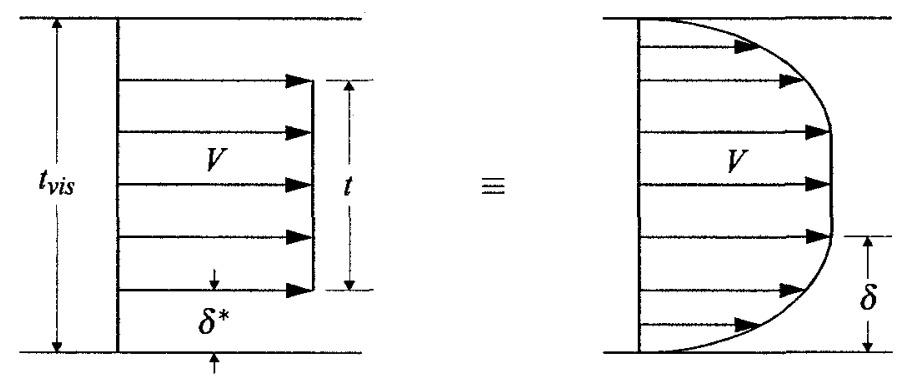

Figure 2.20: Boundary layer definition

\section{Edenfield's Displacement Thickness}

Edenfield [31] developed an empirical formulation based on experimental data for a conical nozzle in a hypersonic wind tunnel. To satisfy a boundary layer thickness calculated using

$$
\delta=0.195 L \frac{M^{0.375}}{R e_{L}^{0.166}}
$$

where

$$
\operatorname{Re}_{L}=\frac{\rho_{i} V_{i} L}{\mu_{i}}
$$

the displacement thickness relation

$$
\delta^{*}=\frac{21}{50} \frac{L}{R e_{r e f}^{0.2775}}
$$

is suggested where $L$ is the physical location downstream as measured from the nozzle throat along the given inviscid nozzle wall from $i=1$ at the throat to cross $\operatorname{section} N_{i}$

$$
L=\sum_{i=2}^{N_{i}} \sqrt{\left(x_{i}-x_{i-1}\right)^{2}+\left(y_{i}-y_{i-1}\right)^{2}+\left(z_{i}-z_{i-1}\right)^{2}}
$$

To obtain the displacement thickness correction for the inner wall $\delta_{i n}^{*}$, Eq. (2.43) is evaluated along points $P 3$, the outer wall $\delta_{\text {out }}^{*}$ evaluates Eq. (2.43) along points $P 4$, and the swept 
wall $\delta_{s w}^{*}$ defines $L$ along points $P 1$.

The reference Reynolds number in Eq. (2.42) is defined as

$$
R e_{r e f}=\frac{\rho_{r e f} V_{i} L}{\mu_{r e f}}
$$

where the freestream velocity $V_{i}$ can be obtained from

$$
V_{i}=M_{i} \sqrt{\gamma R T_{i}}
$$

Since cross section areas for the inviscid region are known from Eq. (2.36), the Mach number for a given cross section can be obtained from Eq. (2.1). The user is required to specify a constant specific heat ratio $\gamma$ and molar mass $M W$ to define the fluid such that the gas constant is found from

$$
R=\frac{R_{u}}{M W}
$$

For the expected temperature range, secondary reactions and formation of additional species occurs if the flow is a mixture of products from a combustion reaction; however, this thesis is not concerned about developing a comprehensive combustion model. Assuming zero reaction rates and defining constant $M W$ and $\gamma$ is acceptable since reactions have effectively ceased once the flow reaches the nozzle and so the fluid can be treated as a single species [9].

The cross section static temperature $T_{i}$ in Eq. (2.45) can be obtained from the isentropic relation

$$
T_{i}=\frac{T_{0}}{1+\frac{\gamma-1}{2} M_{i}^{2}}
$$

where a user defined throat static temperature $T_{t h}$ and knowing that the velocity at the throat is sonic $M_{t h}=1$ gives the total temperature $T_{0}$ through the relation

$$
T_{0}=\frac{T_{t h}(\gamma+1)}{2}
$$


Viscosity $\mu$ in Eq. (2.41) is evaluated at a freestream temperature obtained from Eq. (2.47) whereas the reference viscosity $\mu_{r e f}$ in Eq. (2.44) is evaluated at a reference temperature $T_{r e f}$, where $T_{r e f}$ is obtained from the enthalpy relation

$$
h_{r e f}=\frac{1}{2}\left(h_{w}+h_{0}\right)-\frac{151}{1000} V_{i}^{2}
$$

The wall enthalpy $h_{w}$ is evaluated using a user specified wall temperature $T_{w}$ whereas the total enthalpy $h_{0}$ is determined from the total temperature $T_{0}$. For a single species fluid, coefficients for a temperature dependent curvefit enthalpy equation,

$$
h(T)=R_{u}\left(a_{1} T+a_{2} \frac{T^{2}}{2}+a_{3} \frac{T^{3}}{3}+a_{4} \frac{T^{4}}{4}+a_{5} \frac{T^{5}}{5}\right)
$$

are defined in McBride and Gordon and are valid over the range 300-5000 [K] [34]. Once $T_{r e f}$ is known, the reference viscosity is calculated from the curvefit equation

$$
\ln \mu(T)=b_{1} \ln T+\frac{b_{2}}{T}+\frac{b_{3}}{T^{2}}+b_{4}
$$

using the viscosity coefficients provided in McBride and Gordon [34].

Density in Eq. (2.41) is calculated using the ideal gas law based on the freestream static pressure $P_{i}$ and freestream temperature $T_{i}$

$$
\rho_{i}=\frac{P_{i}}{R T_{i}}
$$

Similarly, the ideal gas law defines the reference density $\rho_{\text {ref }}$ in Eq. (2.44) as

$$
\rho_{\text {ref }}=\frac{P_{i}}{R T_{r e f}}
$$

Owing to the fact that the flow is compressible, a validity check was completed on the 
applicability of the ideal gas law assumption using air. White [35] reports that the compressibility factor does not need to be included for $\pm 10 \%$ accuracy so long as

$$
1.8 \leq \frac{T}{T_{\text {crit }}} \leq 15 \text { and } 0 \leq \frac{P}{P_{\text {crit }}} \leq 10
$$

where the critical properties for air are $T_{\text {crit }}=133[\mathrm{~K}]$ and $P_{\text {crit }}=3952[\mathrm{kPa}]$ [35]. The check is based upon setting the throat properties to $T_{t h}=3300[\mathrm{~K}]$ and $P_{t h}=2724[\mathrm{kPa}]$ corresponding to $M_{e}=2.75$ and results in the ranges of

$$
15 \leq \frac{T}{T_{\text {crit }}} \leq 25 \text { and } 0.05 \leq \frac{P}{P_{\text {crit }}} \leq 0.74
$$

Since the temperature range is outside the accepted limits, the Beattie-Bridgeman (B-B) equation of state as presented in Çengel and Boles [36] is implemented to predict density based on the provided temperature and pressure. Table 2.2 shows the equations of state results evaluated at three locations. The comparisons at the throat and outlet locations give confidence that the ideal gas law is applicable for the diverging nozzle region.

Table 2.2: Deviation from ideal gas law behaviour

\begin{tabular}{cccccc}
\hline \hline Location & $\mathrm{T}[\mathrm{K}]$ & $\mathrm{P}[\mathrm{kPa}]$ & Eq. (2.52) $\rho\left[\frac{\mathrm{kg}}{\mathrm{m}^{3}}\right]$ & $\mathrm{B}-\mathrm{B} \rho\left[\frac{\mathrm{kg}}{\mathrm{m}^{3}}\right]$ & Difference \% \\
\hline Throat & 3300 & 2724 & 2.85 & 2.86 & 0.4 \\
Outlet & 1989 & 170 & 0.30 & 0.30 & 0.0 \\
Combustion chamber & 3668 & 4864 & 4.57 & 4.60 & 0.7 \\
\hline \hline
\end{tabular}

Since temperature is known at a given cross section from Eq. (2.47), the isentropic simplification

$$
P_{i}=P_{0}\left(\frac{T_{i}}{T_{0}}\right)^{\frac{\gamma}{\gamma-1}}
$$

can solve for pressure in Eq. (2.52) where total pressure $P_{0}$ requires a user defined throat 
static pressure $P_{t h}$ to solve the isentropic relation

$$
P_{0}=P_{t h}\left(\frac{T_{0}}{T_{t h}}\right)^{\frac{\gamma}{\gamma-1}}
$$

\section{Integral Equation Displacement Thickness Derivation}

Hunter [33] and Barnhart's [32] contributions to the Nozzle Performance Analysis Code (NPAC) provide an analytical solution for 2D converging-diverging nozzles to the compressible flow displacement thickness integral

$$
\delta^{*}=\int_{0}^{\delta} 1-\frac{\tilde{\rho} \bar{u}}{\rho V} d r^{\prime}
$$

where $\rho$ is the freestream density and $\tilde{\rho}$ is the boundary layer density. The boundary layer density $\tilde{\rho}$ is evaluated using a freestream pressure $P$ and a boundary layer temperature $\tilde{T}$. Schlichting [37] shows that the energy equation assuming no heat transfer can be integrated directly to give a boundary layer temperature expression

$$
\frac{\tilde{T}}{T}=1+R F \frac{\gamma-1}{2} M^{2}\left[1-\left(\frac{\bar{u}}{V}\right)^{2}\right]
$$

that can be used to define the thermal boundary layer since it varies with respect to the boundary layer velocity $\bar{u}$. The boundary layer velocity $\bar{u}$ increases in the normal direction $r^{\prime}$ to the radial contour $r(z)$ and is calculated from a fully developed turbulent boundary layer $1 / 7^{\text {th }}$ similarity velocity profile

$$
\frac{\bar{u}}{V}=\left(\frac{r^{\prime}}{\delta}\right)^{1 / 7}
$$


The recovery factor $R F$ in Eq. (2.59) is known to be a function of Prandtl's number

$$
\operatorname{Pr}=\frac{\mu C_{p}}{\lambda}
$$

where $C_{p}$ is the specific heat at constant pressure and $\lambda$ is the thermal conductivity. Since the flow is supersonic, the turbulent flat plate recovery factor

$$
R F=\sqrt[3]{\operatorname{Pr}}
$$

defined by Barnhart [32] is implemented.

Evaluation of the boundary layer thickness $\delta$ in Eq. (2.60) is determined from a Blasius skin friction coefficient $C_{f}$ equation for a turbulent boundary layer

$$
\delta=\left(\frac{0.0456}{C_{f}}\right)^{4} \frac{\mu_{a w}}{\rho V}
$$

where the adiabatic wall viscosity $\mu_{a w}$ is evaluated at an adiabatic wall temperature $T_{a w}$. The heat transfer term in Schlichting's [37] boundary layer temperature expression is dependent on $\left(T_{w}-T_{a w}\right)$ meaning that Eq. (2.59) can solve for the adiabatic wall temperature when $T_{w}=T_{a w}$ and $\overline{u_{w}}=0$ as

$$
T_{a w}=T\left(1+R F \frac{\gamma-1}{2} M^{2}\right)
$$

In order to define the skin friction coefficient in Eq. (2.63), Barnhart [32] implements White and Christoph's [35] flat plate compressible turbulent skin friction coefficient formulation

$$
C_{f}=\frac{0.455}{\Omega^{2} \ln ^{2}\left(\frac{0.06}{\Omega} \operatorname{Re}_{L} \frac{\mu}{\mu_{w}} \sqrt{\frac{T}{T_{w}}}\right)}
$$


where

$$
\begin{aligned}
\Omega & =\frac{\sqrt{\frac{T_{o w}}{T}-1}}{\sin ^{-1}\left(\frac{2 a^{2}-b}{\sqrt{b^{2}+4 a^{2}}}\right)+\sin ^{-1}\left(\frac{b}{\sqrt{b^{2}+4 a^{2}}}\right)} \\
a & =\sqrt{\frac{\gamma-1}{2} M^{2} \frac{T}{T_{w}}} \\
b & =\frac{T_{a w}}{T_{w}}-1
\end{aligned}
$$

Additionally, Eq. (2.65) is dependent on a flat plate Reynolds number $R_{L}$ where Barnhart's [32] calculation uses an effective length based on lateral surface area and Sutherland's law for viscosity calculations. Since the proposed nozzle design is not axially symmetric and curvefit correlations are available, Eq. (2.41) is equated using Eq. (2.43) to define the length $L$ and the viscosity is calculated at a freestream temperature $T$ using McBride and Gordon's [34] coefficients.

Since both the boundary layer temperature and freestream temperature are evaluated based upon the freestream pressure, the ideal gas law can redefine the density expression in Eq. (2.58) as

$$
\frac{\tilde{\rho}}{\rho}=\frac{T}{\tilde{T}}
$$

Substituting Eqs. (2.60) and (2.59) through Eq. (2.69) into Eq. (2.58) gives

$$
\delta^{*}=\int_{0}^{\delta} \frac{1+R F \frac{\gamma-1}{2} M^{2}\left[1-\left(\frac{r^{\prime}}{\delta}\right)^{2 / 7}\right]-\left(\frac{\gamma^{\prime}}{\delta}\right)^{1 / 7}}{1+R F \frac{\gamma-1}{2} M^{2}\left[1-\left(\frac{\gamma^{\prime}}{\delta}\right)^{2 / 7}\right]} d r^{\prime}
$$

Hunter [33] uses Simpson's rule for numerical integration that is derived using quadratic 
interpolation to solve Eq. (2.70) and define the displacement thickness as

$$
\delta^{*}=\frac{\delta}{6}\left[1+4\left(\frac{1+R F \frac{\gamma-1}{2} M^{2}\left[1-\left(\frac{1}{2}\right)^{2 / 7}\right]-\left(\frac{1}{2}\right)^{1 / 7}}{1+R F \frac{\gamma-1}{2} M^{2}\left[1-\left(\frac{1}{2}\right)^{2 / 7}\right]}\right)\right]
$$

\subsubsection{Adding Displacement Thickness to Geometry}

Figure 2.21 shows how the displacement thickness $\delta^{*}$ is added to the inviscid inner, outer, and swept walls at a given cross section. Additionally, Fig. 2.22 notes that the inner and outer displacement thicknesses, $\delta_{\text {in }}^{*}$ and $\delta_{\text {out }}^{*}$, are added along the $r^{\prime}$-axis to ensure that a cross section remains on a $z^{\prime}$-plane. (see Fig. 2.17 for inviscid 2D orientation). It follows that the viscous $P 4$ points are located at

$$
P 4_{v i s_{i}}=\left(\left[r_{v i s_{i}} \cos \chi\right],\left[r_{v i s_{i}} \sin \chi\right], z_{v i s_{i}}\right)
$$

where

$$
r_{v i s_{i}}=r_{i}+\delta_{o u t_{i}}^{*} \cos \Phi_{i}
$$

and

$$
z_{\text {visi }}=z_{i}-\delta_{o u t_{i}}^{*} \sin \Phi_{i}
$$

In a similar fashion, the viscous $P 3$ points are located at

$$
P 3_{v i s_{i}}=\left(\left[\left(r_{v i s_{i}}-t_{v i s_{i}} \cos \Phi_{i}\right) \cos \chi\right],\left[\left(r_{v i s_{i}}-t_{v i s_{i}} \cos \Phi_{i}\right) \sin \chi\right],\left[z_{v i s_{i}}+t_{v i s_{i}} \sin \Phi_{i}\right]\right)
$$

where

$$
t_{v i s_{i}}=t_{i}+\delta_{i n_{i}}^{*}+\delta_{o u t_{i}}^{*}
$$

The swept wall displacement thickness $\delta_{s w}^{*}$ is the distance along the viscous outer wall in the circumferential $\Psi^{\prime}$-direction (refer to Fig. 2.18). Placement of the viscous $P 1$ points 


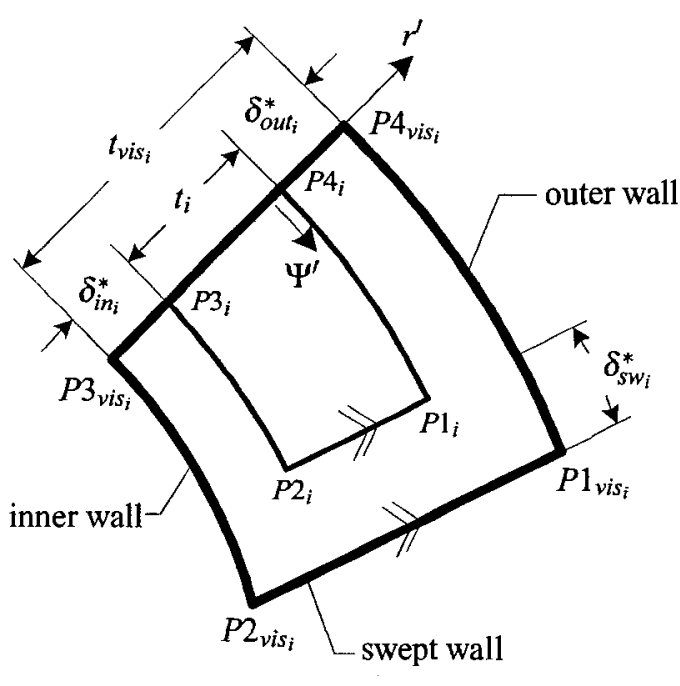

Figure 2.21: Addition of displacement thickness to inviscid design $\left(z^{\prime}\right.$ plane)

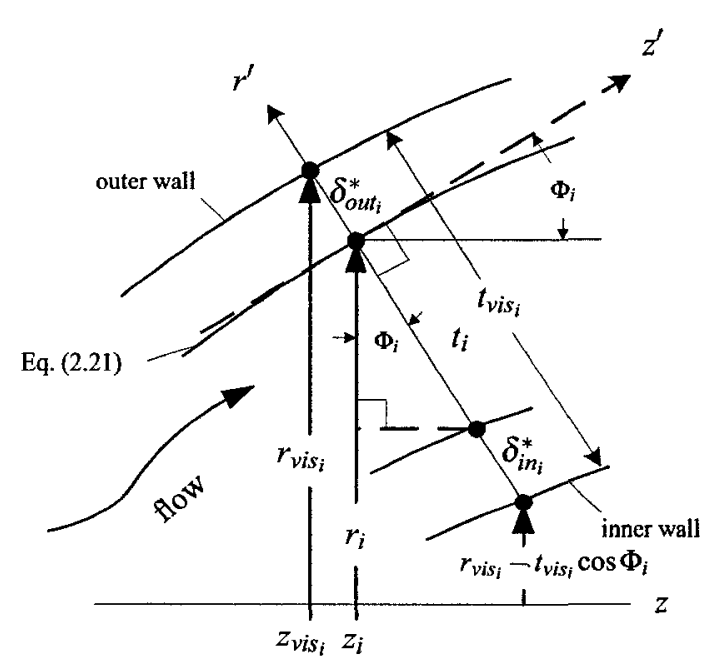

Figure 2.22: Viscous cross section orientation (2D)

can thus be found from

$$
P 1_{v i s_{i}}=\left(\left[r_{v i s_{i}} \cos \left(\chi-\psi_{v i s . o u t_{i}}\right)\right],\left[r_{v i s_{i}} \sin \left(\chi-\psi_{v i s . o u t_{i}}\right)\right], z_{v i s_{i}}\right)
$$

where

$$
\psi_{\text {vis.out }}=\psi_{i}+\frac{\delta_{s w_{i}}^{*}}{r_{v i s_{i}}}
$$

To complete a viscous cross section as shown in Fig. 2.21, the viscous $P 2$ points are placed at

$$
\begin{aligned}
P 2_{v i s_{i}}= & \left(\left[\left(r_{v i i_{i}}-t_{v i s_{i}} \cos \Phi_{i}\right) \cos \left(\chi-\psi_{v i s . i_{i}}\right)\right],\right. \\
& {\left.\left[\left(r_{v i s_{i}}-t_{v i s_{i}} \cos \Phi_{i}\right) \sin \left(\chi-\psi_{v i s . n_{i}}\right)\right],\left[z_{v i s_{i}}+t_{v i i_{i}} \sin \Phi_{i}\right]\right) }
\end{aligned}
$$

where

$$
\psi_{v i s . i_{i}} \approx \psi_{i}+\frac{\delta_{s w_{i}}^{*}}{r_{v i i_{i}}-t_{v i s_{i}} \cos \Phi_{i}}
$$


In the event that $P 2_{v i s_{i}}$ drops below the $x$-axis, Fig. 2.23 shows that the point is relocated to the intersection between a circle of radius $\left(r_{v i s_{i}}-t_{v i s_{i}} \cos \Phi_{i}\right)$ and the $x$-axis. Additionally, $P 1_{v i s_{i}}$ is shifted on a circle of radius $r_{v i s_{i}}$ such that the swept wall angle $\left(\chi-\psi_{i}\right)$ does not change; however, this causes a reduction to $\delta_{s w_{i}}^{*}$.

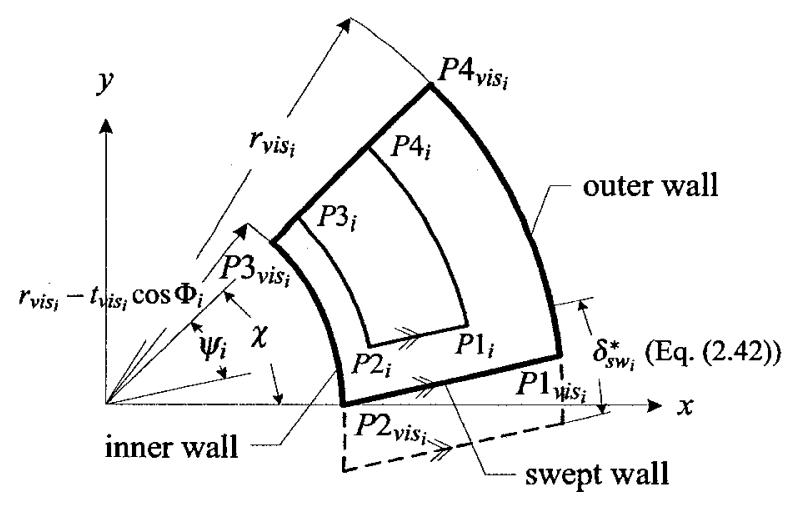

Figure 2.23: Swept wall correction

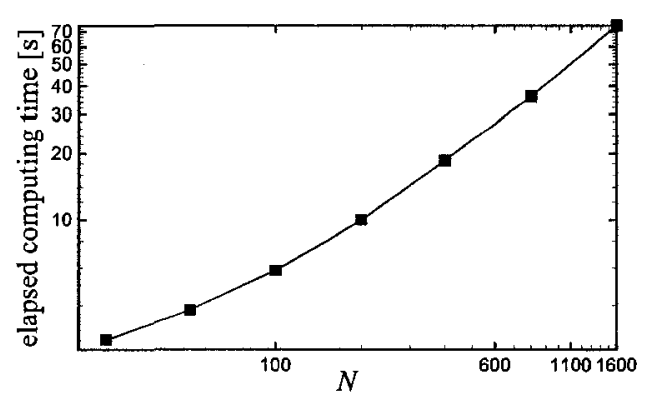

Figure 2.24: Processor computing times for nozzle design generation

\subsection{Computational Implementation}

MATLAB ${ }^{\circledR} 7.0 .1$ was selected as the computer language for developing a nozzle modelling program using the provided methodology. Results were obtained using an Intel Core Duo processor T2300 (1.66 GHz, $2.00 \mathrm{~GB}$ RAM). Figure 2.24 shows computational solver time with respect to number of cross sections $N$ for a code that generates both an inviscid geometry design and a viscous geometry design through consideration of a displacement thickness correlation. These geometry designs can then be loaded into an external meshing software that creates grids for computational fluid dynamics analyses. 


\section{Chapter 3}

\section{Numerical Setup}

\subsection{Design Selection}

The design to be considered in the computational fluid dynamics analyses is developed from the Mach number distribution shown in Fig. 3.1 (and is the data set used to obtain the area profile shown in Fig. 2.1). This $M(z)$ distribution reaches $M_{e}=2.75$ at the outlet and is created using the theory described in Etele [21] through matching specific impulse at sea level $I_{s p}=220[\mathrm{~s}]$ and total pressure $P_{0}=48[\mathrm{~atm}]$ to an Atlas E/F LR-105-5 sustainer engine. The exhaust flow properties correspond to the products from a kerosene $\mathrm{C}_{12} \mathrm{H}_{24}$ and air reaction with $100 \%$ combustion efficiency and an equivalence ratio of 1.49 . The required input fluid properties that represent the exhaust mixture are molar mass $M W=$ $29.54\left[\frac{\mathrm{kg}}{\mathrm{kmol}}\right]$ and specific heat ratio $\gamma=1.22$. Additionally, the total temperature is set to $T_{0}=3668[\mathrm{~K}]$ such that the input throat temperature can be found from Eq. (2.48) as $T_{t h}=3300[\mathrm{~K}]$ and Eq. (2.57) solves for the input throat pressure as $P_{t h}=2724[\mathrm{kPa}]$.

Based on the $P_{t h}$ and $T_{t h}$ values, Eq. (2.45) calculates the throat velocity as $V_{t h}=$ $1066\left[\frac{\mathrm{m}}{\mathrm{s}}\right]$ and the ideal gas law gives $\rho_{t h}=2.93\left[\frac{\mathrm{kg}}{\mathrm{m}^{3}}\right]$. An exhaust mass flow rate of $\dot{m}_{e}=29.8\left[\frac{\mathrm{kg}}{\mathrm{s}}\right]$ for the entire nozzle is implemented such that the throat radius can be 


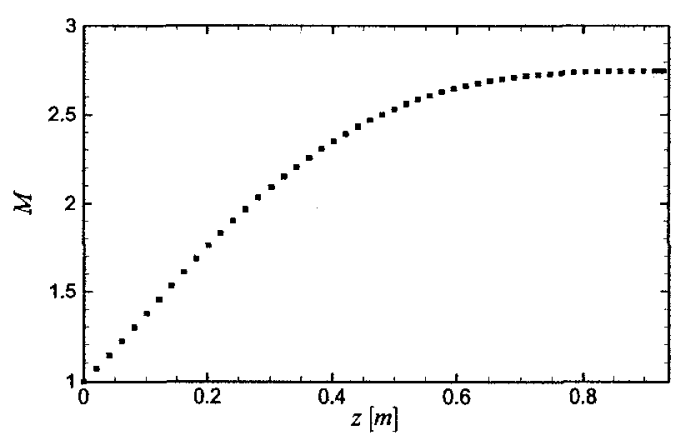

Figure 3.1: Predefined Mach number distribution

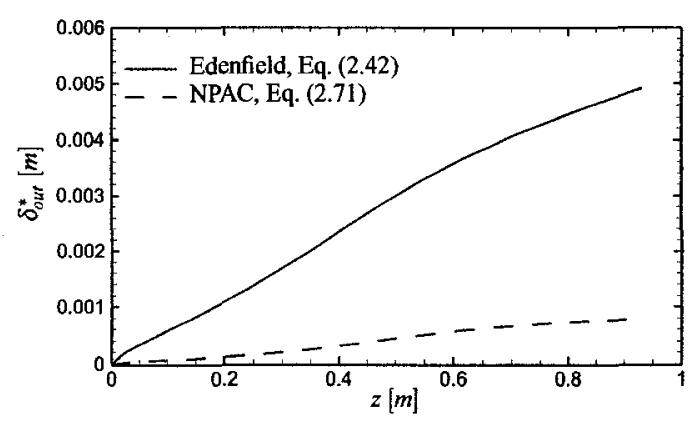

Figure 3.2: Displacement thickness comparison

found from

$$
r_{t h}=\sqrt{\frac{\dot{m}_{e}}{\pi \rho_{t h} V_{t h}}}
$$

as $r_{t h}=0.0551[\mathrm{~m}]$. Solving for $A(z)$ from Eq. (2.1) based on non-dimensionalizing using Eq. (2.5) for the given $M(z)$ distribution calculates the outlet area for a four-clover configuration as $A_{e}=0.0054\left[\mathrm{~m}^{2}\right]$ at a depth of $z_{e}=0.93[\mathrm{~m}]$. Since an axisymmetric nozzle gives an outlet radius of $r_{e}=0.12[\mathrm{~m}]$ for the given $A_{e}$, the proposed nozzle design is set to an arbitrary value in the range of four times greater to account for the air intake area and so the outlet radius is defined as $r_{e}=0.5[\mathrm{~m}]$.

Additionally, the nozzle should span the entire circumference at the outlet. The swept wall displacement thickness must be considered when choosing the outlet arc angle. Given the two options available for viscous consideration, Fig. 3.2 plots the displacement thickness curves along the outer wall for $T_{w}=500[\mathrm{~K}]$. A wall temperature of $500[\mathrm{~K}]$ is defined as a conservative value based on the expectation that the nozzle material is an aluminum alloy where the material strength has not been compromised since the melting temperature for aluminum is $930[\mathrm{~K}][3]$. Edenfield's method gives $\delta_{\text {out }}^{*}=0.0049[\mathrm{~m}]$ whereas NPAC calculates $\delta_{\text {out }}^{*}=0.0018[\mathrm{~m}]$. As a result, Edenfield's method is implemented since it is the more conservative estimate. Along the swept wall, Edenfield's method calculates $\delta_{s w_{e}}^{*}=0.0053[\mathrm{~m}]$ and so to accommodate for this addition to the inviscid design, the outer 
wall arc angle is defined as $\psi_{e}=44.5^{\circ}$.

Completion of the nozzle design requires values for the gate variables. To ensure that the flow remains attached through the domain, it is best to avoid rapid or abrupt changes in the geometry. Developing smooth geometry wall contours should prevent shock wave formation and allow the expected inviscid region to remain approximately isentropic. Based on the observations provided for Figs. 2.9(a) and 2.9(b), the best location for $r_{g}$ and $z_{g}$ to reduce the radial contour slope $\frac{d r}{d z}$ magnitude along the $r(z)$ contour is to specify $r_{g} \approx \frac{1}{2}\left(r_{e}-r_{t h}\right)$ and $z_{g} \approx \frac{1}{2} z_{e}$.

The outlet radial contour angle $\Phi_{e}$ shown in Fig. 2.11 also has a strong influence on the $r(z)$ contour. Because of the trade-off between maximum thrust for $\Phi_{e}=0^{\circ}$ and the reduction in radial slope for higher $\Phi_{e}$, a value of $\Phi_{e}=1^{\circ}$ is selected. It is felt that thrust direction is the more important criteria due to the performance impact; however, Fig. 2.11 shows that even the $\Phi_{e}=2^{\circ}$ curve has effectively levelled off at the outlet and so the slight increase in $\Phi_{e}$ can be of benefit to reducing the radial contour slope along the contour. With respect to the swept wall curvature, Figs. 2.7 and 2.10 both show that maximizing the fillet radius creates a smoother swept wall surface.

In addition to designing smooth walls, maximizing the air intake area is expected to increase the amount of air mass flow entrainment. Figures 2.5(a) and 2.7 show that increasing $r_{g}$ and $r_{f}$ result in an increase to $A_{\text {intake }}$ whereas Fig. 2.5(b) identifies that an increase in $\psi_{g}$ causes $A_{\text {intake }}$ to decrease. Since some of the motivations for reducing wall curvature are in conflict with those for increasing the size of the air intake area, Table 3.1 lists the values selected. Definition of these variables produce the nozzle shown in Fig. 3.3. 
Table 3.1: Input geometry variables for selected design

\begin{tabular}{cccc}
\hline \hline Variable & Value & Variable & Value \\
\hline$r_{t h}[\mathrm{~m}]$ & 0.0551 & $z_{g}[\mathrm{~m}]$ & 0.5 \\
$r_{f}[\mathrm{~m}]$ & 0.17 & $r_{e}[\mathrm{~m}]$ & 0.5 \\
$r_{g}[\mathrm{~m}]$ & 0.37 & $\psi_{e}$ & $44.5^{\circ}$ \\
$\psi_{g}$ & $17.6^{\circ}$ & $\Phi_{e}$ & $1^{\circ}$ \\
\hline \hline
\end{tabular}

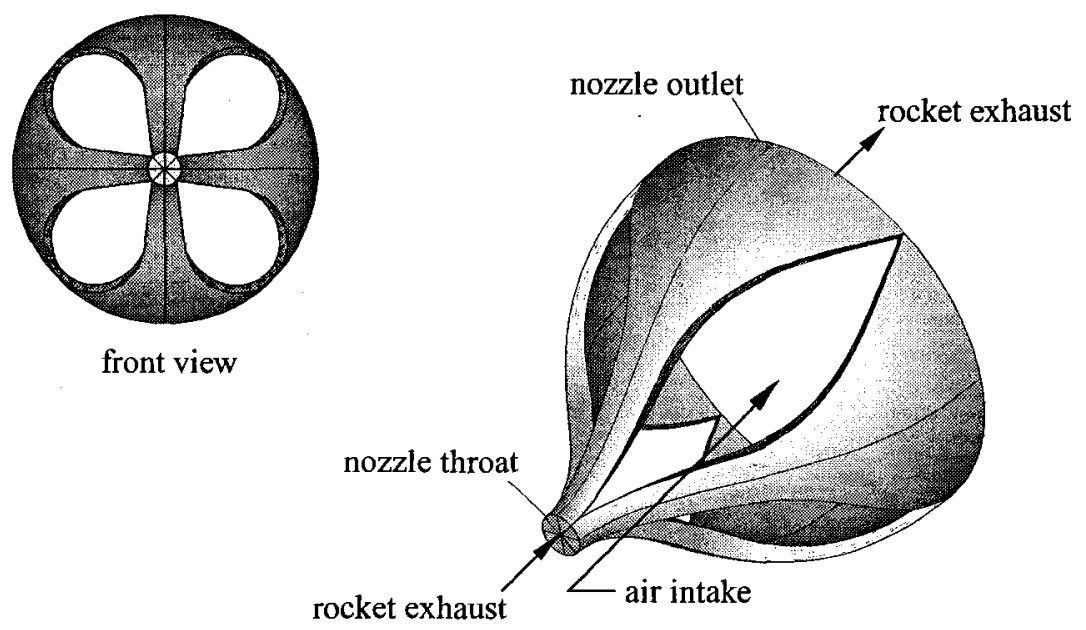

Figure 3.3: Selected nozzle design

\subsection{Numerical Methods}

The computational fluid dynamics (CFD) commercially available code ANSYS ${ }^{\circledR}$ CFX 10.0 (and CFX 11.0) is used to compute flow properties within the considered nozzle domain using time-dependent, three-dimensional, compressible Navier-Stokes equations. The CFX turbulence models being used are referred to as statistical turbulence models since the original unsteady Navier-Stokes equations are modified through the introduction of averaged and fluctuating quantities to produce the Reynolds Averaged Navier-Stokes equations. For 
steady flow, CFX offers numerous two-equation turbulence models to account for the fluctuating quantities [38]. The well-established $k$ - $\varepsilon$ model has proven to be stable and numerically robust where $k$ is the turbulence kinetic energy

$$
k=\frac{1}{2} \overline{u_{i}^{\prime} u_{i}^{\prime}}
$$

and $\varepsilon$ is turbulence eddy dissipation

$$
\varepsilon=-\frac{\mu}{\rho} \overline{\frac{\partial u_{i}^{\prime}}{\partial x_{j}} \frac{\partial u_{j}^{\prime}}{\partial x_{i}}}
$$

The $k-\varepsilon$ turbulence model uses scalable wall functions that are dependent on an alternative velocity scale

$$
u^{*}=C_{\mu} k^{\frac{1}{2}}
$$

where $C_{\mu}=0.09$ rather than the dimensionless near wall velocity $u^{+}$that is typically used in the law of the wall correlations that determine the velocity profile in a boundary layer. Implementation of scalable wall functions allows for a coarser near-wall grid resolution of

$$
y^{+}<100
$$

The effective viscosity that accounts for turbulence is calculated using

$$
\mu_{e f f}=\mu+\mu_{t}
$$

where turbulence viscosity is defined as

$$
\mu_{t}=\frac{\rho C_{\mu} k^{2}}{\varepsilon}
$$

In comparison, the $k-\omega$ turbulence model accounts for near wall treatment by linking 
turbulence viscosity to turbulence kinetic energy and turbulent frequency $\omega$ from

$$
\mu_{t}=\rho \frac{k}{\omega}
$$

and requires at least

$$
y^{+}<2
$$

Additional models exist that are derived from these two turbulence models include Menter's shear stress transport (SST) model. The SST model uses $k$ - $\omega$ for near wall treatment and $k-\varepsilon$ is implemented in the outer wake region and in free shear layers [39].

Figures 3.4 and 3.5 compare area-averaged Mach number and pressure distributions for three turbulent schemes on the selected nozzle configuration obtained using the values provided in Table 3.1. The RNG $k-\varepsilon$ turbulence model is similar to the $k-\varepsilon$ turbulence model with the exception that the model constants in the transport equation for turbulence dissipation are slightly different [38]. The trends on both graphs show that the examined turbulence models agree well with each other to the effect that Table 3.2 shows a 0.06 range between schemes in outlet Mach number and a $2.0[\mathrm{kPa}]$ difference in outlet pressure. Subsequently, results shown in the viscous analysis are calculated using the $k-\varepsilon$ turbulence model and can be taken as representative of results obtained by any of the two-equation turbulence models considered.

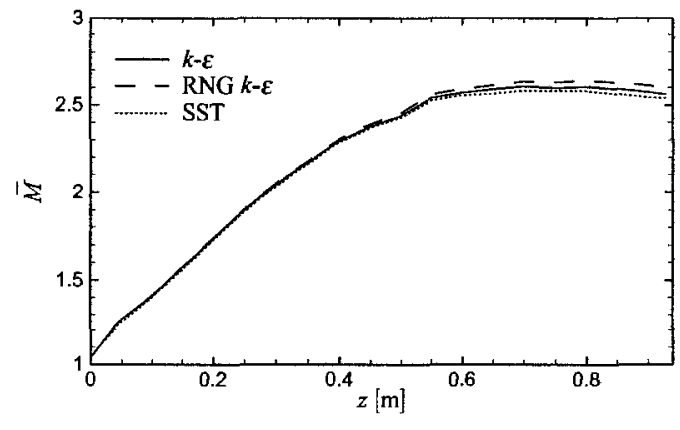

Figure 3.4: Turbulence model influence on Mach number distribution

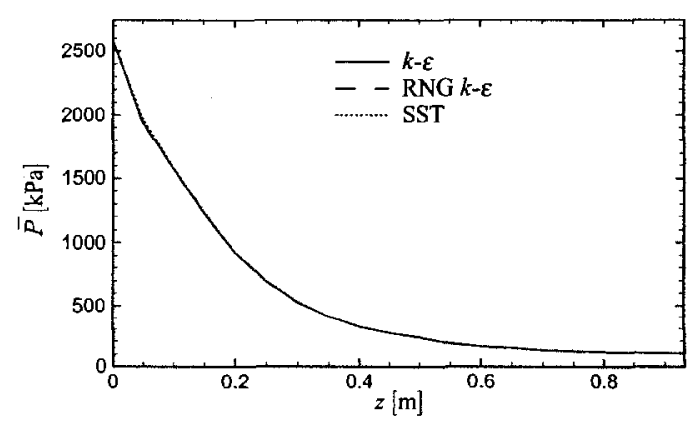

Figure 3.5: Turbulence model influence on pressure distribution 
Table 3.2: Turbulence model influence on outlet values

\begin{tabular}{ccc}
\hline \hline Turbulence model & $\bar{M}_{e}$ & $\bar{P}_{e}[\mathrm{kPa}]$ \\
\hline$k-\varepsilon$ & 2.56 & 106.6 \\
RNG $k-\varepsilon$ & 2.60 & 104.7 \\
SST & 2.54 & 106.7 \\
\hline \hline
\end{tabular}

The CFX solution algorithm is based on a finite volume scheme for an arbitrarily shaped three-dimensional cell that uses a coupled solver [38]. The coupled solver solves all of the hydrodynamic equations as a single system at each finite volume. The finite volumes are formed by generating a mesh to represent the spatial domain. The solution variables are stored at the nodes; however, the discretized form of the governing mass and momentum equations are dependent on properties at integration points (ip):

$$
\mathbb{V} \frac{\Delta \rho}{\Delta t}+\sum_{i p}\left(\rho u_{j} \Delta n_{j}\right)_{i p}=0
$$

and

$$
\mathbb{V} \frac{\Delta\left(\rho u_{i}\right)}{\Delta t}+\sum_{i p} \dot{m}_{i p}\left(u_{i}\right)_{i p}=\sum_{i p}\left(P \Delta n_{i}\right)_{i p}+\sum_{i p}\left[\mu_{e f f}\left(\frac{\partial u_{i}}{\partial x_{j}}+\frac{\partial u_{j}}{\partial x_{i}}\right) \Delta n_{j}\right]_{i p}
$$

where $\mathbb{V}$ is a discrete control volume. Figure 3.6 shows that the integration points are between an element face centre and an element edge. The elements identify one side of a control volume. Shape functions are implemented to calculate geometric properties required by the advection, pressure, diffusion, and velocity terms at the integration point coordinates based on the surrounding nodes defining the given element. The exact location of the integration point within the element is dependent on a user specified value; this choice can range from 0 to 1 and is influential on the order of accuracy of the spatial domain where a value of 0 gives a first-order accurate upwind differencing scheme, and 1 corresponds to a second-order accurate scheme [38]. 


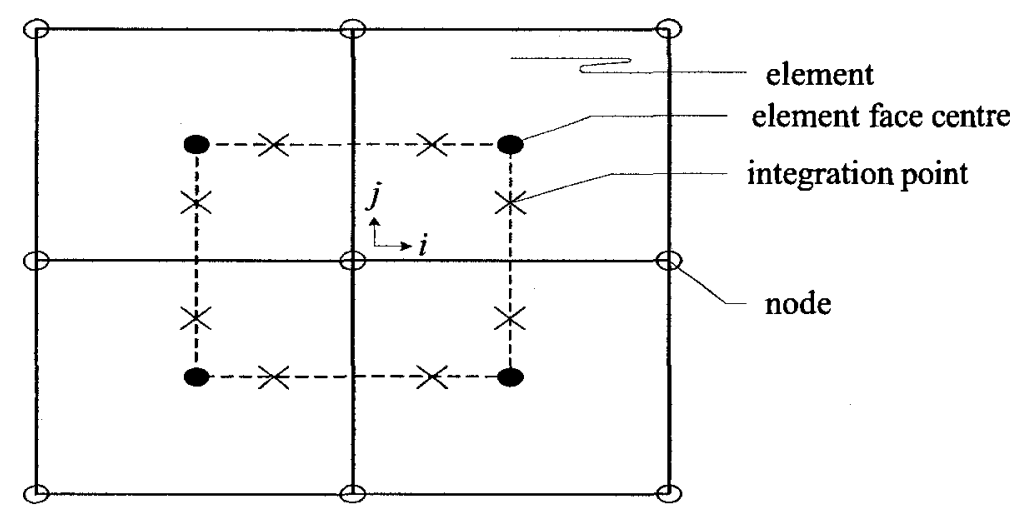

Figure 3.6: Mesh element

For steady state analyses, the transient term in Eq. (3.11) is discretized such that a marching method using a timestep $\Delta t$ is implemented to converge the implicit equations to a solution. The mass $\dot{m}_{i p}$ term is calculated at the previous timestep and along a length identified by a discrete outward normal surface vector $\Delta n$. For compressible flow, the $\rho u_{j}$ terms are solved based on previous and current iteration values

$$
\left(\rho u_{j}\right)^{\text {new }} \approx \rho^{\text {new }} u_{j}^{\text {old }}+\rho^{\text {old }} u_{j}^{\text {new }}-\rho^{\text {old }} u_{j}^{\text {old }}
$$

Subsequently, a second mass conservation calculation is beneficial and thus implemented at each iteration to actively linearize both $\rho$ and $u_{j}$. To solve Eqs. (3.10) and (3.11) simultaneously at each timestep, CFX uses an incomplete lower upper factorization iterative technique that is described in the CFX user manual [38]. 


\subsection{Fluid Properties}

Table 3.3 shows that the thermodynamic properties required to define a fluid in CFX are consistent with those used to generate the selected geometry design based on the input values provided in Table 3.1. The reference values for enthalpy $h_{r e f}$ and entropy $s_{r e f}$ are with respect to a pressure of $1[\mathrm{~atm}]$ and temperature of $298[\mathrm{~K}]$ and are non-zero because the fluid mixture considers the products of a $\mathrm{C}_{12} \mathrm{H}_{24}$ /air reaction. Products by molar fractions consist of $13 \%$ carbon dioxide, $13 \%$ water vapour, $73.4 \%$ nitrogen, and $0.6 \%$ of unburned $\mathrm{C}_{12} \mathrm{H}_{24}$ hydrocarbon.

Table 3.3: Design fluid properties

\begin{tabular}{cc}
\hline \hline Variable & Value \\
\hline$M W\left[\frac{\mathrm{kg}}{\mathrm{kmol}}\right]$ & 29.54 \\
$C_{p}\left[\frac{\mathrm{J}}{\mathrm{kg} \mathrm{K}}\right]$ & 1543 \\
$h_{\text {ref }}\left[\frac{\mathrm{J}}{\mathrm{kg}}\right]$ & 459,670 \\
$S_{\text {ref }}\left[\frac{\mathrm{J}}{\mathrm{kgK}}\right]$ & 8,788 \\
$\mu\left[\frac{\mathrm{kg}}{\mathrm{ms}}\right]$ & $7.276 \cdot 10^{-5}$ \\
$\lambda\left[\frac{\mathrm{W}}{\mathrm{mK}}\right]$ & 0.154 \\
\hline \hline
\end{tabular}

Although the nozzle design calculates viscosity $\mu$ and conductivity $\lambda$ as functions of temperature, constant values are used in CFX. The values shown in Table 3.3 are averaged over the temperature range obtained by Eq. (2.47) that correspond to the Mach number distribution shown in Fig. 3.1. To ensure that this viscosity difference does not cause large errors, a displacement thickness at the outlet outer wall is calculated as $\delta_{\text {out }_{e}}^{*}=0.0051$ [m] for a constant $\mu=7.276 \cdot 10^{-5}\left[\frac{\mathrm{kg}}{\mathrm{ms}}\right]$ and translates into a $3.1 \%$ increase in displacement thickness over the value found when $\mu$ is a function of $T$. If all three sides are adjusted at the outlet, the constant $\mu$ cross sectional area is $1.3 \%$ greater. 


\subsection{Boundary Conditions}

For the computations presented throughout this thesis, the throat surface shown in Fig. 3.7 is specified as an inlet boundary condition. A uniform flow with $V=1114\left[\frac{\mathrm{m}}{\mathrm{s}}\right]$ acting normal to the throat cross section is used. This value equates to $M=1.05$ and is used instead of $M=1$ to avoid potential shock wave issues due to the fact that the flow at the throat is within the transonic range. It has been found that best convergence occurs when static pressure and total temperature $T_{0}=3668[\mathrm{~K}]$ are specified as the two remaining throat parameters. In order to agree with the adjusted velocity value, $P=2577[\mathrm{kPa}]$ is calculated from Eq. (2.56) since Eq. (2.47) gives $T=3266$ [K]. No information could be located regarding the turbulence intensity for three-dimensional diverging nozzle configurations so the default value of medium. $5 \%$ is used; however, several turbulence intensity values were tested and did not have any appreciable influence on the results.

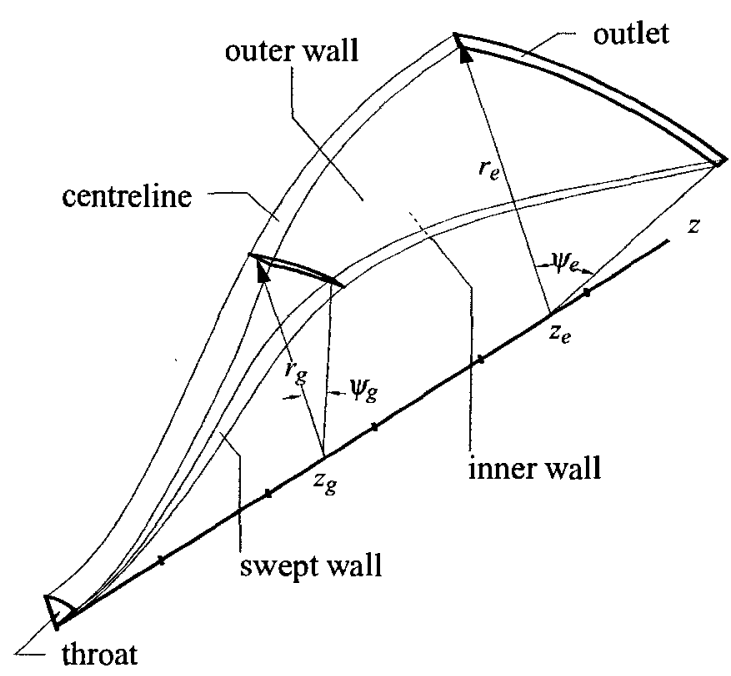

Figure 3.7: Nozzle boundary labels

The inner, outer, and swept walls as shown in Fig. 3.7 are assigned wall boundary 
conditions. For the inviscid, no turbulence model analysis, adiabatic walls are defined as free-slip. A free-slip wall is defined such that both the wall shear stress and the normal velocity component equal zero [38]. The viscous analysis defines walls as no-slip to ensure that velocity equals zero at the wall. For compatibility with the designed nozzle, a constant wall temperature of $500[\mathrm{~K}]$ is specified. Given that Edenfield's $\delta^{*}$ procedure (Eq. (2.42)) is not based on a surface roughness, walls are specified as smooth for $k-\varepsilon$ simulations.

The final two surfaces shown in Fig. 3.7 to define the computational domain are the centreline and the outlet. Symmetry about the $\chi$-plane allows the centreline to use a symmetry boundary condition whereas a supersonic boundary condition that does not require specification of any flow properties is applied at the outlet.

\subsection{Mesh Generation and Convergence Study}

Three structured grids are created using ANSYS ${ }^{\circledR}$ ICEM CFD 10.0 and are distinguished as coarse, medium, and fine. The medium grid consists of 750,000 nodes with 50 placed along the thickness $t$ as shown in Fig. 3.8 using a bigeometric inflated boundary layer technique that geometrically increases space size from small distances near both walls to larger distances in the middle. The first space from both the inner and outer walls is $4 \cdot 10^{-5}[\mathrm{~m}]$. A space increment of $4 \cdot 10^{-5}[\mathrm{~m}]$ is sufficient to ensure at least 10 nodes are within the boundary layer and corresponds to a boundary layer dimensionless wall distance range of $18<y^{+}<119$ on the outer wall. The enlarged views in Fig. 3.8 show the placement of the first node on the wall and the second and third nodes off the indicated walls. The space increments along the thickness $r^{\prime}$ direction are found from

$$
\Delta t_{1}=4 \cdot 10^{-5}[\mathrm{~m}]
$$




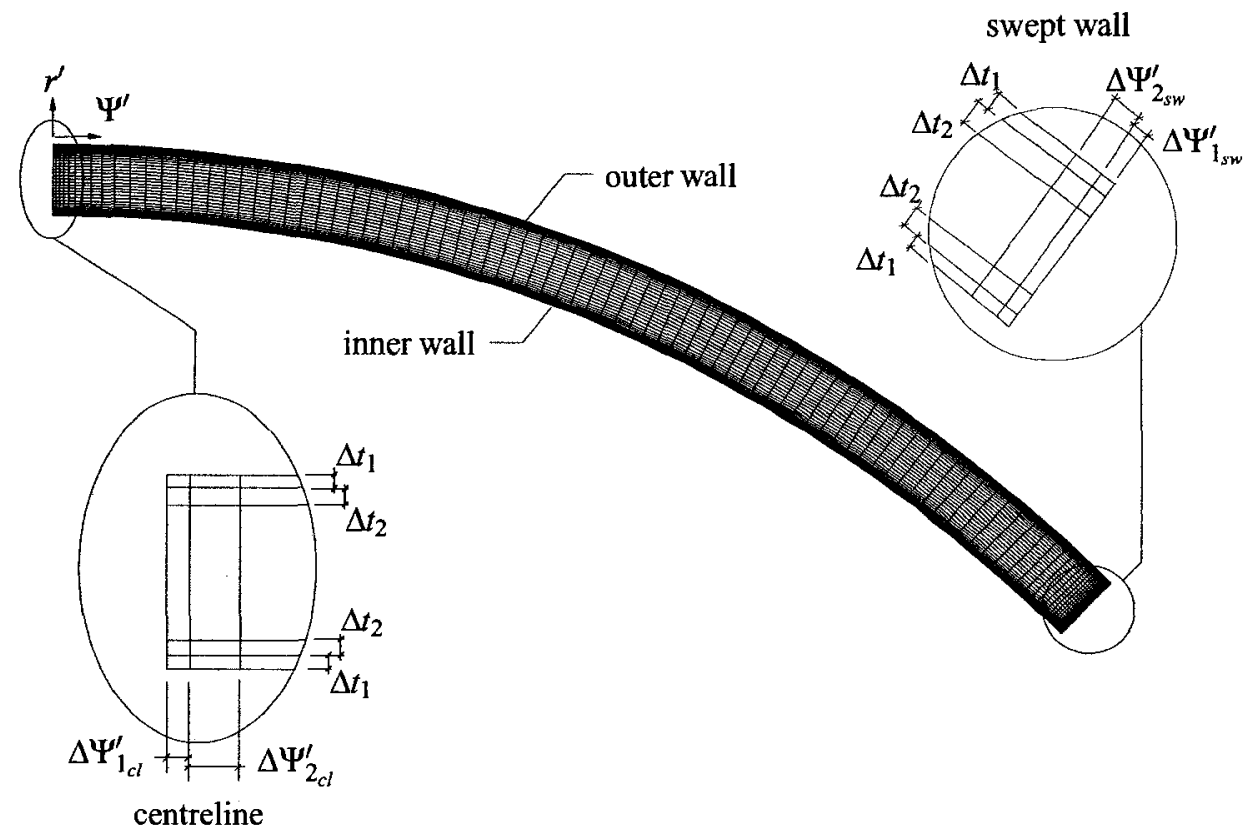

Figure 3.8: Outlet mesh

and

$$
\Delta t_{i}=1.2 \cdot \Delta t_{i-1}
$$

A geometric ratio specified at the outlet plane of 1.2 (increases to 1.27 at the throat because of the thickness variation over the depth) is multiplied by each previous increment to calculate the next increment until the point that $1.2 \cdot \Delta t_{i-1}$ is greater than a uniform $\Delta t_{i}$. A uniform $\Delta t_{i}$ can be calculated based on the remaining distance and number of nodes required to fill in the distance. For the inviscid analysis, a first space of $0.001[\mathrm{~m}]$ is defined since wall shear forces are ignored and number of nodes in the thickness direction is reduced to 25 .

Figure 3.8 also shows that 100 nodes are specified in the circumferential $\Psi^{\prime}$-direction with the first spaces adjacent to the centreline (cl) and swept wall (sw) set to $\Delta \Psi_{1_{c l}}^{\prime}=$ $0.001[\mathrm{~m}]$ and $\Delta \Psi_{1_{s w}}^{\prime}=4 \cdot 10^{-5}[\mathrm{~m}]$ respectively with geometric ratios of 1.2 at the arclength 
on the outlet edge. Similarly to the procedure for locating nodes in the $r^{\prime}$-direction, the bigeometric technique is implemented to define the locations of the remaining nodes in the $\Psi^{\prime}$-direction.

Figure 3.9 shows that the 150 nodes in the streamwise $z^{\prime}$-direction maintain orthogonality with respect to the radial contour. Since the shape of a cross section does not dramatically change in the $\Psi^{\prime}$-direction within the first third of the domain, spaces are increased to $0.020[\mathrm{~m}]$ from $0.001[\mathrm{~m}]$ at the throat; however, to better resolve the circumferential expansion caused by $\Psi^{\prime}(z)$ beyond the gate, spaces are reduced to $0.006[\mathrm{~m}]$. Further reductions occur within the last eighth of the domain to a final space of 0.001 [m] adjacent to the outlet. Maximum spaces developed are $0.0036[\mathrm{~m}]$ along the thickness, $0.0054[\mathrm{~m}]$ in the $\Psi^{\prime}$-direction, and $0.020[\mathrm{~m}]$ in the $z^{\prime}$-direction.

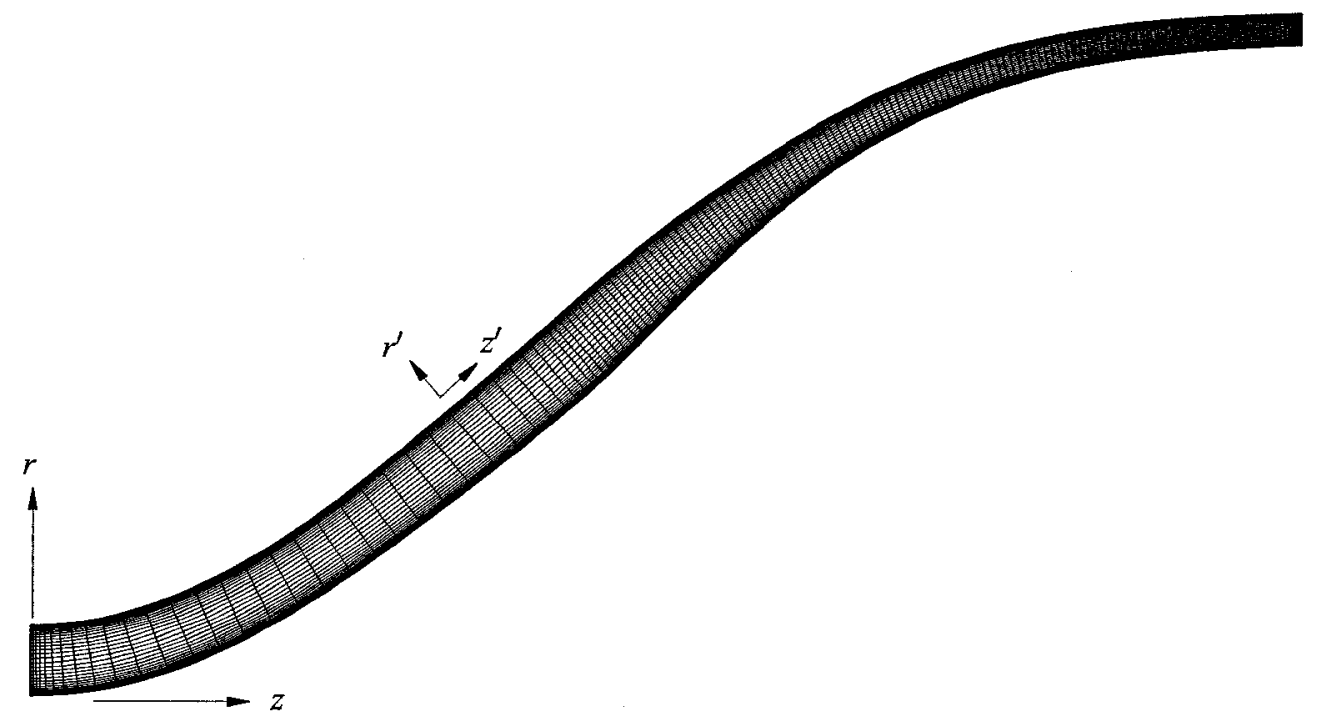

Figure 3.9: Centreline mesh

To avoid singularity difficulties when generating solutions using CFX, the throat is defined as a four-sided shape. Subsequently, a correction is made to the inner wall to ensure a finite length at the throat's cross section. An inner radius of $0.05 r_{t h}$ is used and represents 
a loss in $A_{t h}$ of $0.25 \%$, or more importantly, a loss in mass flow of $0.25 \%$ thus making it more appropriate to compare CFD area-averaged values to the isentropic equations.

With respect to the medium grid, the coarse mesh doubles all of the values at the boundaries such that the maximum spaces developed are $0.0072[\mathrm{~m}]$ along the thickness, $0.011[\mathrm{~m}]$ in the $\Psi^{\prime}$-direction, and $0.040[\mathrm{~m}]$ in the $z^{\prime}$-direction. The resulting number of nodes is 131,040 . Similarly, the fine mesh consists of $3,678,908$ nodes where all of the values at the boundaries assigned to the medium grid are halved such that the maximum spaces are $0.0018[\mathrm{~m}], 0.0027[\mathrm{~m}]$, and $0.010[\mathrm{~m}]$ respectively. The consistency between the grids result in grid refinement factors $G R F$ of two using

$$
G R F=\frac{\Delta h_{\text {coarse }}}{\Delta h_{\text {medium }}}=\frac{\Delta h_{\text {medium }}}{\Delta h_{\text {fine }}}=2.0
$$

where the representative grid sizes $\Delta h$ are obtained from

$$
\Delta h=\left[\Delta t_{\max } \Delta \Psi_{\max }^{\prime} \Delta z_{\max }^{\prime}\right]^{1 / 3}
$$

Table 3.4 summarizes the characteristics of each of the three meshes. In order to obtain $G R F=2.0$ between two meshes, the maximum spaces (and similarly all spaces at the surfaces) were halved and doubled with respect to the medium grid; however, because of the bigeometric spacing technique implemented, this does not translate into halving and doubling the number of nodes in a given direction, thus explaining why there is not a factor of eight difference in total number of nodes between grids. The provided $y^{+}$values are obtained along the outer wall at the $P 4_{v i s}$ points and further support the decision to use the $k-\varepsilon$ turbulence model since a near wall resolution of $y^{+}<2$ is not present.

Figures 3.10 and 3.11 show similar area-averaged Mach number $\bar{M}(z)$ and pressure $\bar{P}(z)$ distributions for the three grids. A comparison of values between the medium and fine grids at several locations is listed in Table 3.5. The errors calculated are with respect 
Table 3.4: Mesh characteristics

\begin{tabular}{c|cccc|cc|ccc}
\hline \hline & \multicolumn{4}{|c|}{ Number of nodes } & \multicolumn{2}{|c|}{ outer wall $y^{+}$} & \multicolumn{3}{|c}{ maximum space $[\mathrm{m}]$} \\
Grid & $r^{\prime}$ & $\Psi^{\prime}$ & $z^{\prime}$ & Total & Throat & Outlet & $\Delta t_{\max }$ & $\Delta \Psi_{\max }^{\prime}$ & $\Delta z_{\max }^{\prime}$ \\
\hline Coarse & 26 & 63 & 80 & 131,040 & 214 & 38 & 0.0072 & 0.0110 & 0.040 \\
Medium & 50 & 100 & 150 & 750,000 & 119 & 18 & 0.0036 & 0.0054 & 0.020 \\
Fine & 73 & 172 & 293 & $3,678,908$ & 66 & 9 & 0.0018 & 0.0027 & 0.010 \\
\hline \hline
\end{tabular}

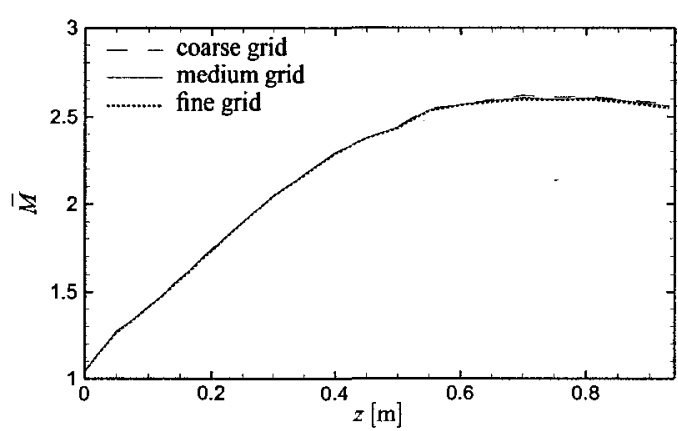

Figure 3.10: Comparison of grid Mach number distributions

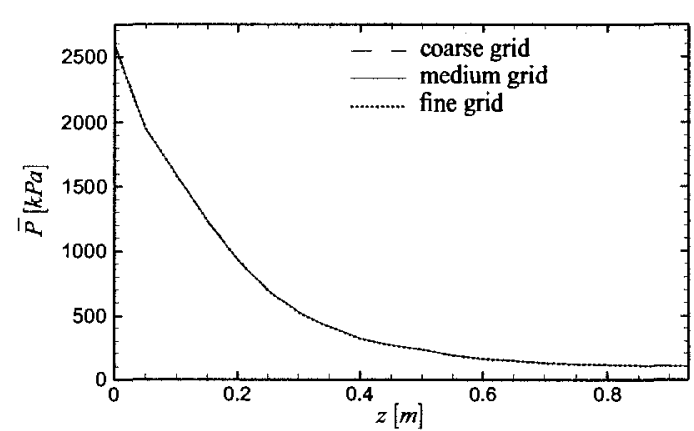

Figure 3.11: Comparison of grid pressure distributions

Table 3.5: $M$ and $P$ variation between medium and fine meshes

\begin{tabular}{ccccccc}
\hline \hline$z$-Plane $[\mathrm{m}]$ & $\bar{M}_{\text {fine }}$ & $M$ error, \% & $M$ GCI, \% & $\bar{P}_{\text {fine }},[\mathrm{kPa}]$ & $P$ error, $\%$ & $P \mathrm{GCI}, \%$ \\
\hline 0.05 & 1.27 & 0.39 & 0.16 & 1955.7 & 0.46 & 0.19 \\
0.5 & 2.44 & 0.18 & 0.08 & 235.0 & 0.07 & 0.03 \\
0.93 & 2.55 & 0.35 & 0.15 & 107.2 & 0.57 & 0.24 \\
\hline \hline
\end{tabular}

to the finest grid and are all less than $1.0 \%$. For uniformity of reporting computational results, the grid convergence index (GCI) is a method for reporting error estimates in grid convergence studies without restrictions placed on integer refinement (for example, grid doubling) and involves the comparison of discrete solutions at two different grid spacings [40]. Determination of the GCI is based on a suggested factor of safety of $1.25[40,41]$ such that there is a $95 \%$ confidence interval in the error estimates. For example, the Mach number at the outlet is reported as $\bar{M}_{e}=2.55 \pm 0.004( \pm 0.15 \%)$. Subsequently, there is 
confidence that the computational results are independent of grid and leads to the choice that the medium grid is sufficient for use in all subsequent calculations.

\subsection{Convergence}

Examination of the residual convergence history shown in Fig. 3.12 can further the confidence that the properties calculated by the individual control volume equations are conserved. Figure 3.12 shows root-mean-square (RMS) residuals for mass and the three momentum equations on the medium grid for a viscous analysis. The abrupt change at the forty-eighth iteration is caused by switching advection schemes. The stability of the upwind differencing scheme provided little difficulty in marching through the solution to $R M S=10^{-4}$ convergence (in $97[\mathrm{~min}]$ ) based on constant global initialization values of $V_{z}=1990\left[\frac{\mathrm{m}}{\mathrm{s}}\right], P=494[\mathrm{kPa}]$, and $T=2400[\mathrm{~K}]$. The initial values are taken as averages of the $N$ cross section velocity, pressure, and temperature values that are calculated using the isentropic equations based on the Mach number distribution shown in Fig. 3.1. After the forty-eighth iteration, the second order accurate advection scheme in the spatial domain is implemented. Due to machine roundoff issues in CFX for convergence below $10^{-5}$, properties are stored to double precision after the $83^{\text {rd }}$ iteration.

The linear decay on the semi-log plot shown in Fig. 3.12 of the residuals is obtained using an automatic timescale method such that the timestep is on the order of $2 \cdot 10^{-5}[\mathrm{~s}]$. The auto timescale option is similar but more conservative than the physical timescale and is described in the CFX user manual [38]. The physical timescale option considers the time for a fluid parcel to travel through the domain. Calculation of the physical timestep using the isentropic calculated average velocity value and outlet depth is

$$
\Delta t \approx 0.3 \frac{z_{e}}{V}=0.3 \frac{0.93[\mathrm{~m}]}{1990\left[\frac{\mathrm{m}}{\mathrm{s}}\right]}=1 \cdot 10^{-4}[\mathrm{~s}]
$$




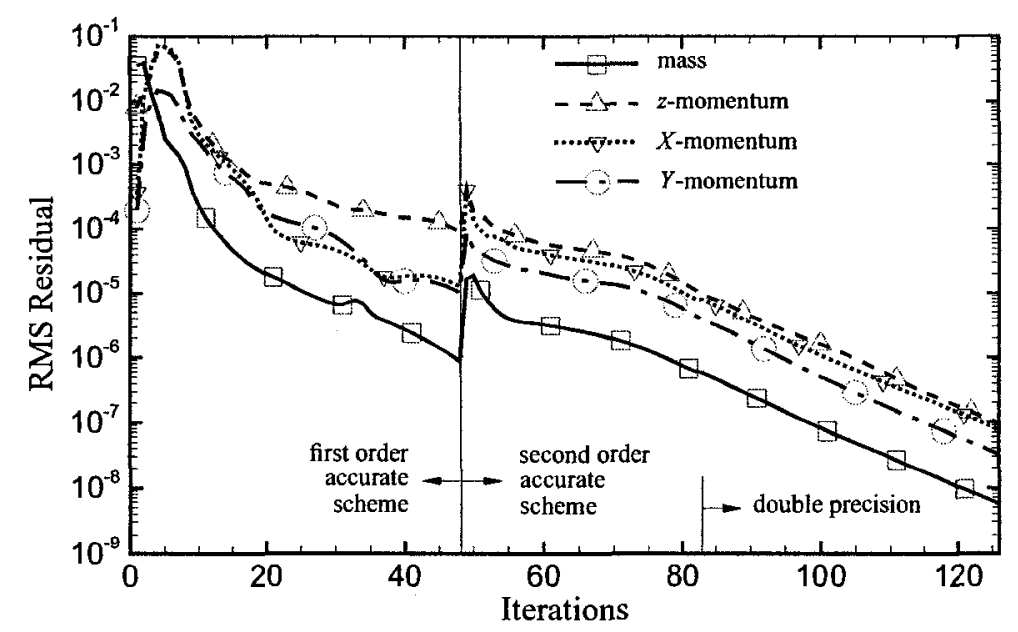

Figure 3.12: Residual convergence history

A factor of 0.3 is multiplied in Eq. (3.17) to allow a fluid parcel to spend at least three iterations within the domain and is traditionally included for advection dominated flows. Since the value obtained by the auto timescale is more conservative, it equates to slower convergence; however, after switching advection schemes, 180 [min] of computational time is required to reach $R M S=10^{-7}$ convergence using two Intel Pentium 4 processors $(2.00$ GB RAM).

To ensure that there were no localized problems in the domain, maximum mass and momentum residuals were also monitored and adhere to the expectation of being one order of magnitude greater than the RMS residuals. Additionally, Fig. 3.13 plots velocity at four selected points with respect to the iteration number. Three points are located along the centreline at $z=0.01[\mathrm{~m}], z=0.4[\mathrm{~m}]$, and $z=0.9[\mathrm{~m}]$ and the fourth monitor is placed near the swept wall at $z=0.72[\mathrm{~m}]$. The maximum difference between the monitor points at $R M S=10^{-5}$ and $R M S=10^{-7}$ is $0.043 \%$. Therefore, the solutions are considered converged when the $R M S$ residuals are reduced by four orders of magnitude to a value of $10^{-5}$. 


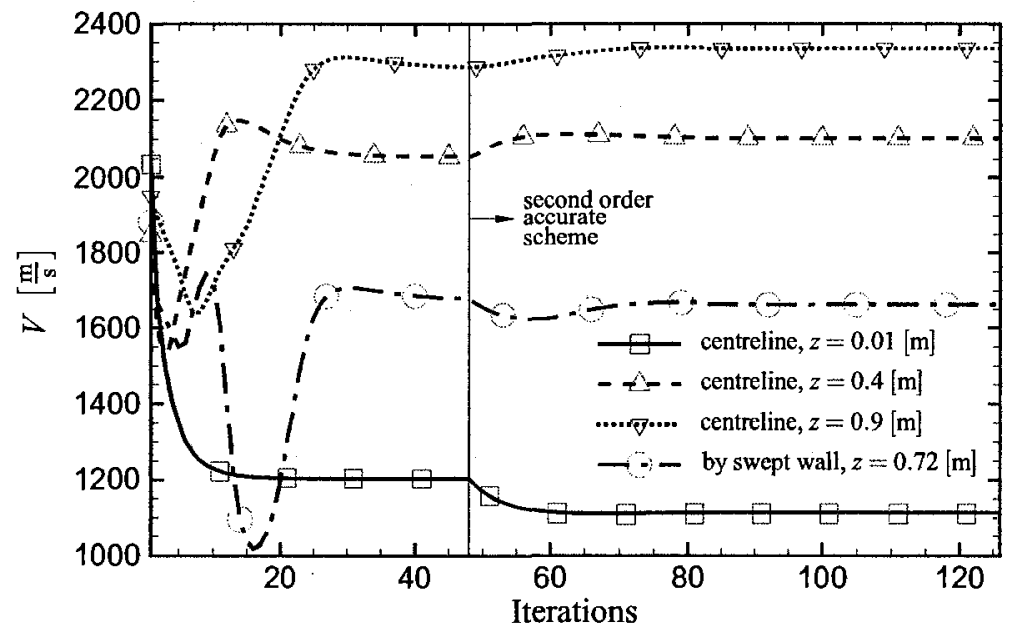

Figure 3.13: Velocity monitor points convergence history 


\section{Chapter 4}

\section{Inviscid Results}

Figures 4.1 and 4.2 compare the inviscid CFD area-averaged $\bar{M}(z)$ and $\bar{P}(z)$ results to the predefined $M(z)$ distribution and the isentropic pressure calculated using the $M(z)$ distribution respectively. Computational results predict outlet values of $\bar{M}_{e}=2.70$ and $\bar{P}_{e}=183.1[\mathrm{kPa}]$. In comparison, the predefined $M(z)$ gives $M_{e}=2.75$ and $P_{e}=170.0[\mathrm{kPa}]$ and translate into differences of $1.6 \%$ and $7.6 \%$ respectively. A maximum $M$ variation of $5.0 \%$ occurs at $z=0.0[\mathrm{~m}]$ whereas a maximum $P$ variation of $8.5 \%$ occurs at $z=0.8[\mathrm{~m}]$. Prior to $z=0.1[\mathrm{~m}]$, variations occur because of the slightly higher Mach 1.05 throat inlet condition used to generate the CFD results. If the first $0.1[\mathrm{~m}]$ is ignored, the maximum variation in Mach number reduces to $1.6 \%$ and occurs from $z=0.85[\mathrm{~m}]$ to the outlet.

Figure 4.3 plots the velocity field on several $\Psi^{\prime}$-planes varying from $0.0 \Psi^{\prime}$ corresponding to the centreline to $1.0 \Psi^{\prime}$ that corresponds to the swept wall as shown in Fig. 4.4. The contours show that velocity increases through the nozzle since cross-sectional area increases and that the flow stays attached to all of the walls as indicated by the velocity vectors. Additionally, the increase in velocity originates along a convex surface-along the outer wall near the inlet $(z=0.0[\mathrm{~m}])$ and along the inner wall just past the gate $(z=0.5[\mathrm{~m}])$-and develops through the thickness downstream. This observation is in agreement with the expectation that the localized area expansion along a convex surface 


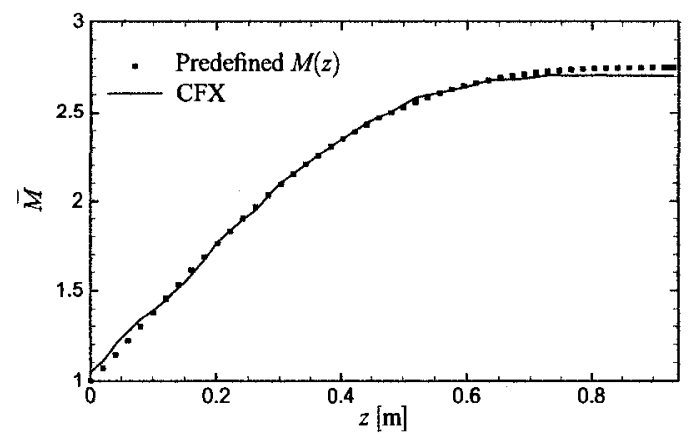

Figure 4.1: Inviscid analysis Mach number distribution

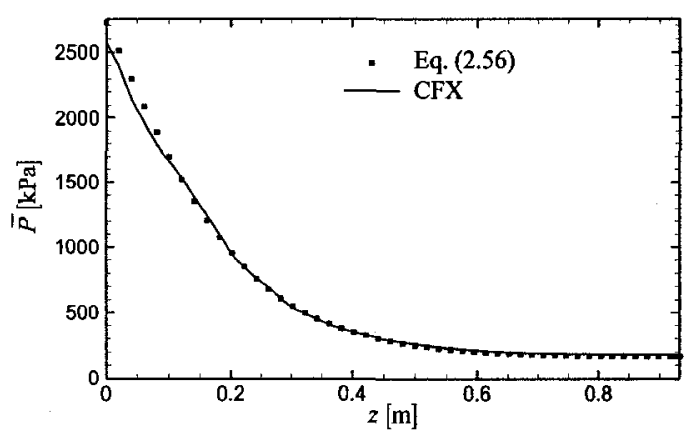

Figure 4.2: Inviscid analysis pressure distribution

$\begin{array}{ccccccccccccccc}\text { Level } & 1 & 2 & 3 & 4 & 5 & 6 & 7 & 8 & 9 & 10 & 11 & 12 & 13 & 14 \\ V\left[\frac{m}{8}\right] & 1200 & 1300 & 1400 & 1500 & 1600 & 1700 & 1800 & 1900 & 2000 & 2100 & 2200 & 2300 & 2400 & 2500\end{array}$

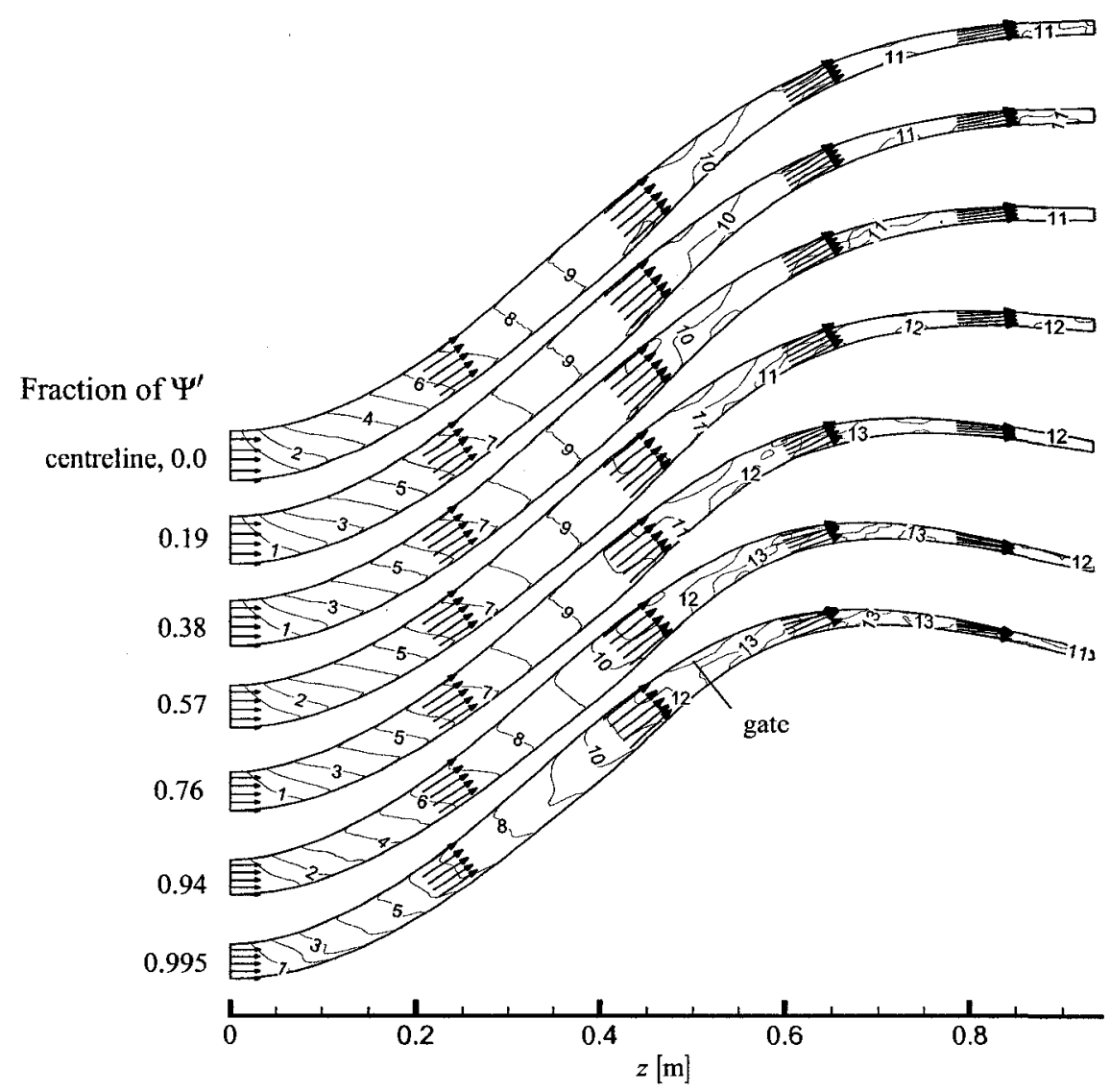

Figure 4.3: Inviscid analysis $\Psi^{\prime}$-plane velocity contours 


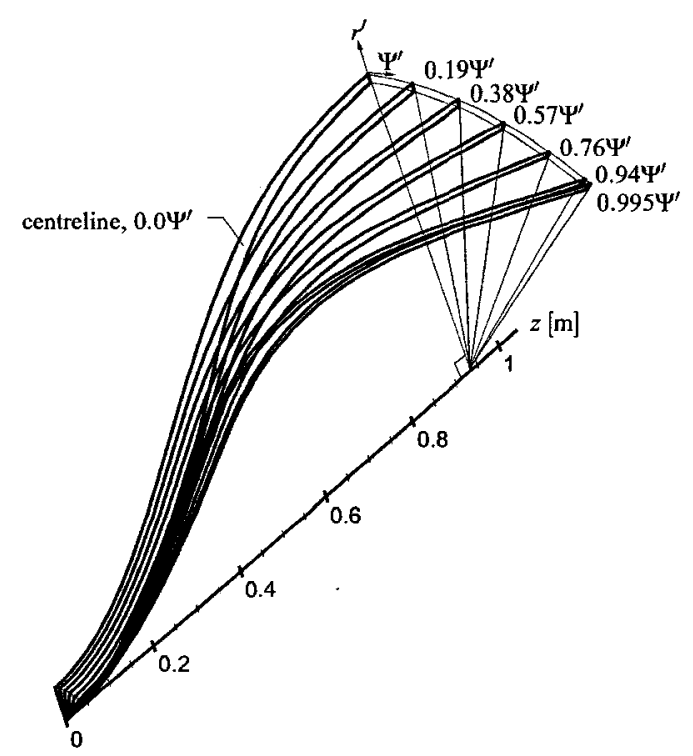

Figure 4.4: $\Psi^{\prime}$-plane sections

supports the trends expected for gradual isentropic expansion on a convex surface since velocity increases and the contours diverge. Of further interest is that the $1900\left[\frac{\mathrm{m}}{\mathrm{s}}\right]$ and $2000\left[\frac{\mathrm{m}}{\mathrm{s}}\right]$ velocity contours regain orthogonality to the radial contour. In comparison, the outer wall radial contour point of inflection is located at $z=0.33[\mathrm{~m}]$.

Figure 4.5 shows the velocity field on $z$-planes taken at the locations indicated in Fig. 4.6. To assist in explanation of the trends observed, the curve shown in Fig. 4.7 defines the arclength $(\psi r)$ change with depth and hence can be used to obtain the $\frac{d \Psi^{\prime}}{d z}$ slope of the swept wall (recall Fig. 2.10). Prior to $z=0.4[\mathrm{~m}]$ the curve is relatively flat, which is in agreement with the absence of circumferential velocity variation in the first five planes shown in Fig. 4.5. From $z \approx 0.4[\mathrm{~m}]$ to $z \approx 0.8[\mathrm{~m}]$, Fig. 4.7 shows that the swept wall has convex curvature. In agreement to the expectation of isentropic expansion along convex surfaces, velocity near the swept wall on the $z=0.47[\mathrm{~m}]$ to $z=0.74[\mathrm{~m}]$ planes in Fig. 4.5 (see also Fig. 4.3) is greater than the velocity nearer to the centreline. The slight decrease in velocity on the $z=0.84[\mathrm{~m}]$ and $z=0.93[\mathrm{~m}]$ planes near the swept wall can be contributed 


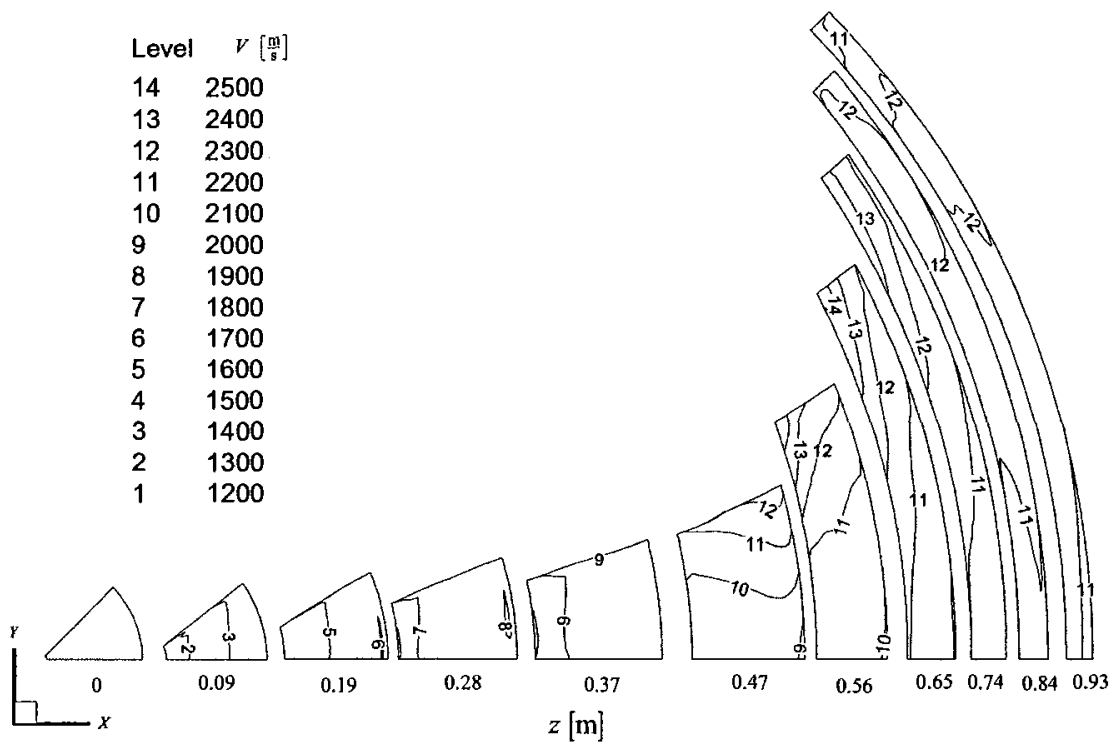

Figure 4.5: Inviscid analysis $z$-plane velocity contours

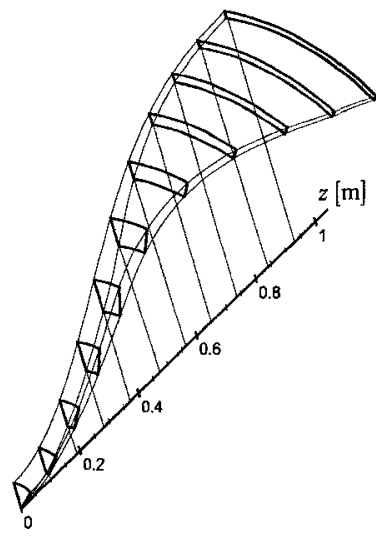

Figure 4.6: $z$-plane sections

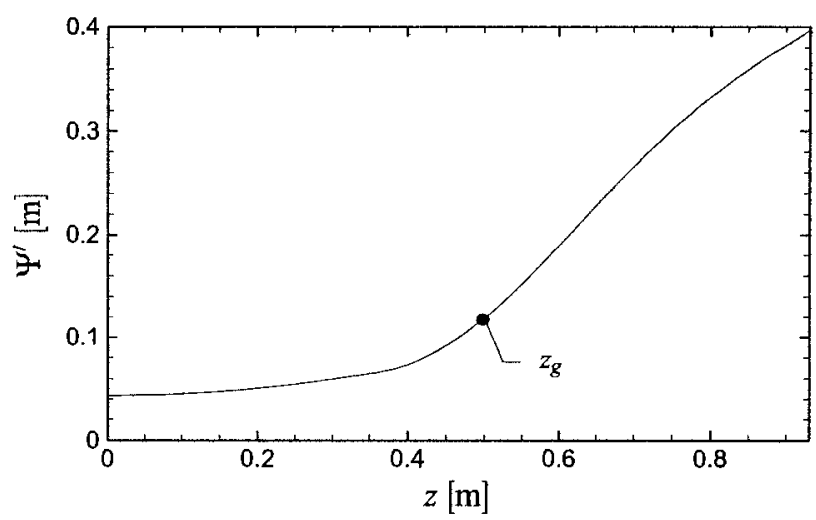

Figure 4.7: Swept wall $\Psi^{\prime}(z)$ profile

to the slightly concave curvature shown in Fig. 4.7 after $z \approx 0.8[\mathrm{~m}]$. Opposite to convex surfaces, concave surfaces cause essentially isentropic compression and result in a velocity decrease.

Figures 4.3 and 4.5 have shown velocity magnitudes whereas the tangential velocity vectors (vectors tangent to the $z$-planes) shown in Fig. 4.8 give 3D direction to the velocity. Since no external forces are applied, streamlines are expected to parallel the nozzle walls 


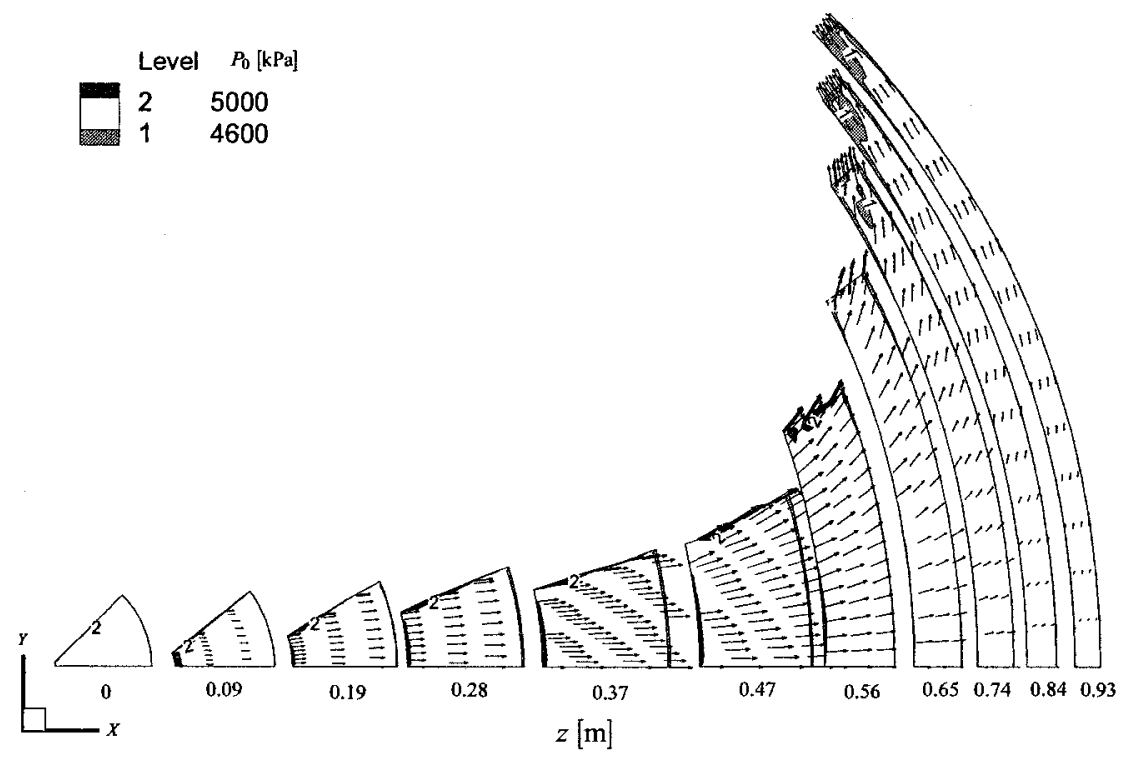

Figure 4.8: Inviscid analysis $z$-plane total pressure contours and tangential velocity vectors

and proceed in the $z^{\prime}$-direction (refer to Fig. 2.17). Subsequently, the vector components that act most noticeably in the $X$-direction shown in Fig. 4.8 are the result of the $\cos \Phi$ components introduced by the radial contour curvature. The vector tangents drawn in Fig. 4.8 are also dependent on a circumferential velocity component. Figure 4.7 shows that the swept wall slope $\frac{d \Psi^{\prime}}{d z}$ prior to $z=0.4[\mathrm{~m}]$ can be taken as zero and agrees with the absence of circumferential components in the first four planes (also observed in Fig. 4.5). After $z=0.4[\mathrm{~m}]$, the nozzle begins to span more of the circumference and so the vectors that appear to pass through the swept wall on the $z=0.56[\mathrm{~m}]$ to $z=0.93[\mathrm{~m}]$ planes are actually in agreement to the swept wall direction calculated by $\frac{d \Psi_{s w}^{\prime}}{d z}$; this ensures that streamlines near the swept wall proceed in a direction parallel to the swept wall.

Also shown on Fig. 4.8 are total pressure contours or lack thereof. Since adiabatic walls are implemented, the consistency of total pressure throughout the domain validates the isentropic assumption and proves that the presumed isentropic expansion and compression developed on convex and concave surfaces are in fact essentially isentropic. It is evident by 
the slight total pressure decrease on the $z=0.74[\mathrm{~m}]$ to $z=0.93[\mathrm{~m}]$ planes near the swept wall that compression caused by the swept wall concave surface requires a larger but still acceptable tolerance to lead to the isentropic conclusion. Additionally, the uniformity of the tangential velocity vectors throughout the thickness on a given plane shows the absence of shear forces and hence the assignment of free-slip walls in CFX does simulate inviscid flow.

To better quantify the outlet velocity distribution shown in Fig. 4.5, a central arcline drawn at $\frac{t_{e}}{2}$ as shown in Fig. 4.9 is considered. For the nearest $55 \%$ to the centreline along the arcline, the velocity under-predicts the expected $V_{e}=2276\left[\frac{\mathrm{m}}{\mathrm{s}}\right]$ by a maximum of $3.0 \%$. The next $35 \%$ along the arcline over-predicts by as much as $1.8 \%$. The remaining $10 \%$ of the arcline nearest to the swept wall under-predicts the outlet velocity by a maximum $5.0 \%$. This behaviour can be attributed to the circumferential expansion caused by the swept wall curvature. Also calculated at the outlet is an area-averaged velocity of $\bar{V}_{e}=2254\left[\frac{\mathrm{m}}{\mathrm{s}}\right]$, which is $1.0 \%$ less than the isentropic value.

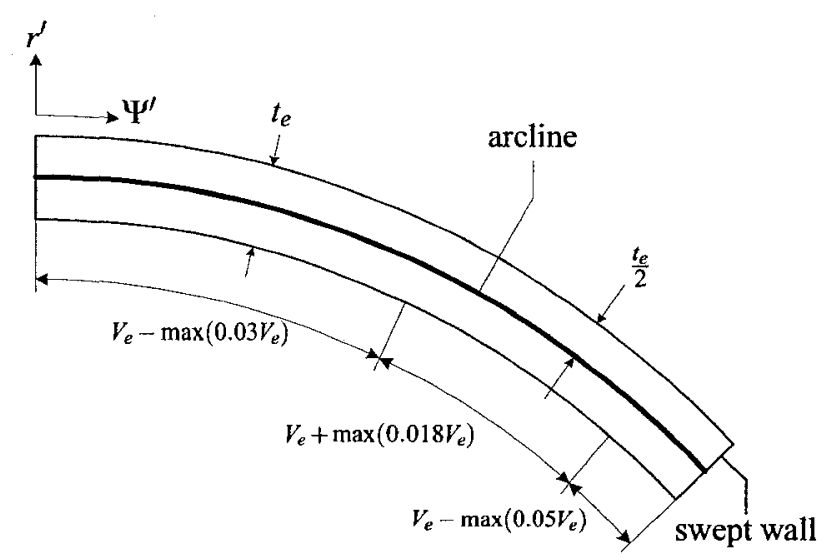

Figure 4.9: Comparison of outlet velocity to design value of $V_{e}=2276\left[\frac{\mathrm{m}}{\mathrm{s}}\right]$ along midthickness arcline of exit plane

Now that the velocity behaviour is understood whereby velocity increases as area increases for supersonic flow and also increases near convex surfaces first, consideration is 
given to temperature and pressure. Replacing Mach number in Eq. (2.47) with the Mach number definition of Eq. (2.45) allows $T$ for the given isentropic flow to be defined as a function of velocity only and hence the temperature contours shown in Fig. 4.10 behave in a similar manner to the velocity contours shown in Fig. 4.5. The maximum variation between area-averaged temperatures and Eq. (2.47) occurs at the outlet and is 1.6\%.

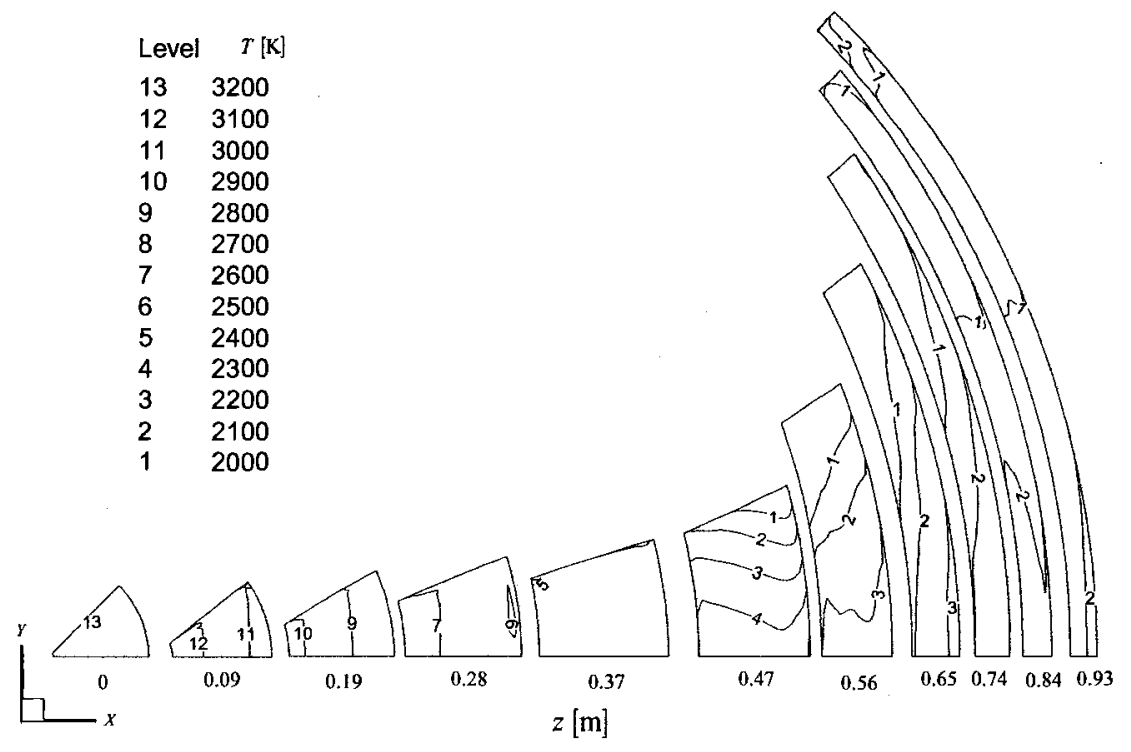

Figure 4.10: Inviscid analysis $z$-plane temperature contours

Similarly, the pressure calculated by Eq. (2.56) is a function of temperature only and hence velocity. As a result, the pressure field shown in Fig. 4.11 matches the characteristics of the velocity field in Fig. 4.5 and temperature field in Fig. 4.10. It is because of the velocity variation on a given cross section that the area-averaged pressure distribution shown in Fig. 4.2 deviates from the isentropic calculation by as much as $8.5 \%$.

Based on the minimal variations between velocity, temperature, and pressure to the isentropic equations, it is evident that the isentropic equations are capable of calculating good initial guesses for the flow properties. The differences however are attributed to the fact that the isentropic equations are calculated using one-dimensional flow whereas the 


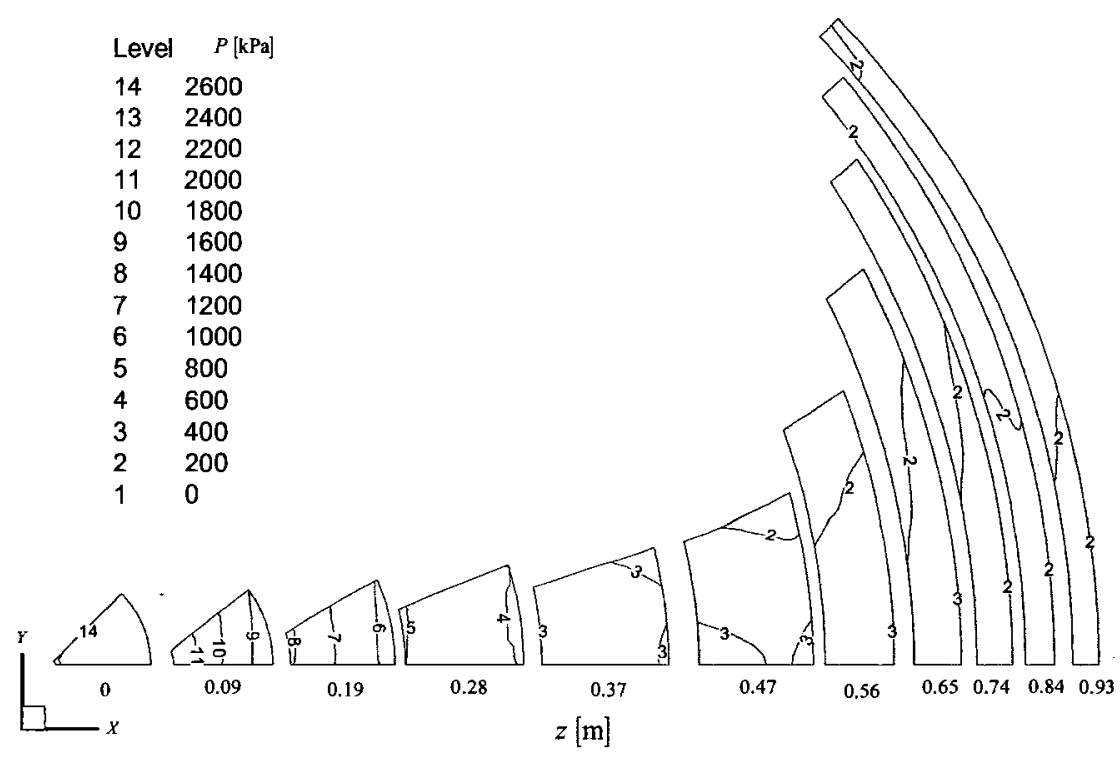

Figure 4.11: Inviscid analysis $z$-plane pressure contours

geometry's radial contour curvature and swept wall curvature both influence the fluid properties at a given cross section and so the flow can only be treated as essentially isentropic: it is the total pressure variation that accounts for the slightly larger deviation in the static pressure comparison. This means that the flow must be treated as fully three-dimensional and so a CFD study is a good method for better prediction of the flow properties. 


\section{Chapter 5}

\section{Viscous Results}

Figure 5.1 compares the viscous CFD area-averaged $\vec{M}(z)$ results to the predefined $M(z)$ distribution. Computational results predict an outlet value of $\bar{M}_{e}=2.56$ that translates into a $6.8 \%$ difference from the predefined value. A maximum $M$ variation of $8.1 \%$ occurs at $z=0.04[\mathrm{~m}]$. Similarly to the inviscid analysis, the throat Mach number is defined as $M_{t h}=1.05$ so if the first $0.1[\mathrm{~m}]$ of nozzle depth is ignored, the maximum variation in Mach number occurs at the outlet.

Between $z=0.1[\mathrm{~m}]$ and $z=0.5[\mathrm{~m}]$, Fig. 5.1 shows that the area-averaged Mach number is within $2.4 \%$ of the predefined distribution. This is considered to be a small

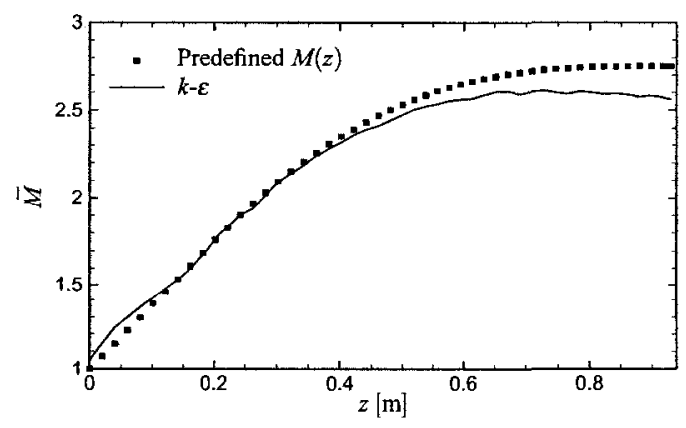

Figure 5.1: Viscous analysis Mach number distribution 
variation and so there is confidence that the amount of displacement thickness added to all three walls is sufficient to account for the viscous effects in the boundary layers within this range. After $z=0.5[\mathrm{~m}]$, the area-averaged Mach number increases to 2.61 at $z=0.73[\mathrm{~m}]$ and then decreases to the outlet value. This observation does not appear in the inviscid analysis and so viscous effects are responsible for the additional decrease.

Figure 5.2 plots velocity fields within several $\Psi^{\prime}$-planes as shown in Fig. 4.4. Figure 5.2

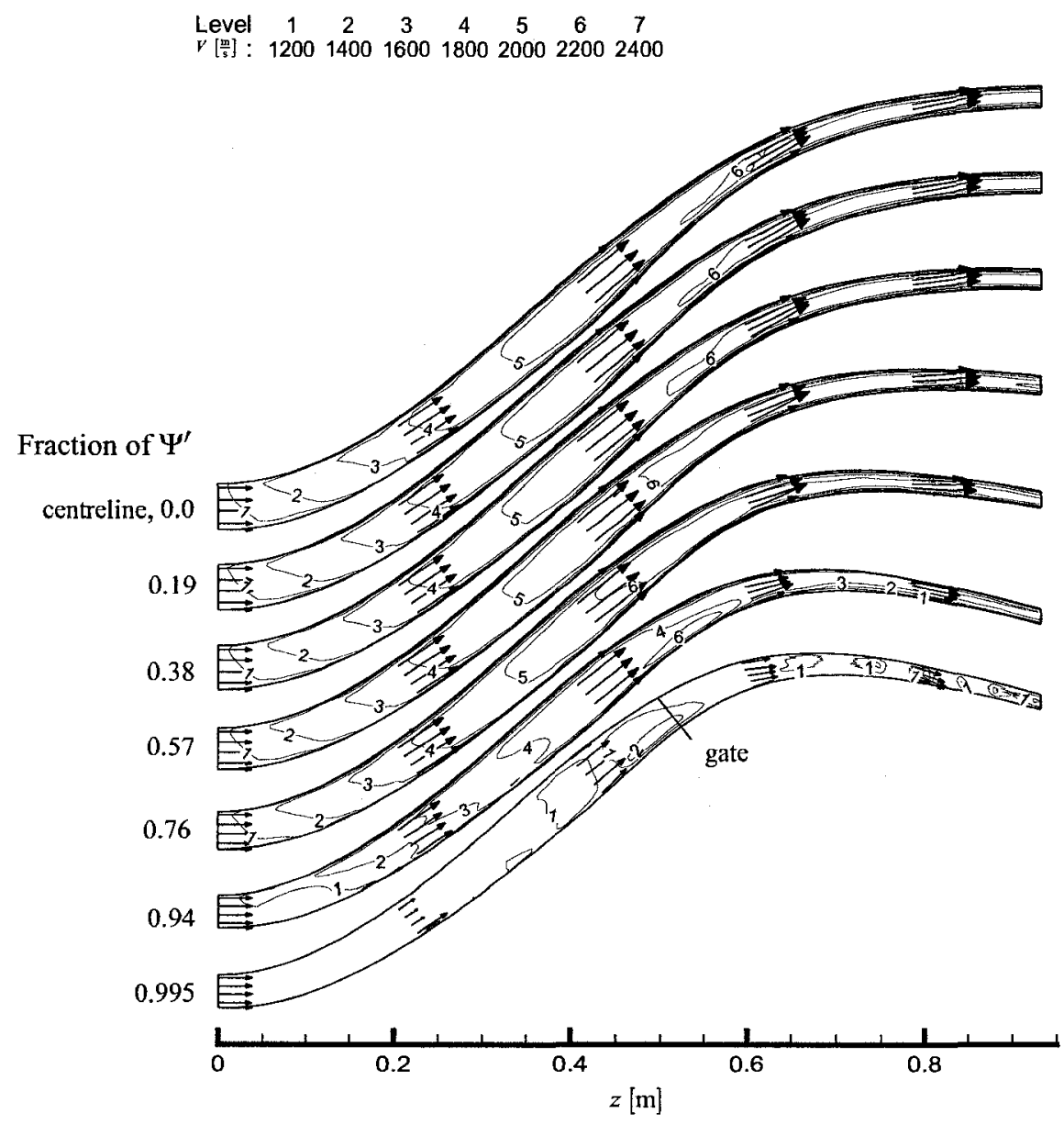

Figure 5.2: Viscous analysis $\Psi^{\prime}$-plane velocity contours 
shares several similar characteristics that are apparent on the $0.0-0.76 \Psi^{\prime}$-planes to the inviscid results shown in Fig. 4.3: the $1200\left[\frac{\mathrm{m}}{\mathrm{s}}\right], 1400\left[\frac{\mathrm{m}}{\mathrm{s}}\right]$, and $1600\left[\frac{\mathrm{m}}{\mathrm{s}}\right]$ contours diverge away from the outer wall convex surface; the $1800\left[\frac{\mathrm{m}}{\mathrm{s}}\right]$ contour approximately regains orthogonality with respect to the radial contour; the $2200\left[\frac{\mathrm{m}}{\mathrm{s}}\right]$ contour in Fig. 5.2 behaves similar to the $2100\left[\frac{\mathrm{m}}{\mathrm{s}}\right]$ contour in Fig. 4.3 (only apparent on the $0.0-0.38 \Psi^{\prime}$-planes) in that the contour originates on the inner wall at $z \approx 0.5[\mathrm{~m}]$ and develops through the thickness downstream; and the vectors show that the flow stays attached throughout the nozzle and that streamlines proceed from the throat to the outlet.

There are also several differences between the inviscid and viscous results on the $\Psi^{\prime}$ planes: the velocity magnitude in Fig. 5.2 is much lower on the $0.94 \Psi^{\prime}$ and $0.995 \Psi^{\prime}$-planes because the no-slip swept wall boundary condition forces $V_{s w}=0\left[\frac{\mathrm{m}}{\mathrm{s}}\right]$; and the coalescing of contours along the inner and outer walls show the existence of inner and outer wall boundary layers. Since a core without velocity gradients is still present inside the $2200\left[\frac{\mathrm{m}}{\mathrm{s}}\right]$ contour, the boundary layers have not yet merged and so the flow does not become fully developed inside the nozzle. In other words, there is still an inviscid core region near the centreline out to approximately $0.75 \Psi^{\prime}$ that has relatively constant freestream velocity at a given cross section.

To obtain more information regarding the inner and outer wall boundary layers, the cuts shown in Fig. 5.3 correspond to the velocity profile locations shown in Fig. 5.4 where the inner wall is at $t=0[\mathrm{~m}]$. Figure 5.4 is representative of $75 \%$ of the nozzle domain nearer to the centreline. Comparison of averaged velocities on cross section edges along the centreline $\left(0.0 \Psi^{\prime}\right)$ to the isentropic velocity calculated from Eq. (2.45) (which exist within any inviscid core region) are within $9.9 \%$ with the maximum occurring at $z=0.04[\mathrm{~m}]$. If the first $z=0.1[\mathrm{~m}]$ is ignored, the maximum variation reduces to $4.9 \%$ and occurs at $z=0.12[\mathrm{~m}]$. In comparison, the inviscid area spanning $75 \%$ of the circumference in the $\Psi^{\prime}$-direction from the centreline has a maximum area-averaged velocity variation from the isentropic equations after $z=0.1[\mathrm{~m}]$ of $4.6 \%$ and also occurs at $z=0.12[\mathrm{~m}]$. Between 


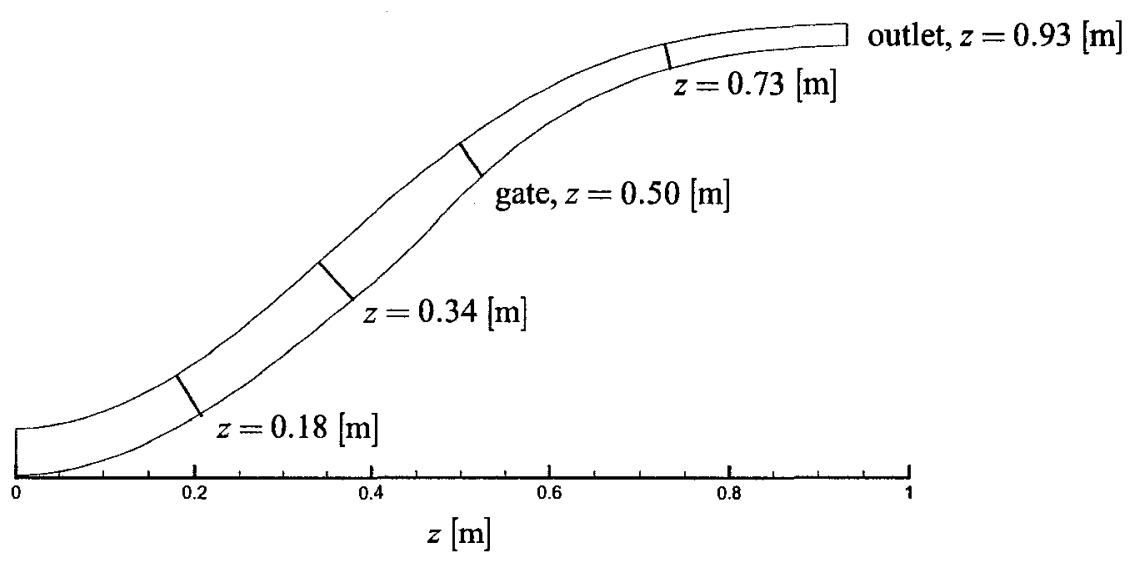

Figure 5.3: Velocity profile cross section locations throat to outlet

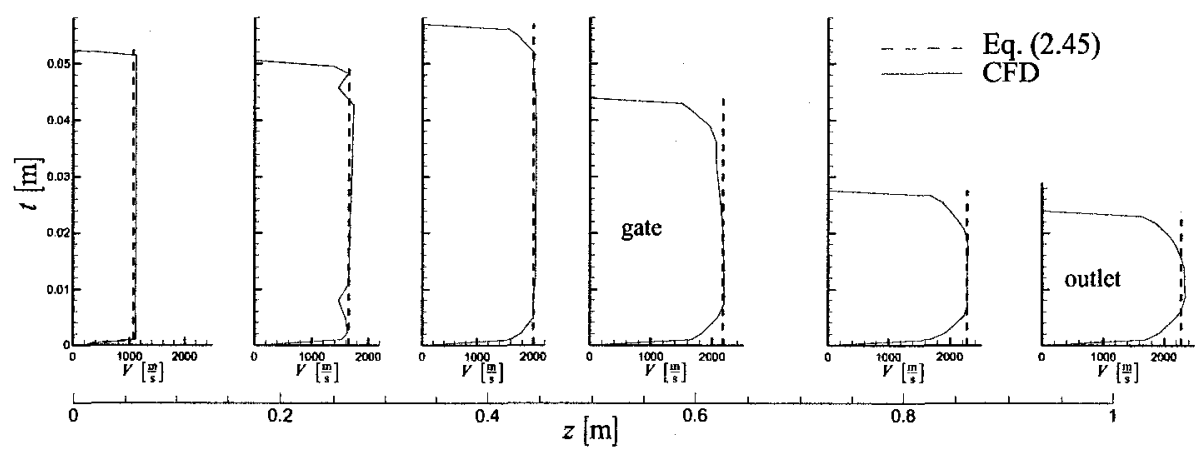

Figure 5.4: Velocity profiles at $0.0 \Psi^{\prime}$ (representative of profiles from $0.0-0.75 \Psi^{\prime}$ )

the inviscid core and the inner and outer walls are regions that experience an exponential decrease in velocity and hence define the inner and outer wall boundary layer thicknesses.

The data used to create the velocity profiles shown in Fig. 5.4 is used to produce the boundary layer profiles shown in Fig. 5.5. The edge of the boundary layer is selected to be at the location that has $99 \%$ of the freestream velocity at a given cross section. Unfortunately, although an inviscid core is present, definition of the freestream velocity is somewhat arbitrary. Since the inviscid analysis reports that convex wall curvature is responsible for expansion contours, the inviscid region shown in Fig. 5.2 has a velocity range as much as $200\left[\frac{\mathrm{m}}{\mathrm{s}}\right]$ on some cross sections (particularly evident between $z=0.0[\mathrm{~m}]$ and 


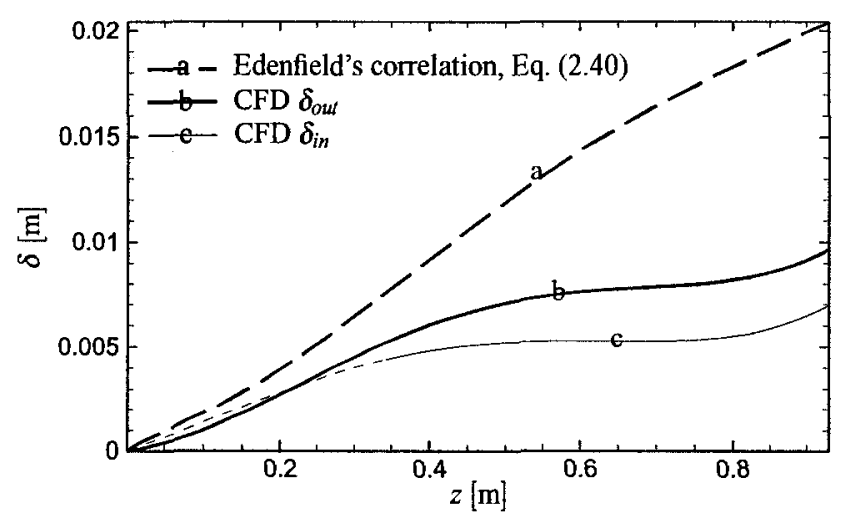

Figure 5.5: Comparison of boundary layer thicknesses on the centreline (representative of boundary layers from $0.0-0.75 \Psi^{\prime}$ )

$z=0.2[\mathrm{~m}])$. Although it may be possible to identify a freestream velocity for a particular wall at a transition point between the exponential profile in the boundary layer and the approximately linear profile in the inviscid core, dispersion errors introduced by the second order accurate advection scheme are the likely cause of wiggles (as shown on the $z=0.18[\mathrm{~m}]$ velocity profile in Fig. 5.4) that introduce uncertainty into the transition point location. Instead, the freestream velocity is selected to be the value obtained at the midthickness $\frac{t_{v i s_{i}}}{2}$ location.

The choice to use the mid-thickness velocity as the freestream velocity however is incapable of properly defining the inner wall boundary layer between $z=0.0[\mathrm{~m}]$ and $z=0.35[\mathrm{~m}]$ and so the dashed length on line (c) is an estimate. Furthermore, the calculated $\delta_{i}$ data at $0.99 V_{i}$ oscillates to some extent so the presented boundary layer curves are fourth-order polynomials that ensure the calculated $\delta_{i}$ s are within $\pm 0.001[\mathrm{~m}]$ of the curvefit $\delta_{i} \mathrm{~s}$. There is more confidence in the outlet values since the inviscid velocity range is only $\sim 20\left[\frac{\mathrm{m}}{\mathrm{s}}\right]$ and so the outlet boundary layer thicknesses are $\delta_{i n_{e}}=0.0070[\mathrm{~m}]$ and $\delta_{\text {out }}=0.0097[\mathrm{~m}]$.

Also shown on Fig. 5.5 is Edenfield's boundary layer thickness obtained using 
Eq. (2.40) that is calculated for the outer wall (the inner wall calculation is basically the same since the inner wall length calculated by Eq. (2.43) is $L_{i n_{e}}=1.08$ [m] as opposed to the outer wall length of $L_{\text {oute }}=1.06[\mathrm{~m}]$ ). Edenfield's equation calculates the outlet outer boundary layer thickness as $\delta_{\text {out }}=0.0204[\mathrm{~m}]$. The trends show that Eq. (2.40) overpredicts the CFD boundary layer thicknesses by a factor of two and does not reflect the apparent levelling of the boundary layer thicknesses between $z \approx 0.5[\mathrm{~m}]$ and $z \approx 0.8[\mathrm{~m}]$.

Figure 5.6 shows the velocity field on $z$-planes taken at the locations shown in Fig. 4.6. The absence of circumferential contours within $0.75 \Psi^{\prime}$ of the centreline support the observation that the boundary layer profile does not change with respect to $\Psi^{\prime}$ in this region and thus the region can be treated as two-dimensional. This $75 \%$ region is area-averaged at the outlet to calculate $\bar{M}_{e}=2.66$ and is within $1.5 \%$ of the value obtained in the inviscid analysis. The good agreement of Mach numbers suggest that the displacement thickness added to the inner and outer walls is sufficient to account for the viscous effects near these walls to the extent that the viscosity inconsistency (a variable $\mu$ is used in the nozzle design whereas a constant $\mu$ is defined in CFX) may be responsible for the variation from the predefined value.

Figure 5.7 shows the total pressure field on $z$-planes taken at the locations shown in Fig. 4.6. The region inside the $4500[\mathrm{kPa}]$ contour represents the inviscid freestream region whereas the gradients present near the walls shows the presence of a viscous region. The region of $P_{0}$ reduction near the walls is not isentropic so Eq. (2.56) cannot be used to evaluate the pressure in the boundary layer. The loss in $P_{0}$ is associated to increasing viscous forces (friction) necessary to reduce the velocity to zero at a wall. Viscous forces are present near a wall since turbulence viscosity increases from zero in the inviscid region to a value on the order of $\mu_{t}=0.02\left[\frac{\mathrm{kg}}{\mathrm{ms}}\right]$ closer to a wall (recall that $\mu=7.276 \cdot 10^{-5}\left[\frac{\mathrm{kg}}{\mathrm{ms}}\right]$ ) or three orders of magnitude increase in viscosity. Consideration of the Navier-Stokes momentum equation (for example, Eq. (3.11)) proves that for steady flow and advection term known, if viscous friction forces increase, static pressure losses must occur. These 


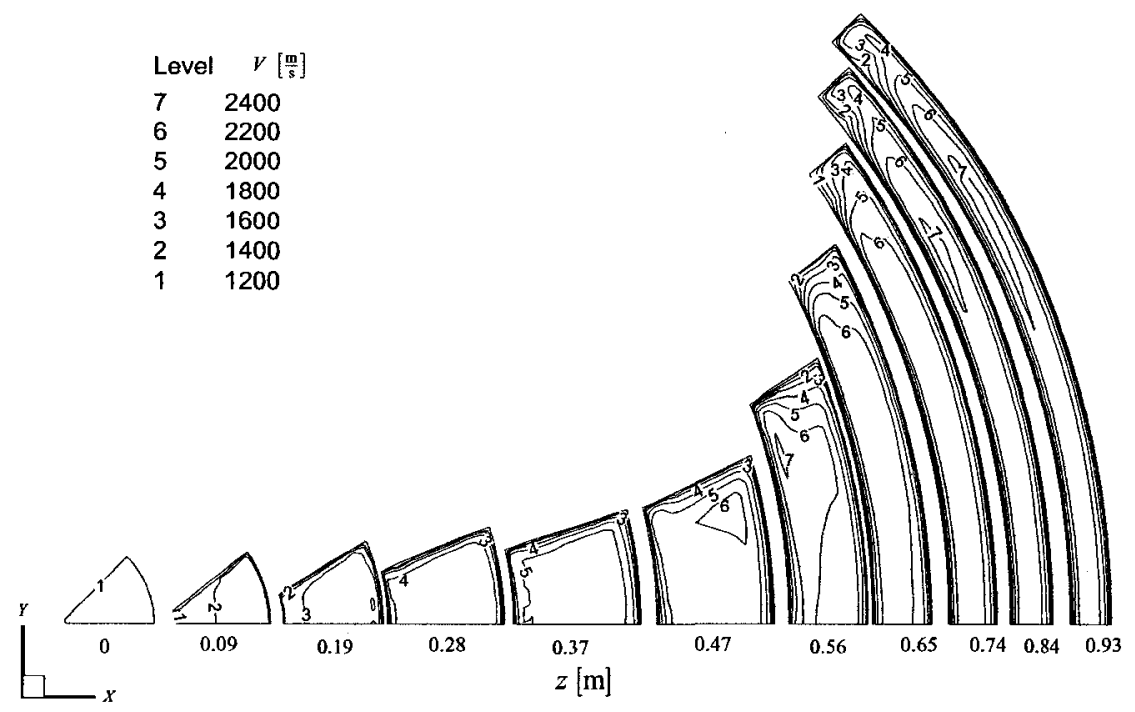

Figure 5.6: Viscous analysis $z$-plane velocity contours

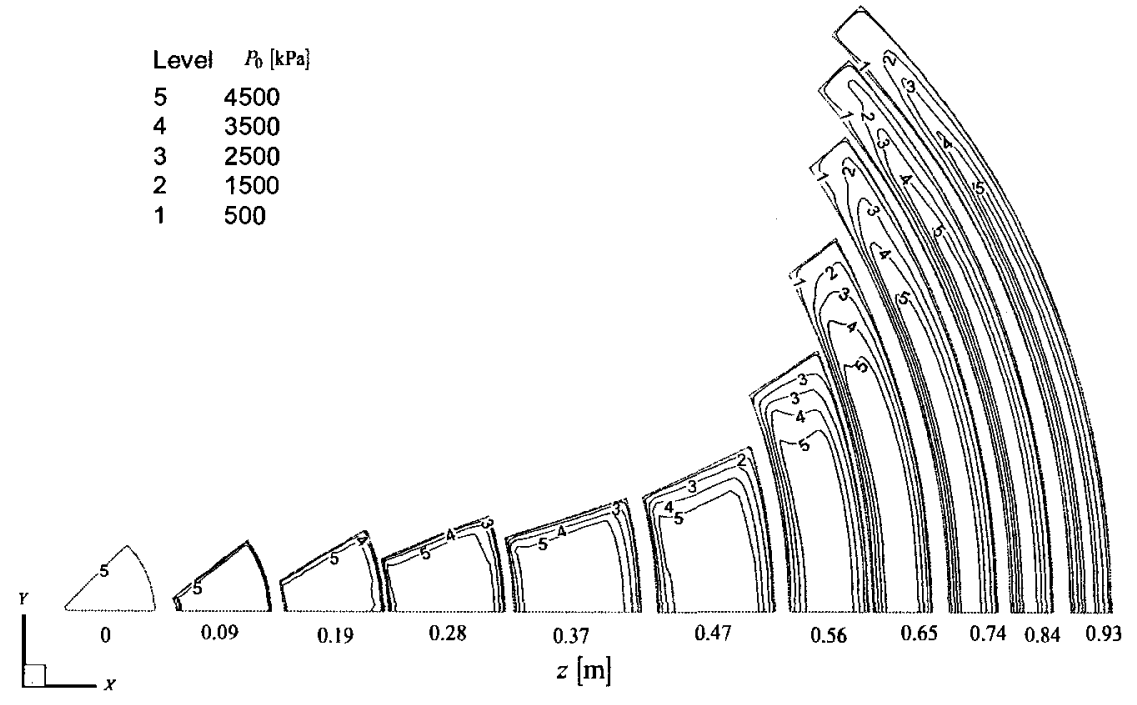

Figure 5.7: Viscous analysis $z$-plane total pressure contours 
pressure losses account for a $41.4 \%$ pressure variation between $\bar{P}_{e}=106.6[\mathrm{kPa}]$ and the value calculated by the inviscid results.

The coalescing of velocity contours near the walls in Fig. 5.6 are now known to define the boundary layer regions. It is also evident that viscous forces (shown by the related $P_{0}$ losses in Fig. 5.7) are more influential to the contours than geometry since the convex surface around the swept wall fails to produce the localized velocity increase observed in Fig. 4.5 on the $z=0.47[\mathrm{~m}]$ to $z=0.74[\mathrm{~m}]$ planes. Instead, the increasing velocity gradients developing off the swept wall in this region are much more gradual than the velocity gradients along either the inner or outer walls. Computational results estimate the swept wall boundary layer thickness based on it spanning $0.25 \Psi^{\prime}$ from the swept wall where the velocity at $\frac{t_{v i s_{i}}}{2}$ is roughly $99 \%$ of that of the inviscid core at the outlet as $\delta_{s w_{e}} \approx 0.09[\mathrm{~m}]$; in comparison, Eq. (2.40) calculates a value of $\delta_{s w_{e}}=0.021[\mathrm{~m}]$.

Figures 5.8-5.10 plot velocity profiles on $\Psi^{\prime}$-planes closer to the side wall. The profiles shown in Fig. 5.8 are similar to those in Fig. 5.4 except that the inner and outer wall boundary layers are slightly larger. The velocity profiles in Fig. 5.9 show slight decreases in velocity magnitude whereas the velocity magnitude in Fig. 5.10 is approximately half of that calculated by Eq. (2.45).

The fully viscous region shown by the total pressure contours in Fig. 5.7 is responsible for the velocity reduction in the nearest $0.25 \Psi^{\prime}$ to the swept wall as shown in Figs. 5.85.10. Since flow in this region parallels two sets of walls that are joined at common edges (the flow parallels two corners), the flow characteristics developed individually by each wall combine in a cumulative manner to result in the larger viscous region than those observed nearer to the centreline along the inner and outer walls. It is because of this three-dimensionality that Edenfield's formulation cannot accurately predict the swept wall displacement thickness. 


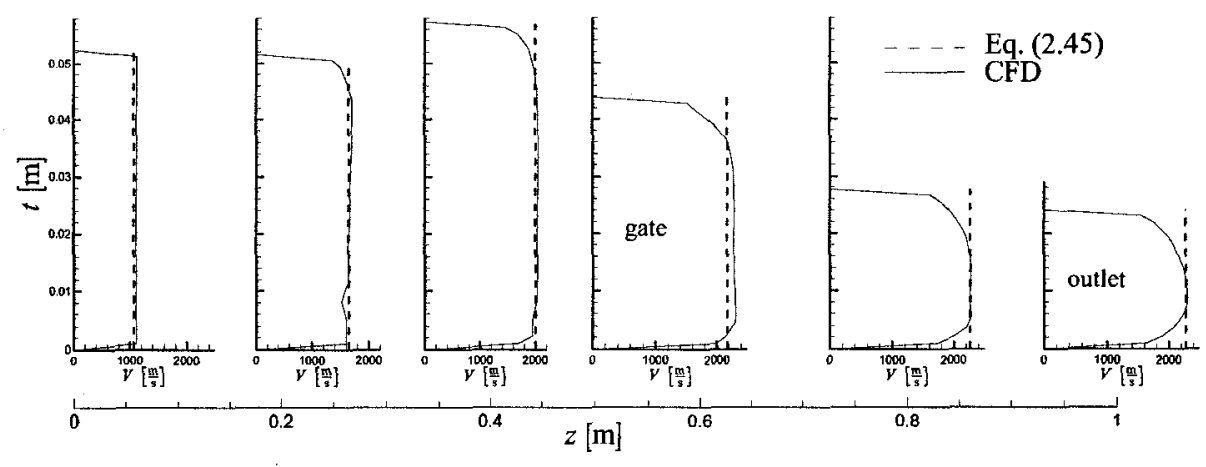

Figure 5.8: Velocity profiles at $0.76 \Psi^{\prime}$

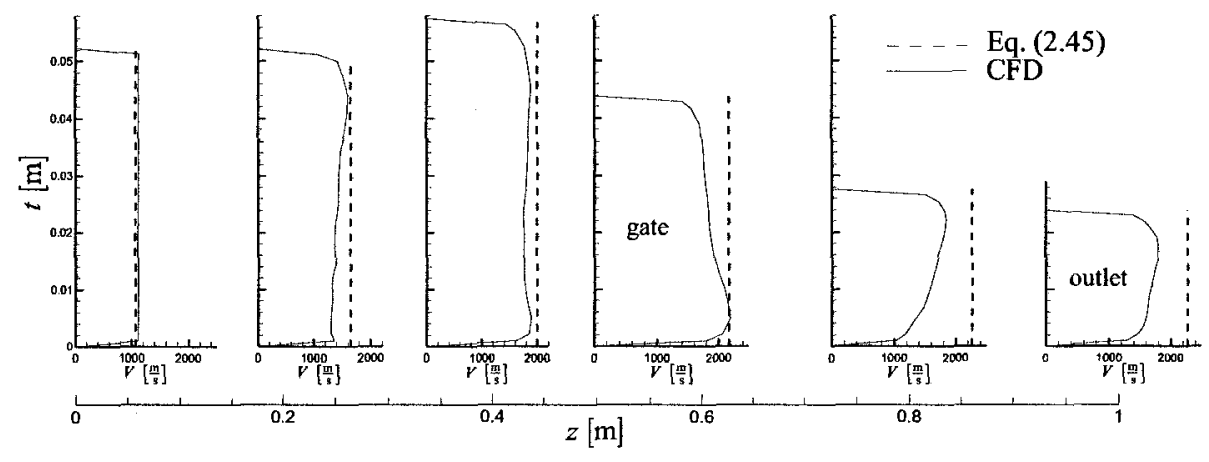

Figure 5.9: Velocity profiles at $0.94 \Psi^{\prime}$

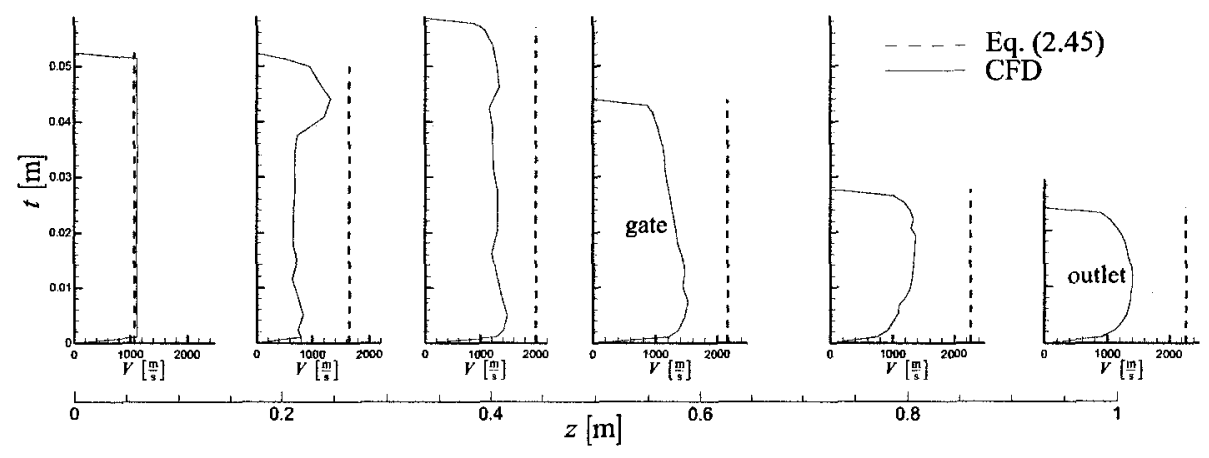

Figure 5.10: Velocity profiles at $0.995 \Psi^{\prime}$ 


\section{Chapter 6}

\section{Conclusions and Recommendations}

Based on provided geometric and fluid property input, the presented theory is capable of generating fully three-dimensional diverging sections of a converging-diverging rocket nozzle. Specification of three fully-constrained cross sections - throat, gate, and outlet—are necessary to establish the progression of the nozzle geometry cross sectional area using a predefined Mach number distribution $M(z)$ and quantify the size of the air intake. Air entrainment into the centre of an annular rocket exhaust stream is a result of the void formed because the gate is placed on the outer perimeter of the nozzle whose shape does not have to remain axisymmetric but defines an intermediate cross section through which the exhaust flow must pass.

Inviscid area-averaged computational results are within $1.6 \%$ of the predefined outlet Mach number of 2.75 and $7.6 \%$ of the isentropic pressure predicted at the outlet. Similarly, maximum variations of $1.0 \%$ in velocity and $1.6 \%$ in temperature also occur at the outlet. The outer wall curvature near the throat is convex and so isentropic expansion is observed whereby velocity contours diverge into the cross sectional thickness. In a similar manner just past the gate, both the inner and swept walls have convex curvature and hence velocity first increases along these surfaces. The direction of the velocity vectors is related to the curvature as the streamlines parallel the nozzle walls: the curvature of the radial contour is 
responsible for a radial velocity component whereas the swept wall curvature is responsible for a circumferential velocity component.

Viscous computational results obtained using the $k$ - $\varepsilon$ turbulence model under-predict the predefined outlet Mach number by $6.8 \%$. Observations from the total pressure field show that the flow does not become fully developed and that viscous effects are contained within the boundary layers at each wall. Since the flow is not isentropic within the boundary layer, there are corresponding pressure losses due to the increase in friction and thus a $41.4 \%$ pressure variation at the outlet when compared to the inviscid analysis. For $75 \%$ of the nozzle nearer to the centreline, the flow can be considered two-dimensional and gives an area-averaged outlet Mach number $1.5 \%$ less than that obtained by the inviscid computational results. This gives confidence in the amount of displacement thickness added to the inner and outer walls.

The remaining $25 \%$ of the area by the swept wall becomes fully viscous at the outlet. This viscous region gives a swept wall boundary layer thickness at the outlet an order of magnitude greater than the boundary layer thicknesses along the centreline for the inner and outer walls. Although streamlines remain parallel to the nozzle walls, the decrease in velocity near the swept wall is contributed to the swept wall corners since the flow characteristics along each wall combine in a cumulative manner. Subsequently, a threedimensional boundary layer correlation must be implemented for better prediction of the swept wall displacement thickness.

Results are provided for one configuration only, which is unlikely to be an optimum configuration and is not representative of all configurations. For example, reduction of the outlet arc angle $\psi_{e}$ should reduce the magnitude of the circumferential velocity components and avoid the likely presence of strong oblique shocks at the nozzle outlet. Furthermore, choice of an axially symmetric radial contour $r(z)$ is somewhat arbitrary. Given the defined 4.3 times increase in outlet diameter over an axisymmetric nozzle design with the same $M(z)$, it may be beneficial to consider profiles that end in elliptical or polygonal shapes 
at the outlet or consider designs with a smaller outlet radius. Additionally, corner point selection of a cross section is simplified to enforce the shape to be representative of a rectangle and a triangle. The viscous analysis shows that $25 \%$ of the flow near the swept wall is fully viscous and results in much more gradual velocity and total pressure gradients than those observed along the inner and outer walls. It may therefore be beneficial to round out the swept wall corners by using a parabolic or higher-order equation as opposed to the linear equation implemented to connect the swept wall corner points $P 1$ and $P 2$.

Since coupling ejector theory to rocket nozzle design has not been previously explored to any great extent, investigation of the thrust and specific impulse performance characteristics are necessary to give confidence that the design concept can provide improvement over existing thrust chambers. Although it is apparent that increasing the air intake size is beneficial for increased mass flow, the air entrainment capability must consider shock waves or expansion fans induced by the geometry design. Likewise, the mixing ability of the rocket and air flows in the ejector is paramount to the overall rocket performance.

Lastly, an experimental investigation will provide invaluable data that can be compared to predicted results using the isentropic equations and CFD simulations, furthering the confidence of the presented results. For experimental analysis, consideration to the compressibility factor in the ideal gas law and a variable specific heat ratio should be given when developing the geometry. 


\section{References}

[1] Turner, M. J. L., Rocket and Spacecraft Propulsion: Second Edition, Praxis Publishing Ltd., 2005.

[2] Tajmar, M., Advanced Space Propulsion Systems, Springer-Verlag/Wien, 2003.

[3] Sutton, G. P., History of Liquid Propellant Rocket Engines, American Institute of Aeronautics and Astronautics, 2006.

[4] Kraemer, R. S., Rocketdyne: Powering Humans into Space, American Institute of Aeronautics and Astronautics, 2006.

[5] Daines, R. and Segal, C., "Combined Rocket and Airbreathing Propulsion Systems for SpaceLaunch Applications," Journal of Propulsion and Power, Vol. 14, No. 5, 1998, pp. 605-12.

[6] Jones, T. D., "Final countdowns: The shuttle's last years," Aerospace America, Vol. 45, No. 1, January 2007, pp. 16-8.

[7] Cáceres, M., "A sputtering market for nanosats and picosats," Aerospace America, Vol. 44, No. 11, November 2006, pp. 16-8.

[8] Braeunig, R. A., "Rocket \& Space Technology," [electronic resource], 2005, URL: http://www.braeunig.us/space/, [cited 11 June 2007].

[9] Shebalin, J.-P. and Tiwari, S. N., "NOZ-OP-2D: A CFD-Based Optimization System for Axially Symmetric Rocket Nozzles," AIAA Paper 2001-1062, 2001, presented at the 31st Joint Propulsion Conference.

[10] Hagemann, G., Immich, H., Nguyen, T. V., and Dumnov, G. E., "Advanced Rocket Nozzles," Journal of Propulsion and Power, Vol. 14, No. 5, September-October 1998, pp. 620-34.

[11] White, F. M., Fluid Mechanics, Boston: McGraw-Hill, 5th ed., 2003.

[12] Hopkins, D. F. and Hill, D. E., "Transonic Flow in Unconventional Nozzles," AIAA Journal, Vol. 6, No. 5, 1968, pp. 838-42.

[13] Corda, S., Neal, B. A., Moes, T. R., Cox, T. H., Monaghan, R. C., Voelker, L. S., Corpening, G. P., Larson, R. R., and Powers, B. G., "Flight Testing the Linear Aerospike SR-71 Experiment (LASRE)," NASA TM-1998-206567, Dryden Flight Research Center, 1998. 
[14] Manski, D. and Hagemann, G., "Influence of Rocket Design Parameters on Engine Nozzle Efficiencies," Journal of Propulsion and Power, Vol. 12, No. 1, 1996, pp. 41-7.

[15] Korst, H. H., Addy, A. L., and Chow, W. L., "Installed Performance of Air-Augmented Nozzles Based on Analytical Determination of Internal Ejector Characteristics," Journal of Aircraft, Vol. 3, No. 6, November-December 1966, pp. 498-506.

[16] Daines, R. L. and Merkle, C. L., "Computational Analysis of Mixing and Jet Pumping in Rocket Ejector Engines," AIAA Paper 95-2477, 1995, presented at the $31^{\text {st }}$ Joint Propulsion Conference.

[17] Tokudome, S. and Kobayashi, K., "Experimental Study on Rocket-Ejector Systems," AIAA Paper 2006-7977, November 2006, presented at the $14^{\text {th }}$ AIAA/AHI Space Planes and Hypersonic Systems and Technologies Conference.

[18] Nayem Jahingir, M. and Huque, Z., "Design Optimization of Rocket-Based Combined-Cycle Inlet/Ejector System," Journal of Propulsion and Power, Vol. 21, No. 4, July-August 2005, pp. 650-5.

[19] Presz Jr., W. M. and Werle, M., "Multi-Stage Mixer/Ejector Systems," AIAA Paper 20024064, July 2002, presented at the $38^{\text {th }}$ AIAA/ASME/SAE/ASEE Joint Propulsion Conference \& Exhibit.

[20] Gujarathi, A., Li, D., Anderson, W., and Sankaran, V., "CFD Modeling of a Ducted Rocket Combined with a Fuel-Rich Primary Thruster," AIAA Paper 2006-4577, July 2006, presented at the $42^{\text {nd }}$ AIAA/ASME/SAE/ASEE Joint Propulsion Conference \& Exhibit.

[21] Etele, J., Computational Study of Variable Area Ejector Rocket Flowfields, Ph.D. thesis, University of Toronto, Institute for Aerospace Studies, Toronto, 2004.

[22] Etele, J., Sislian, J. P., and Parent, B., "Effect of Rocket Exhaust Configurations on Ejector Performance in RBCC Engines," Journal of Propulsion and Power, Vol. 21, No. 4, JulyAugust 2005, pp. 656-66.

[23] Etele, J., Parent, B., and Sislian, J. P., "Analysis of Increased Compression Through Area Constriction on Ejector-Rocket Performance," Journal of Spacecraft and Rockets, Vol. 44, No. 2, March-April 2007, pp. 355-64.

[24] Aoki, S., Lee, J., Masuya, G., Kanda, T., and Kudo, K., "Aerodynamic Experiment on an Ejector-Jet," Journal of Propulsion and Power, Vol. 21, No. 3, May-June 2005, pp. 496-503.

[25] Wikipedia: The Free Encyclopedia, "Earth's atmosphere," [electronic resource], 2007, URL: http://en.wikipedia.org/w/index.php?title=Earth\%27s_atmosphere\&oldid=137434911, [cited 11 June 2007].

[26] Sanz Fernández de Córdoba, S., "100 km. Altitude boundary for astronautics..." [electronic resource], 2004, URL: http://www.fai.org/astronautics/100km.asp, [cited 11 June 2007]. 
[27] Bond, R. B. and Edwards, J. R., "Computational Analysis of an Independent Ramjet Stream in a Combined Cycle Engine," AIAA Journal, Vol. 42, No. 11, November 2004, pp. 2276-83.

[28] Varvill, R. and Bond, A., "A Comparison of Propulsion Concepts for SSTO Reusable Launchers," Journal of the British Interplanetary Society, Vol. 56, 2003, pp. 108-17.

[29] Varvill, R. and Bond, A., "The SKYLON Spaceplane," Journal of the British Interplanetary Society, Vol. 57, 2004, pp. 22-32.

[30] Tuohy, I. R., "Advantages of the Woomera Test Facility for Hypersonic Flight Programs," AIAA Paper 2006-7909, November 2006, presented at the $14^{\text {th }}$ AIAA/AHI Space Planes and Hypersonic Systems and Technologies Conference.

[31] Edenfield, E. E., "Design of a high Reynolds number Mach number 8 contoured nozzle for the hypersonic wind tunnel (f)," AEDC-TR-72-48, Arnold Air Force Station, Tennessee, August 1972, Technical Report, Arnold Engineering Development Centre.

[32] Barnhart, P. J., "NPAC - Nozzle Performance Analysis Code," NASA CR-204129, Lewis Research Center, July 1997, NASA Contractor Report.

[33] Hunter, C. A., "An Approximate Theoretical Method for Modeling the Static Thrust Performance of Non-axisymmetric Two-Dimensional Convergent-Divergent Nozzles," NASA CR195050, Langley Research Center, March 1995, NASA Contractor Report.

[34] McBride, B. J., Gordon, S., and Reno, M. A., "Coefficients for Calculating Thermodynamic and Transport Properties of Individual Species," NASA TM-4513, Lewis Research Center, October 1993, NASA Technical Report.

[35] White, F. M., Viscous Fluid Flow, Boston: McGraw-Hill, 3rd ed., 2006.

[36] Çengel, Y. A. and Boles, M. A., Thermodynamics: An Engineering Approach, Boston: McGraw-Hill, 4th ed., 2002.

[37] Schlichting, H., Boundary-Layer Theory, New York: McGraw-Hill, 7th ed., 1979.

[38] ANSYS ${ }^{\circledR}$, Inc., ANSYS ${ }^{\circledR}$ CFX, Release 11.0 User Guide, 2006.

[39] Menter, F., "Two-Equation Eddy-Viscosity Turbulence Models for Engineering Applications," ALAA Journal, Vol. 32, No. 8, August 1994, pp. 1598-1605.

[40] Roache, P. J., "Verification of Codes and Calculations," AIAA Journal, Vol. 36, No. 5, 1998, pp. 696-702.

[41] Freitas, C., Ghia, U., Celik, I., Roache, P., and Raad, P., "ASME's Quest to Quantify Numerical Uncertainty," AIAA Paper 2003-627, January 2003, presented at the $41^{\text {st }}$ Aerospace Sciences Meeting and Exhibit. 